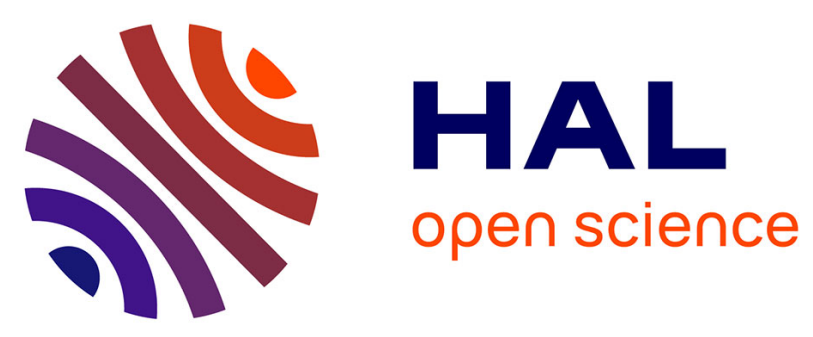

\title{
Discrete Modeling of the Crushing of Nomex Honeycomb Core and Application to Impact and Post-impact Behavior of Sandwich Structures
}

Bruno Castanié, Yulfian Aminanda, Jean-Jacques Barrau, Pascal Thevenet

\section{- To cite this version:}

Bruno Castanié, Yulfian Aminanda, Jean-Jacques Barrau, Pascal Thevenet. Discrete Modeling of the Crushing of Nomex Honeycomb Core and Application to Impact and Post-impact Behavior of Sandwich Structures. Abrate S.; Castanié B.; Rajapakse Y. Dynamic Failure of Composite and Sandwich Structures, 192, 2013, 978-94-007-5329-7. hal-01654038

\section{HAL Id: hal-01654038 \\ https://hal.science/hal-01654038}

Submitted on 2 Dec 2017

HAL is a multi-disciplinary open access archive for the deposit and dissemination of scientific research documents, whether they are published or not. The documents may come from teaching and research institutions in France or abroad, or from public or private research centers.
L'archive ouverte pluridisciplinaire HAL, est destinée au dépôt et à la diffusion de documents scientifiques de niveau recherche, publiés ou non, émanant des établissements d'enseignement et de recherche français ou étrangers, des laboratoires publics ou privés. 


\title{
Discrete Modeling of the Crushing of Nomex Honeycomb Core and Application to Impact and Post-impact Behavior of Sandwich Structures
}

\author{
Bruno Castanié, Yulfian Aminanda, Jean-Jacques Barrau, \\ and Pascal Thevenet
}

\begin{abstract}
In this chapter, an original method for modeling the behavior of sandwich structures during and after impact is proposed and validated. It is based on the demonstration that Nomex honeycomb behaves in a post-buckling mode very early and that compression forces are taken up by the corners or vertical edges of the honeycomb cells in the same way as they are in the stiffeners in aircraft structures. Thus it is possible to represent the honeycomb discretely by a grid of springs located at the six corners of hexagonal cells. This approach represents the phenomenon of indentation on honeycomb alone or on sandwiches very well. This approach provides an understanding of how the sandwich and the core behave under compression after impact. An original criterion based on a local core crush is tested and validated to compute the residual strength. To consider the bending response of sandwich structures, a multi-level approach is also proposed.
\end{abstract}

Keywords Impact • Sandwich • Compression after impact

\section{Introduction}

In this first section, the general context of the study will be presented first, followed by a brief literature survey. Finally, the scope of the study will be explained.

B. Castanié $(\bowtie) \cdot J .-J$. Barrau

INSA, ISAE, Mines-Albi, UPS; ICA (Institut Clément Ader), Université de Toulouse,

135 Avenue de Rangueil, 31077 Toulouse, France

e-mail: bruno.castanie@insa-toulouse.fr

Y. Aminanda

Mechanical Engineering Department, IIUM, Jl. Gombak, P.O. Box 10, 50728

Kuala Lumpur, Malaysia

P. Thevenet

EADS Innovation Works, 12 rue Pasteur, BP 76, 92152 Suresnes Cedex, France 


\subsection{Background}

Sandwich structures consist of two skins, having high mechanical properties, and a lightweight core, which separates the skins. The quality of the skins-core assembly is intrinsically linked to the mechanical characteristics of the core. When the thickness of the core is increased, the bending stiffness and critical load prior to buckling increase significantly while the total mass of the sandwich structure remains small. However, the mechanical properties of the core are low, which leads to weakness of the sandwich structure in terms of its ability to withstand impact loading and local buckling. Therefore, despite their obvious advantages, the application of sandwich structures in aircraft is developing only gradually. It seems that they are reserved only for secondary structures in commercial aircraft. In the case of military helicopters (Eurocopter Tiger and NH90), almost the whole structure is made of sandwich materials and the utilization of composite reaches approximately $90 \%$. The sandwich seems optimum for weakly loaded, nonpressurized structures and its current application as primary structure is limited to business jets (for example the Raython Premier).

With the increasing number of aircraft in service, impacts happen more often and incident management requires more sophisticated, less conservative and faster tools than the existing ones, which are based mainly on experimental data. In practice, when an incident occurs somewhere in the world, the manufacturer must be able to decide quickly if the aircraft can continue flying as it is, or if a repair should be performed or if a subunit has to be changed. The study presented in this paper is constrained to acquire the efficiency of an industrial tool. The ultimate goal is to develop a comprehensive maintenance loop. The work is divided into four main phases:

- Step 1: 3D imaging and measurement of the damage shape at the location of impact.

- Step 2: Reverse engineering by using the available data to reconstruct the projectile shape.

- Step 3: Simulation of the impact and computation of the residual strength of the structure.

- Step 4: Decision on whether the impacted part needs to be repaired or changed before flight clearance can be obtained from the authorities, or whether the aircraft needs to be grounded, or if the structure remains safe for several flights without any repairs.

The research work presented in this chapter is related to the development of step 3. It will be limited to aeronautical types of sandwich structures as defined by Guedra-Degeorges [1] where the maximum thickness of the composite skin is around $3 \mathrm{~mm}$ and the core is made of Nomex honeycomb. In the general case, the impact occurs during maintenance visits or ground operations. These impacts can be considered as low energy/low velocity and they are the only type of impact considered in this chapter. In the following chapter, a brief literature review of this type of impact will be presented. 


\subsection{Literature Survey}

Many significant articles have been published since the late 1980s [2-8]. The research has focused on the identification and characterization of the damage to the laminated skins (delamination and fiber breakage) and the cores (crushing located under the impact area). The effects of boundary conditions and different combinations of materials for skin and core have also received attention. The various material combinations studied experimentally up to 1998 can be found in a comprehensive review by S. Abrate [9].

Although the issue of core crushing was identified in this period, relatively few studies investigated the behavior of core made from a honeycomb type of structure and subjected to compressive loading. And most of the works have studied the capability of honeycomb core made from aluminum alloys to absorb the energy [10-12]. The damage mechanism of honeycomb core under compression has been observed as the formation of lobes during loading and the lobes have been correctly modeled using plastic hinge theory. However, it appears clearly that this methodology cannot be applied to the Nomex honeycomb selected for this study. In this study, only lowvelocity/low-energy impacts will be considered. The experiments conducted in our laboratory and in EADS IW facilities show that, for this type of impact acting on the aircraft type of sandwich structure, an equivalence of behavior between dynamic and static indentation can be considered. The same observations have been reported in numerous earlier papers as mentioned in [8, 13, 14].

The advantage of employing static tests is their simplicity of implementation and the low dispersion of test results. The first mathematical model proposed to identify the indentation on a sandwich structure used the Hertz contact law [9]. Analytical models based on beams or plates and supported by elastic foundations have been developed by some authors. The oldest approaches were based on the theory of elasticity, which had very limited application in practice [9]. Swanson [15], Soden [16] and Olsson [17] have proposed analytical models using a perfect plastic foundation to simulate honeycomb core behavior. In Soden's model [16], linear kinematics was considered and, as for Olsson's model [17], a large displacement was employed.

However, these models are of limited interest for our study because of the plastic deformation of the metallic skin and crushing of the core during indentation [1-8]. Also, the honeycomb is damaged even at very low impact energy. Therefore, understanding the damage mechanism is the key point in any attempt to model the indentation on a sandwich structure. The damage mechanism is very complex, involving the phenomena characterized by the appearance of folds and different fractures on the hexagonal honeycomb cells. That is why some authors have used a global constitutive behavior law by considering the core as continuum material (e.g. [18-20]). Only recently, due to greater computing capabilities and the higher stability of explicit computation strategy, finite element analysis models have been successfully developed to simulate the damage mechanism of Nomex honeycomb core [21]. However, the models require a complex method of parameter 
identification to obtain the micro-mechanical properties of Nomex. The FEA models developed are themselves difficult to implement and require substantial computing time, which makes them unsuitable candidate tools for quick maintenance purposes. Therefore, this study focuses first on phenomenological observations of the crushing of Nomex honeycomb core in order to identify and explain its mechanisms and then propose a relevant model.

\subsection{Scope of the Study}

The state of the art shows that there are only two methods for modeling the crushing of honeycomb cores. The first one uses continuum and global laws and is easy to implement. The second one aims to represent the core finely, even distinguishing the aramid paper and the surface layers of phenolic resin of the Nomex paper [22]. The first approach hides a number of behaviors of the honeycomb structure, while the second succeeds in satisfying the aeronautics-related context of this study but at huge computational cost.

For these reasons, the study focuses first on the phenomenological observation of the crushing of Nomex honeycomb core in order to identify and explain its mechanisms and then propose a relevant model.

Structural effects, such as post-buckling behavior, will be identified and this will allow the core to be modeled by a grid of nonlinear springs. This "third way" of modeling is called discrete modeling or the discrete approach in this chapter. From this analysis, in Sect. 3, the discrete approach is used to model the indentation and impact of sandwich structures with metallic skins. This approach will then be extended to the problems of residual indentation and compression after impact in Sect. 4. The final section will provide a review and point out some perspectives.

\section{Analysis of the Crushing of Honeycomb Core}

In order to propose a relevant model for Nomex honeycomb, the study starts with an understanding and description of the mechanical phenomena involved in crushing as a failure mode for this type of structure. In this chapter, first, micromechanical analysis is presented qualitatively. The result of the study shows that it is possible to reason analogically with folding phenomena found for the damage mechanism on a tube structure subjected to compression loading, where the crushing is mainly controlled by the geometry of the cells.

A series of tests is performed on different honeycomb materials, which will help to identify the influential parameters and to propose a scenario for the mechanism of folding. The observations of the test lead us to propose a model where honeycomb can be represented by an array of springs. Each spring is located at the position of a vertical edge of the honeycomb cells. The proposed analytical model, which 


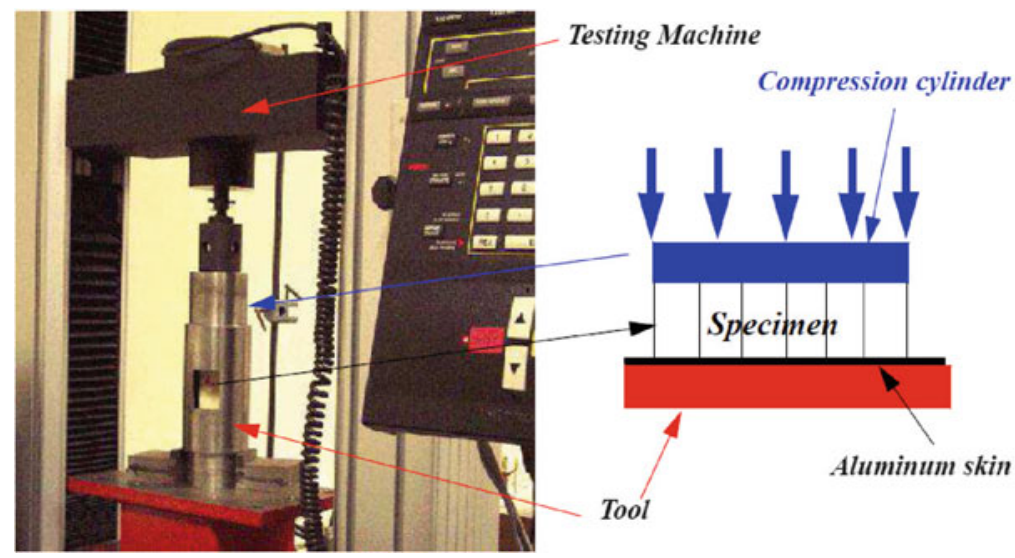

Fig. 1 Test procedure for compression of honeycomb cores

is based on test observations, will be validated by comparison with the results of indentation tests using hemispherical and conical projectiles. The limitations of the model are identified for a cylindrical projectile. A conclusion will be drawn to end the section.

\subsection{Phenomenological Analysis}

\subsubsection{Qualitative Analysis of Crushing}

The specimens made from Nomex (HRH 10-3/16-4) were carefully cut into rectangular shapes containing a total of 100 cells. The specimens were subjected to uniform compression loading using the procedure described in Fig. 1 by controlling the displacement speed at $0.5 \mathrm{~mm} / \mathrm{min}$, which is equivalent to quasi-static compression loading. Thirteen points on the force-displacement curve were selected for further examination.

Nomex honeycomb is a two-component material by its method of manufacture. The phenolic resin is mainly on the surface of an aramid paper. The first pictures in the elastic part (points 1,2,3,4 Fig. 2) show that the phenolic resin breaks throughout the height of the honeycomb (Fig. 3). Breaking occurs up to the maximum force in the force-displacement curve (point 5 and Fig. 4). After the maximum force is reached, the first fold is observed. Subsequently, the first fold flattens and a second fold appears (point 8, Fig. 5). The failure modes appear more and more complex, with tearing and local debonding (Fig. 6).

It is now interesting to refer to the literature on crushing and especially on folding mechanisms of tubes [23-27]. The folding of Nomex honeycomb does not occur symmetrically relative to the cell center. Effectively, the folding follows a 


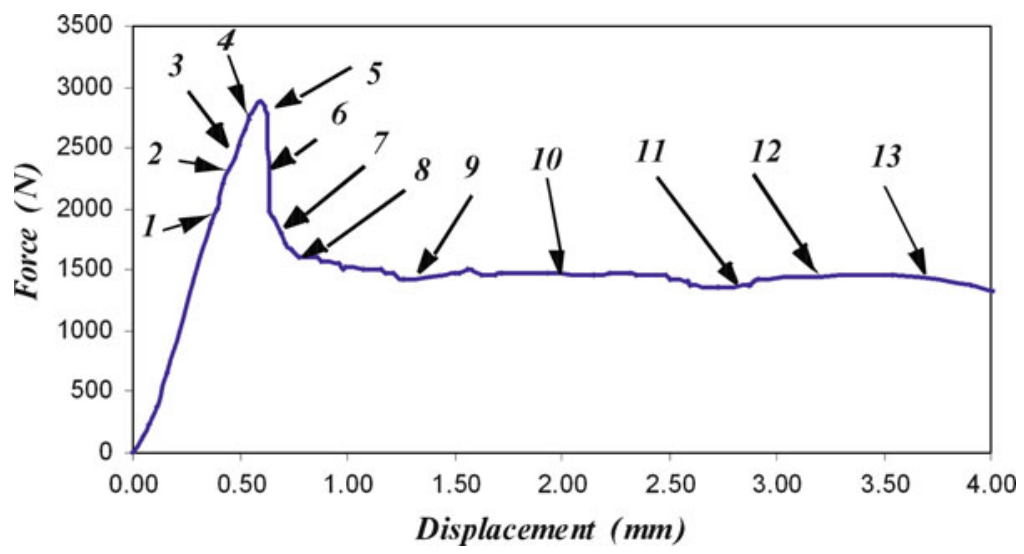

Fig. 2 Observation points during uniform compression loading

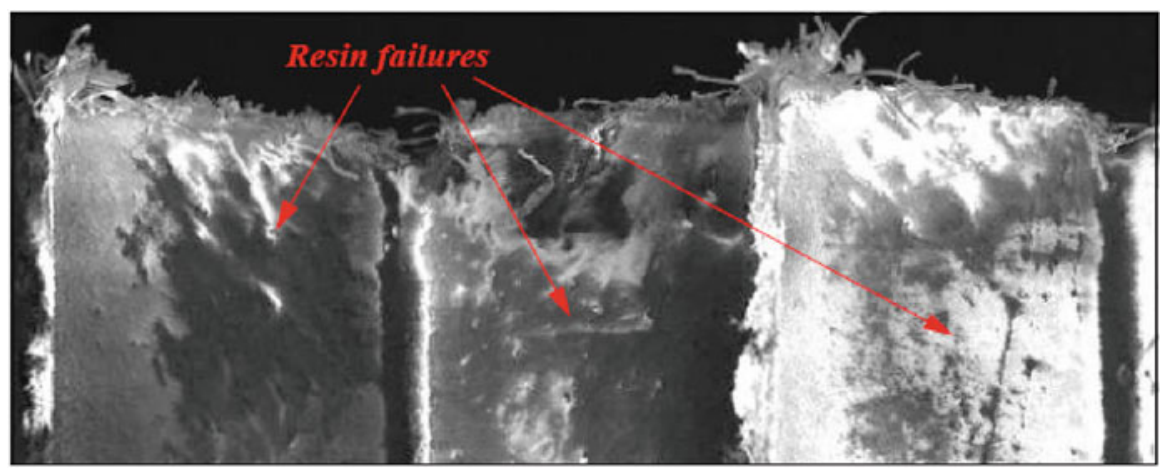

Fig. 3 Picture at point 2, view of resin failures

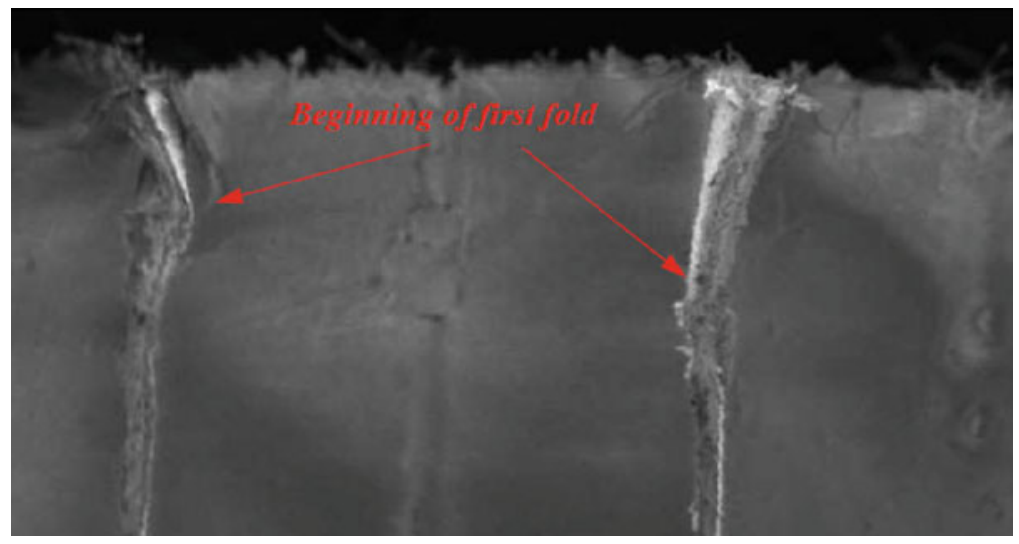

Fig. 4 Picture at point 5, appearance of first fold 


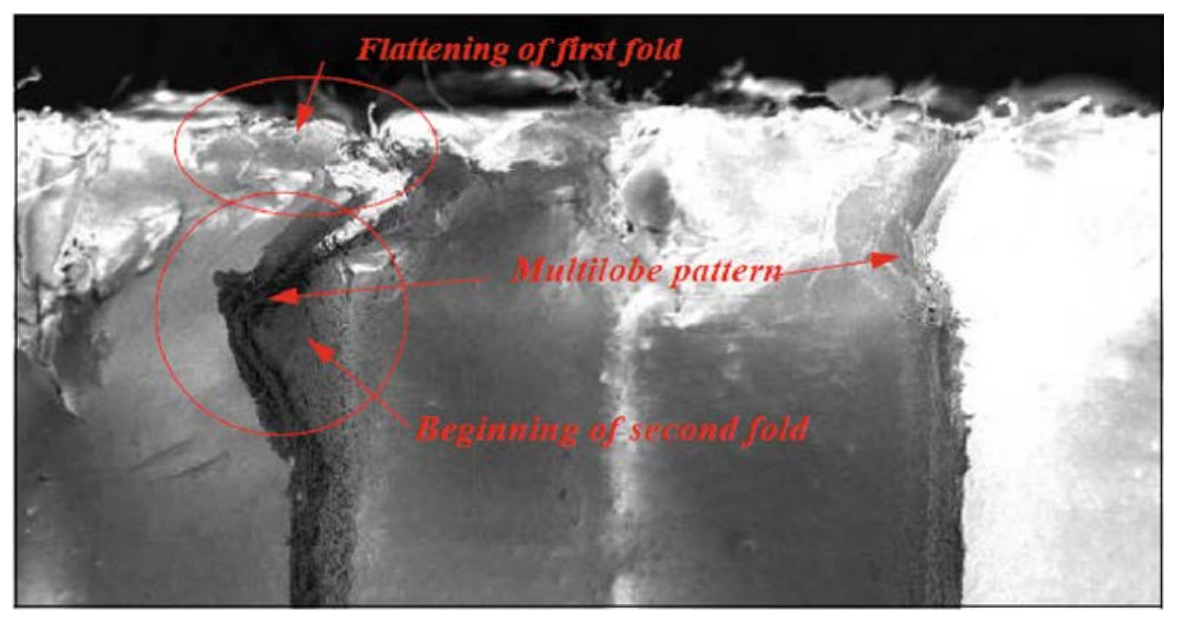

Fig. 5 Picture at point 8. Continuation of folding

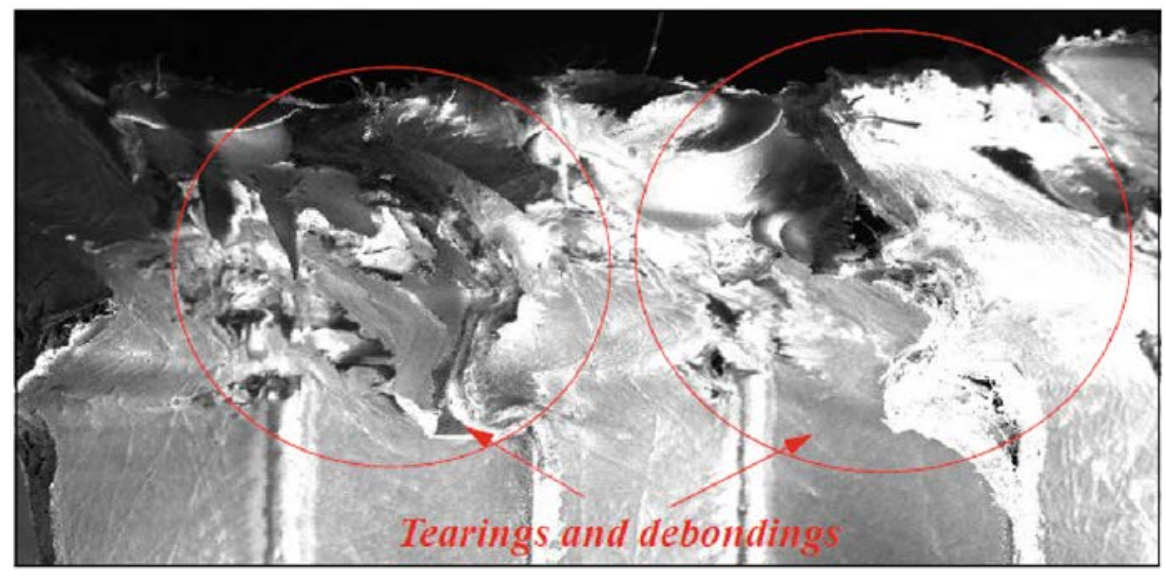

Fig. 6 Picture at point 11, damages in the honeycomb

non-axisymmetrical form or multi-lobe mode. The term is taken from Enboa Wu and Wu-Shung-Jiang's work [25] where the experiments were performed on a hexagonal tube subjected to compression loading. The multi-lobe folds depend on the tube diameter-to-thickness ratio [25-27]. During the crushing, the first folds flatten and new folds appear in relation to the force in the area called a "plateau" on the forcedisplacement curve.

The comparison between folding length $(\mathrm{H})$ and eccentricity factor $(\mathrm{m})$ as defined in Fig. 7, observed using an electron microscope and calculated using the "tube in compression" theory proposed by Singace [23], is shown in Table 1 . The factor $m$ is obtained by minimizing the strain energy of the folding and does not depend on the materials, diameter of the tube, or N. Its value is found to be 0.642 [23]. 


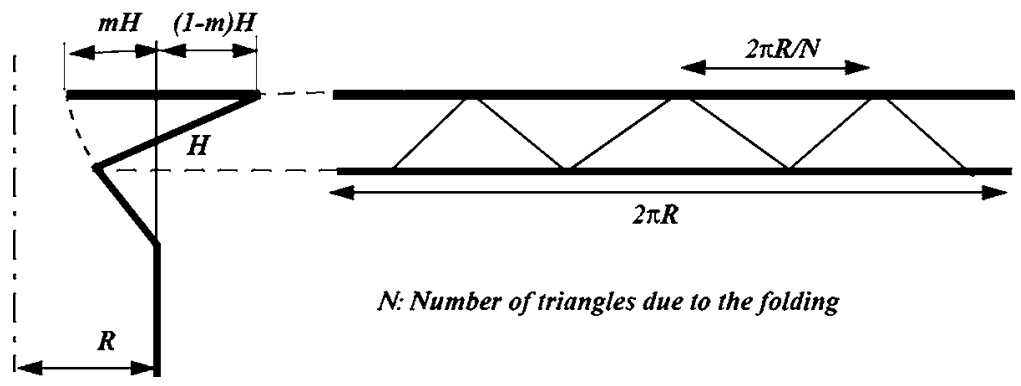

Fig. 7 Definition of factors $m$ and $\mathrm{H}$ [23]

Table 1 Comparison between test and theory of folding

\begin{tabular}{lll}
\hline & Test & Calculation \\
\hline Eccentricity factor $(\mathrm{m})$ & 0.65 & 0.64 \\
Folding length $(\mathrm{H})(\mathrm{mm})$ & 0.667 & 0.518 \\
\hline
\end{tabular}

To determine $\mathrm{H}$, the following equation is used:

$$
\frac{H}{t}=\frac{\pi}{N} \tan \left(\frac{\pi}{2 N}\right) \frac{R}{t} .
$$

where $\mathrm{t}$ is the thickness of the tube and $\mathrm{R}$ its radius.

It is difficult to determine the length of the fold on the pictures obtained from the electron microscope because the images are not very clear. To determine the length of the fold $\mathrm{H}$ using the formula (Eq. 1) given by Singace [23], the number $\mathrm{N}$ is taken equal to 6 (corresponding to the six faces of the honeycomb) and radius (R) is equal to the outer radius of the cell. The test results are similar to the calculation, which shows that the folding of the Nomex honeycomb also obeys the geometric laws. In addition, from a qualitative point of view, the phenomenon of folding occurs at various size scales and is similar for different honeycomb materials. For example, Fig. 8 shows the folding of individual cells of wood (the phenomenon is identical for the cells of foams). Figure 9 shows the folding of corrugated cardboard and Fig. 10 the folding of a steel tube subjected to compression loading.

In this subsection, the folding phenomena of Nomex honeycomb have been observed. It has been shown that complex failure modes are involved. By looking at the research related to other crushing mechanisms, it has been proved that crushing is controlled by the geometry of the honeycomb cell. Qualitative observation also shows that the phenomenon is similar for different cell sizes and materials of the honeycomb. Therefore, for a more detailed understanding of the crushing mechanism of Nomex honeycomb subjected to compression loading, it is possible to use different materials and sizes of honeycomb core. This reasoning by analogy is proposed in the next part. 


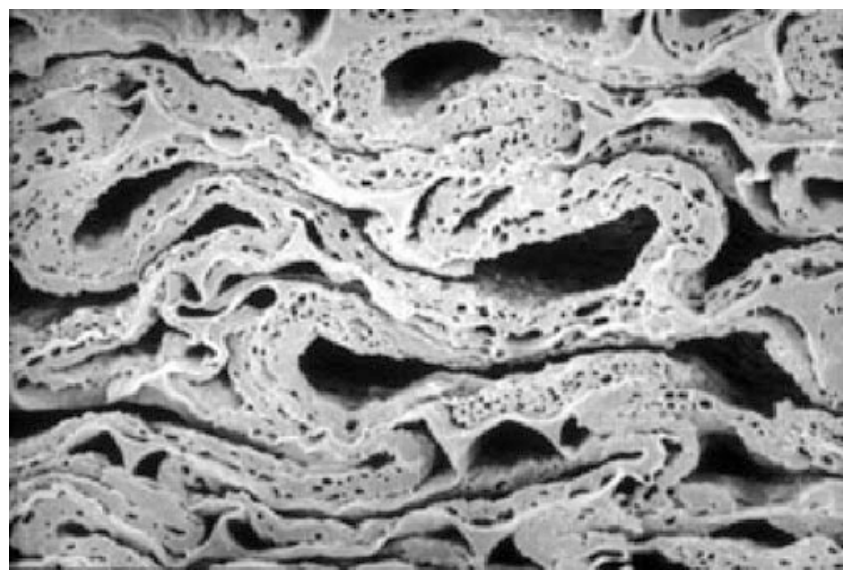

Fig. 8 Crushing of a wood cell

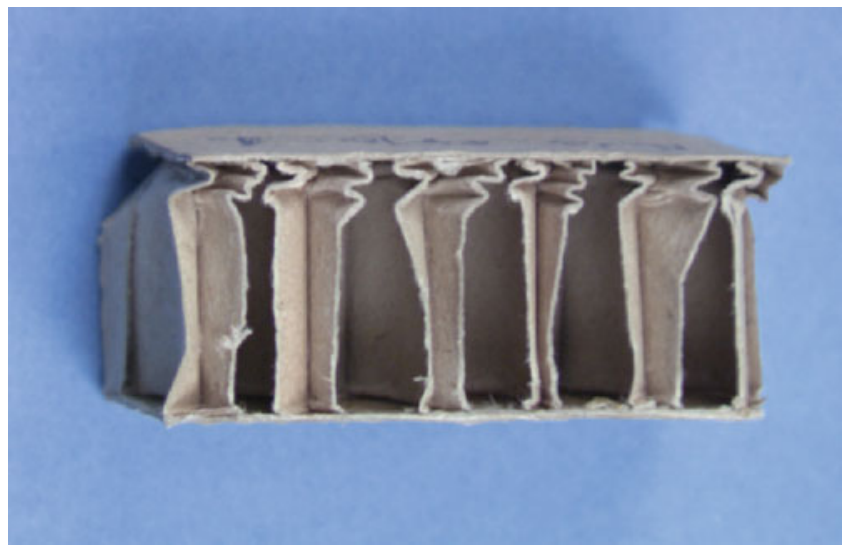

Fig. 9 Crushing of corrugated cardboard

\subsubsection{Identification of the Folding Mechanisms}

Compression tests were conducted on honeycomb blocks. A honeycomb made of drawing paper with a cell size of $35 \mathrm{~mm}$ was made manually in the laboratory. Aluminum honeycomb with a cell size of $6 \mathrm{~mm}$ and Nomex honeycomb, cell size $5 \mathrm{~mm}$, were used to complete the test series. The tests used an Instron machine with a compression speed of $0.5 \mathrm{~mm} / \mathrm{min}$ to obtain a quasi-static test. Each honeycomb tested (Table 2) was composed of two specimen types: with either two honeycomb faces or only one face glued to Plexiglas skins. The local boundary conditions were thus different, which will highlight the importance of this point. Finally, for each test, the force/displacement curves were plotted and the folding mechanism during the test on the drawing-paper honeycomb was filmed as shown in Fig. 11. 
Fig. 10 Crushing of steel

tube (Reproduced from [23])

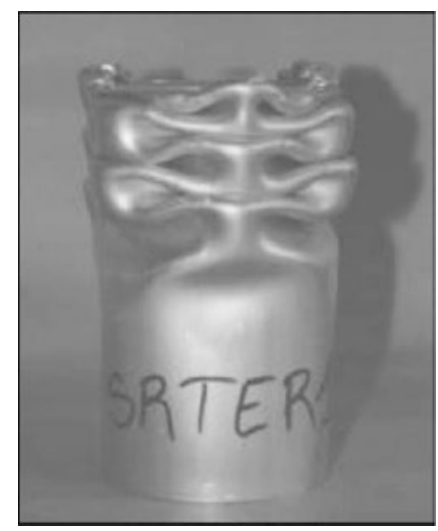

Table 2 Specimens for uniform compression tests

\begin{tabular}{llll}
\hline Material & Drawing paper & Nomex & Aluminum \\
\hline Cell size $(\mathrm{mm})$ & 35 & 5 & 6 \\
Number of cells & 11 & 36 & 10 \\
Specimen dimension $\left(\mathrm{mm}^{2}\right)$ & $140 \times 140$ & $35 \times 35$ & $25 \times 25$ \\
Thickness $(\mathrm{mm})$ & $0.58-0.34$ & & 0.12 \\
Height $(\mathrm{mm})$ & $45-22.5$ & 15 & $45-15$ \\
Number of skins & 1 or 2 & 1 or 2 & 1 or 2 \\
Number of specimens & 8 & 4 & 6 \\
\hline
\end{tabular}
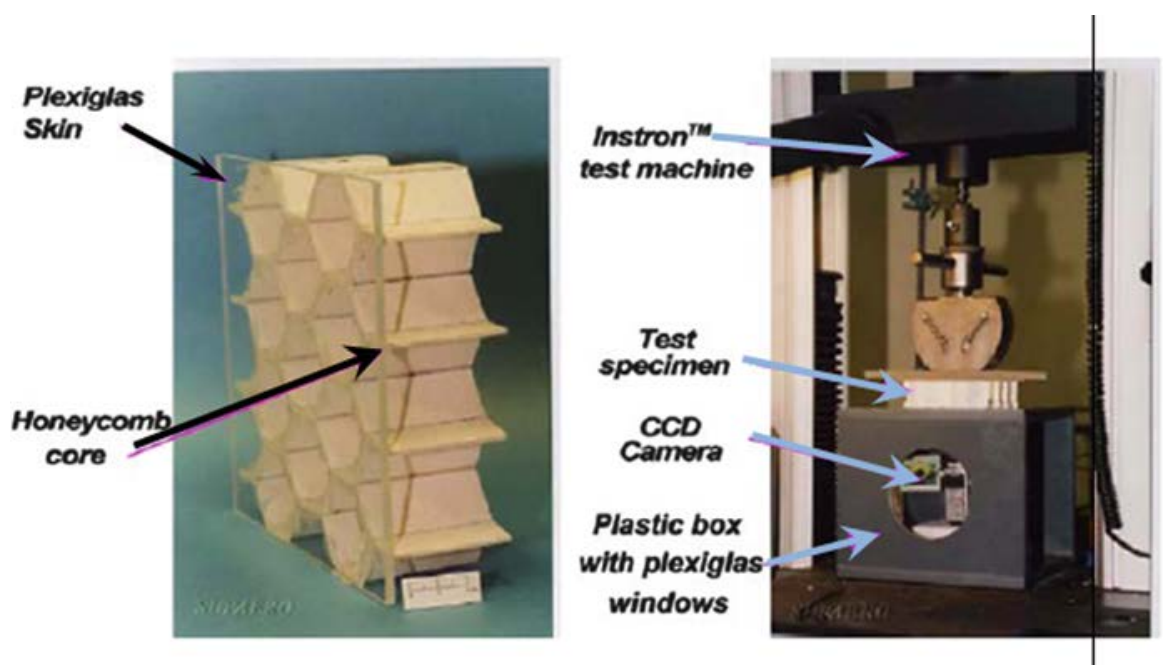

Fig. 11 Test specimen and test rig 


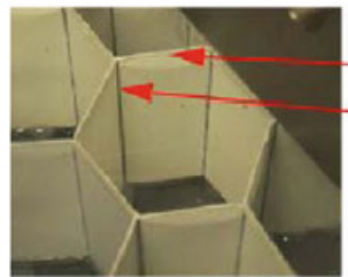

First step
First local buckling

Vertical edge romains stralght

Vertical edges begin to deform

First fold appears

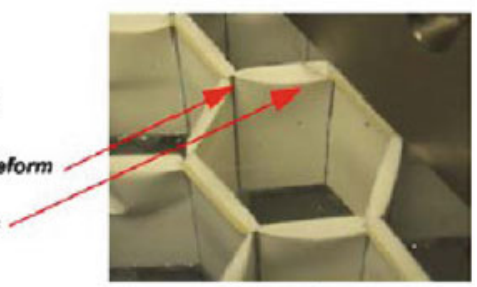

Second step

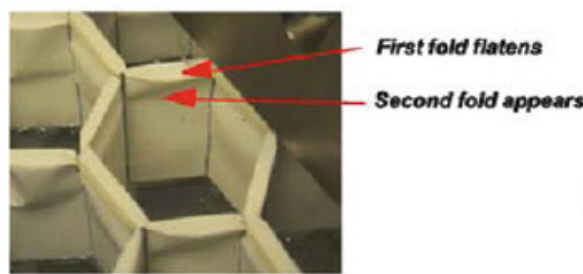

Third Step

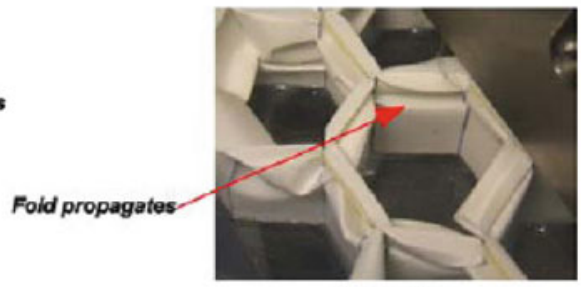

Next Step

Fig. 12 Folding mechanism in the drawing paper honeycomb specimen

The mechanism of deformation observed on drawing-paper honeycomb with only one skin was as follows (Fig. 12).

\section{First step: Initiation of the first fold.}

Local buckling appeared on the free face of the honeycomb (without the Plexiglas skin). In this step the cell vertical edges remained straight. The simply supported boundary conditions authorized local rotation of the free face and seemed to be the origin of this folding initiation.

Second step: Flatness of the first fold and appearance of the second.

In this step, the folding increased gradually and the vertical edge started to deform. During the first folding process, the second fold also started to form. The folds made propagated alternately on one side then the other of the cell wall. During folding, interpenetrating local tears and local separations could be observed on the vertical edge.

Third step: Flattening of the second fold and appearance of the third.

In this step the second fold was flattened and, simultaneously, the third fold appeared. In the same manner, it was observed that the vertical edge either tore or fell apart and the honeycomb vertical edges were deformed according to the symmetrical or anti-symmetrical folding at their three walls. Then, the same mechanism was reproduced at lower height.

Next steps: Successive the honeycomb folding.

Folding and flattening followed one another in the same way as previously. The folding mechanism was the same for all drawing-paper honeycomb specimens. The honeycomb height and density (thus wall thickness) did not influence the mechanism described. The same observations were made for the aluminum and 


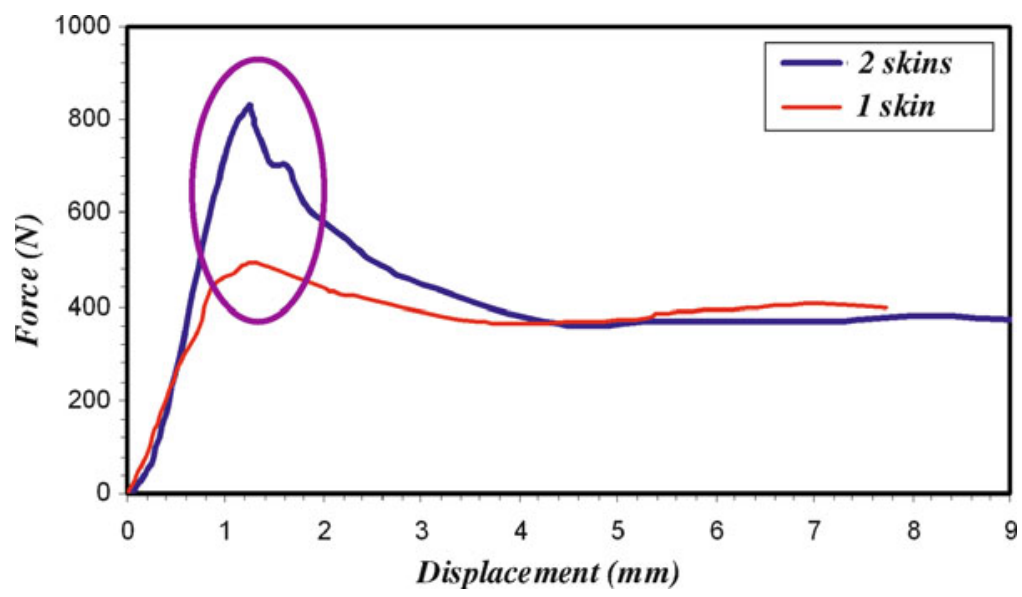

Fig. 13 Compression laws for the drawing-paper honeycomb specimens

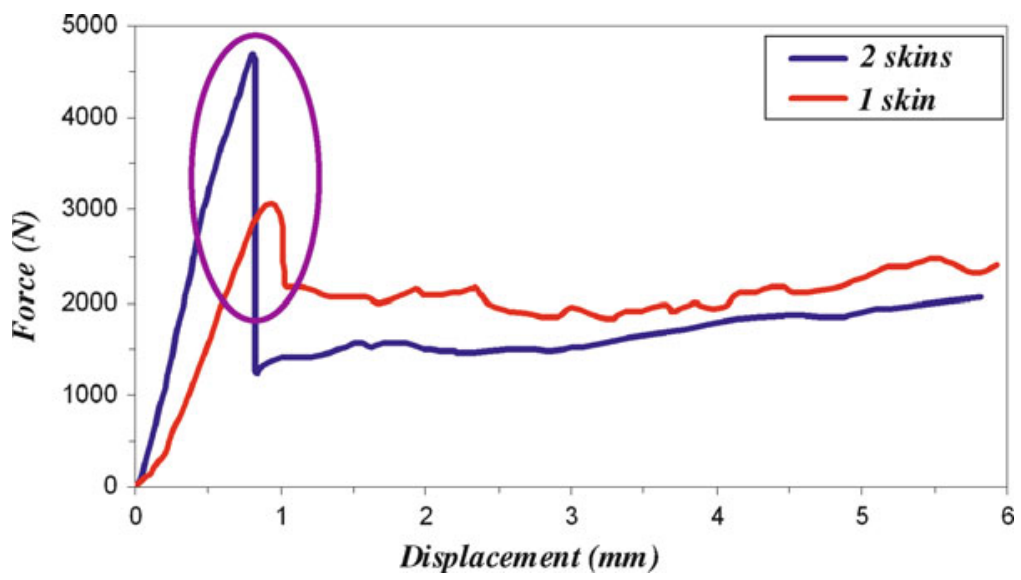

Fig. 14 Compression laws for the Nomex honeycomb specimens

Nomex honeycomb. However, the fold shape differed for each material: rounded for aluminum and with sharp angles for Nomex. This difference of shape can be attributed to the different plasticity of the materials. For the tests using specimens with two skins, folding occurred randomly through the honeycomb height but was never located near the skins. The final deformation pattern of the specimens is presented in reference [28].

The force-displacement curves of the honeycombs tested under uniform compression are given in Figs. 13, 14, and 15 for the different materials and for specimens with one or two skins.

The classic response [12] can be observed for all the cases. The behavior is elastic at the beginning of indentation until a critical load is reached. After the peak load, a 


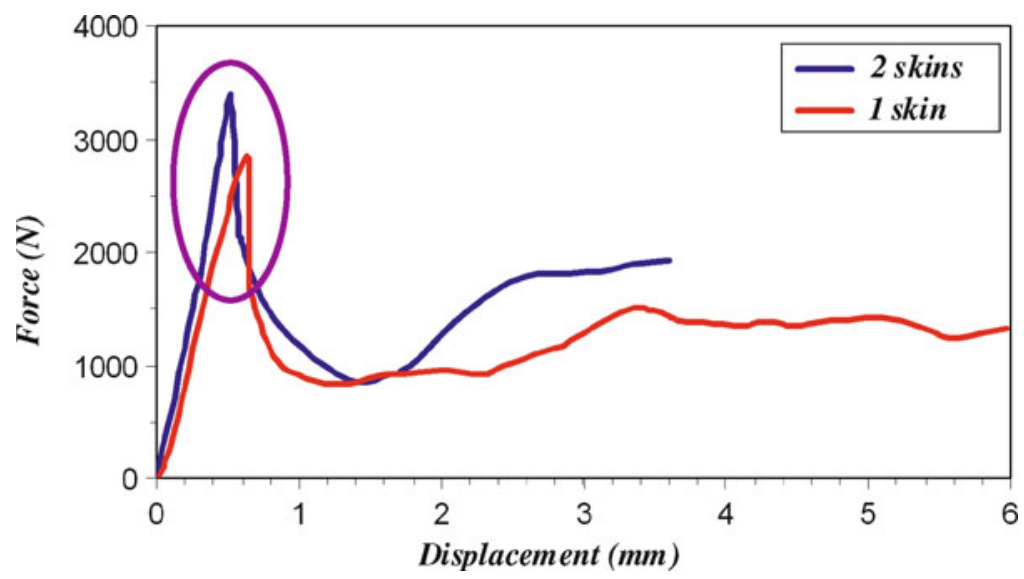

Fig. 15 Compression laws for the aluminum honeycomb specimens

sharp drop in load is observed, especially for two-skin specimens. It corresponds to the beginning of vertical edge deformation. The force decreases to reach a plateau, which corresponds to the succession of fold forming and results in densification of the honeycomb. The critical load for the two-skin specimens is always larger than that for one skin. It seems that there is an analogy with global buckling theory where the critical load is higher for clamped boundary conditions than for the simply supported one. The load drop is sharper for the Nomex honeycomb than for the drawing paper and the aluminum ones. This can be explained by the properties of their respective materials. In fact, the phenolic resin at the surface of the Nomex honeycomb cell wall breaks at the same time as the first fold occurs, which reduces the strength of the cell significantly. In the case of the aluminum honeycomb, a plastic hinge is formed at the fold angle, giving higher residual strength and less abrupt behavior. Another important fact to note is that, for aluminum honeycomb, the maximum peak load is almost the same for one- or two-skin specimens, which is not the case for paper or Nomex material. This highlights the importance of boundary conditions for "soft core materials".

To confirm these interpretations, an implicit finite element model (SAMCEFTM software) of a Nomex honeycomb hexagonal cell was made (see Fig. 16). The honeycomb was made from Aramid paper impregnated with phenolic resin that was then polymerized. This heterogeneous material was rendered homogeneous numerically with $\mathrm{E}_{\text {Vertical }}=2,341 \mathrm{MPa}, \mathrm{E}_{\text {Horizontal }}=3,065 \mathrm{MPa}, \mathrm{G}=800 \mathrm{MPa}, \nu=0.4$. The orders of magnitude of these characteristics were obtained theoretically and they were then used for linear numerical computation on several honeycomb models that fit the elastic stiffness of the experimental test. Once the material characteristics had been found, linear buckling was computed. In the case of the "one-skin" specimen, the first buckling mode was an earlier buckling of the hexagonal cell wall. The same was observed experimentally. Moreover, the deformed shape of this mode clearly showed how the fold was initiated. Also, the buckling force corresponding to this 


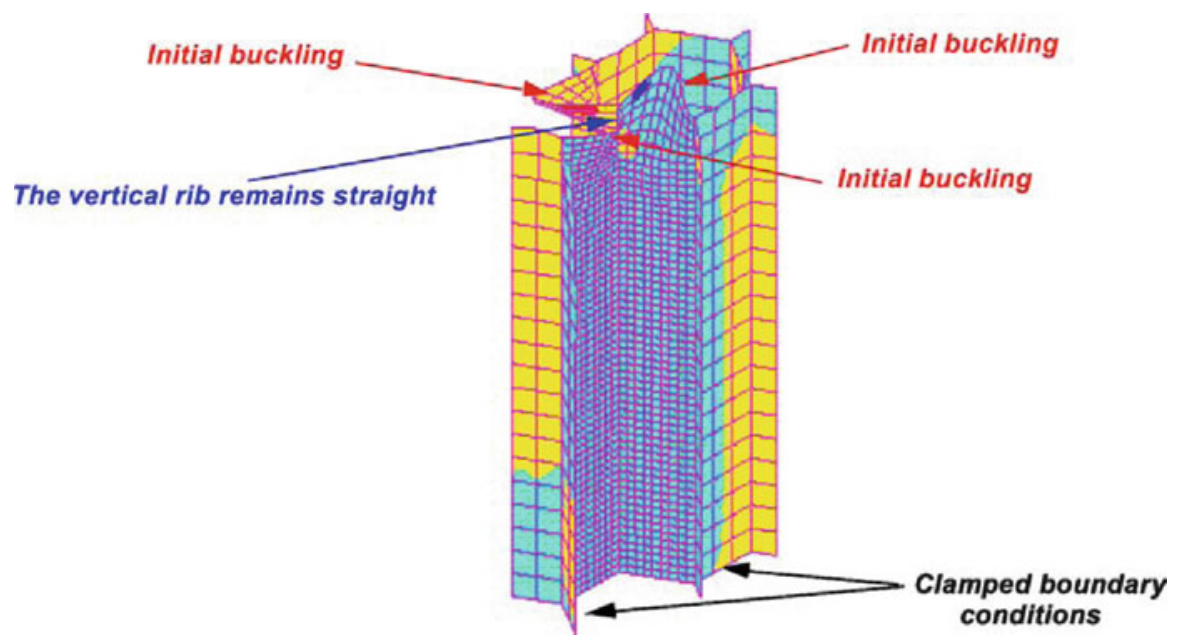

Fig. 16 Initial buckling mode of a Nomex hexagonal cell under uniform compression

mode was about $20-50 \%$ of the critical force observed in testing. The numerical analyses seem to confirm the interpretation of the test results. Since the buckling phenomenon appeared very early in the cell walls made from soft material, it can be assumed that the vertical edges of cells control the crushing behavior. Moreover this observation has already been reported by Wierzbicky [12], who proposed an analytical model for the aluminum honeycomb. Finally, some tests on single edges made of aluminum alloy or glass fibers [28] have demonstrated that, from a qualitative point of view, the compression-displacement curve is almost the same (linear response, peak load and plateau area).

This experimental study and some numerical investigations show that the overall crushing mechanism of the honeycomb structures is linked almost solely to the early buckling of cell walls and the response of the cell edge. These observations lead us to make an analogy with the post-buckling of a stiffened structure. This will be detailed in the next subsection and will lead to a proposal for the discrete modeling of honeycomb core. This approach will be validated on indentation tests on Nomex honeycomb core alone.

\subsubsection{Analogy with Buckling of Stiffened Structures and Discrete Modeling}

Since local buckling occurs early, the honeycomb structure works in a post-buckling mode and an analogy can be made with stiffened thin structures under compression loading such as can be found in aircraft structures (Fig. 17).

The stiffeners in honeycomb are the vertical edges, each of which is formed by the intersection of three thin cell walls. When the skin buckles, the compressive 

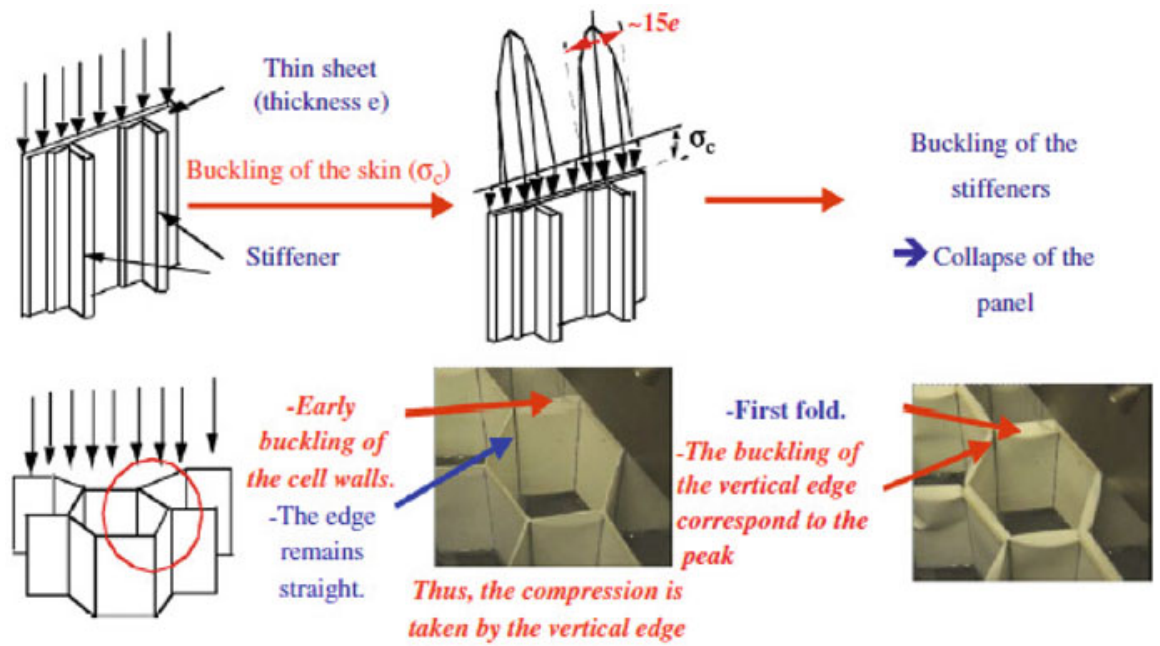

Fig. 17 Analogy with the buckling of stiffened panels

stress in the skin cannot be more than the buckling stress and the excess of compression loading is therefore taken up by the stiffener and a portion of the skin located near the stiffener with an equivalent half-width equal to 15 times the skin thickness [29, 30]. By analogy, for the honeycomb cell, the compression is mainly taken by the vertical edges since the buckling of the walls occurs earlier. Then the collapse of the stiffened structure corresponds to the global buckling of the stiffeners. In the case of honeycomb, there is no collapse but rather folding. The previous analysis shows that only the cell edge plays an important role from a structural point of view. This reasoning leads to the hypothesis that Nomex honeycombs under a crushing force behave like a juxtaposition of cell vertical edges and it is possible to model them by a grid of vertical nonlinear springs located at the angles of the hexagons (see Fig. 18). The compression law can be determined by a uniform compression test. To determine this law, a Nomex honeycomb with 100 cells was carefully selected by cutting the specimen to preserve the vertical edges on its sides. The force-displacement curve obtained in the test was divided by 240 (number of vertical edges) to obtain the force-displacement behavior law of one vertical edge [28].

The modeling proposed in Fig. 18 implies the following assumptions:

1. External loading is taken mainly by the vertical edges of the honeycomb structure.

2. The vertical edges behave independently.

3. The contact between honeycomb and impactor is assumed to be perfect, which means that the honeycomb in contact with the indenter follows the indenter shape during crushing. 


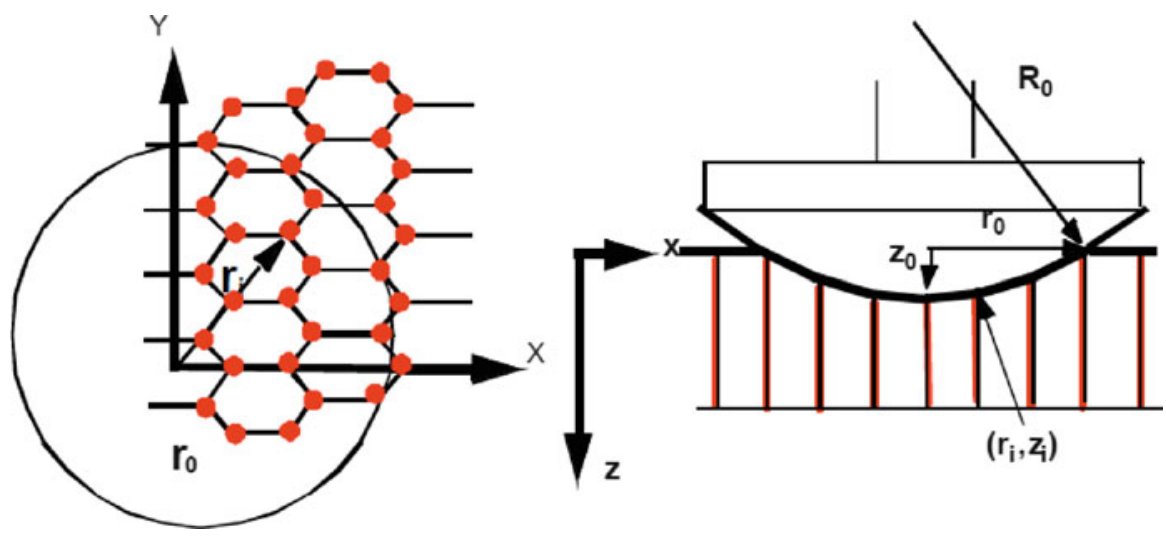

Fig. 18 Principle of honeycomb modeling

By making this assumption and using a polynomial function to discretize the compression law of one vertical edge, it is possible to propose an analytical model to compute the contact law. The computation steps (for a spherical indenter case) are the following:

1. Computation of polar radius $\left(r_{i}\right)$ of the vertical edges.

Since the vertical edges are regularly distributed, their distance is a function of the diameter of the honeycomb cell. At the beginning of contact, the indenter is considered to be at the center of a cell. The problem becomes symmetrical and only a quarter model is considered for the computation.

2. Computation of the damaged surface radius $\left(r_{0}\right)$ when impactor crushes down to $z_{0}$.

The value $\mathrm{r}_{0}$ is calculated as a function of $\mathrm{z}_{0}$ and $\mathrm{R}_{0}$ (indenter radius) by using the following equation:

$$
\mathrm{r}_{0}=\sqrt{\left(\mathrm{R}_{0}{ }^{2}-\left(\mathrm{R}_{0}-z_{0}\right)^{2}\right)}
$$

3. Computation of the penetration of each vertical edge $\left(z_{\mathrm{i}}\right)$.

The penetration of the vertical edges under the damaged surface $\left(r_{i}<r 0\right)$ is calculated using the following equation:

$$
\mathrm{z}_{\mathrm{i}}=\sqrt{\mathrm{R}_{0}^{2}-\mathrm{r}_{\mathrm{i}}^{2}}-\mathrm{R}_{0}+\mathrm{Z}_{0}
$$

4. Computation of the reaction force of each vertical edge $\left(F_{i}\right)$.

Knowing the penetration of each vertical edge $\left(\mathrm{z}_{\mathrm{i}}\right)$ obtained by the previous calculation, the reaction force for each edge $i\left(F_{i}\right)$ is obtained using the curve of its behavior law found as in the previous subsection (Fig. 14, two skins). 


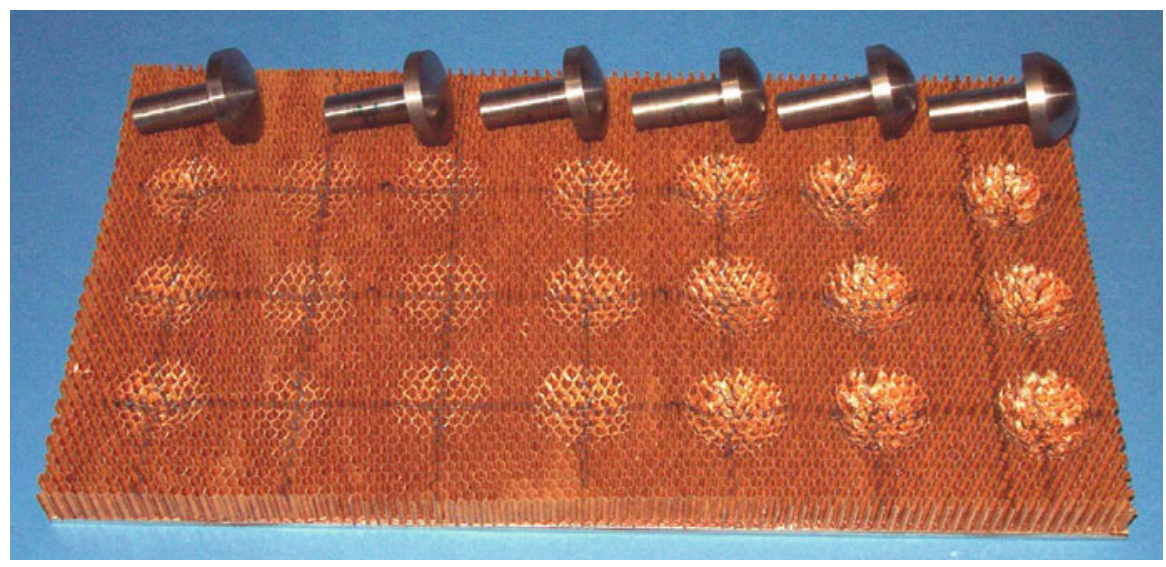

Fig. 19 Indentation tests on Nomex honeycomb alone with spherical indenters of different radii and a conical indenter

\section{Computation of indentation force.}

This is the sum of the reaction forces on each of the vertical edges:

$$
\mathrm{F}=\sum \mathrm{F}_{\mathrm{i}}
$$

To obtain a complete law of indentation force versus indentation crushing, the same step is computed for several increments $\mathrm{z}_{0}$ of indenter displacement.

\subsection{Validation of the Discrete Approach}

In the previous subsection, the honeycomb was considered as a structure that allowed an original discrete model to be proposed, based on the post-buckling phenomenon in stiffened structures. In this new subsection, this approach will be compared to direct indentation tests on a Nomex honeycomb without skins. The discrete approach is based on the assumption of independence of the response of the edges. Also, in a second step, the range of validity of this assumption will be sought.

\subsubsection{Indentation with Spherical Indenters}

The tests carried out for this study used one conical (half-angle $18^{\circ}$ ) and five spherical indenters with different radii $(\mathrm{R}=57.25,30.125,21.75,18.06$, and $16.25 \mathrm{~mm}$ ) but with the same overall diameter (see Fig. 19). Three tests were carried out with each indenter to observe the dispersion related to the impactor position at 


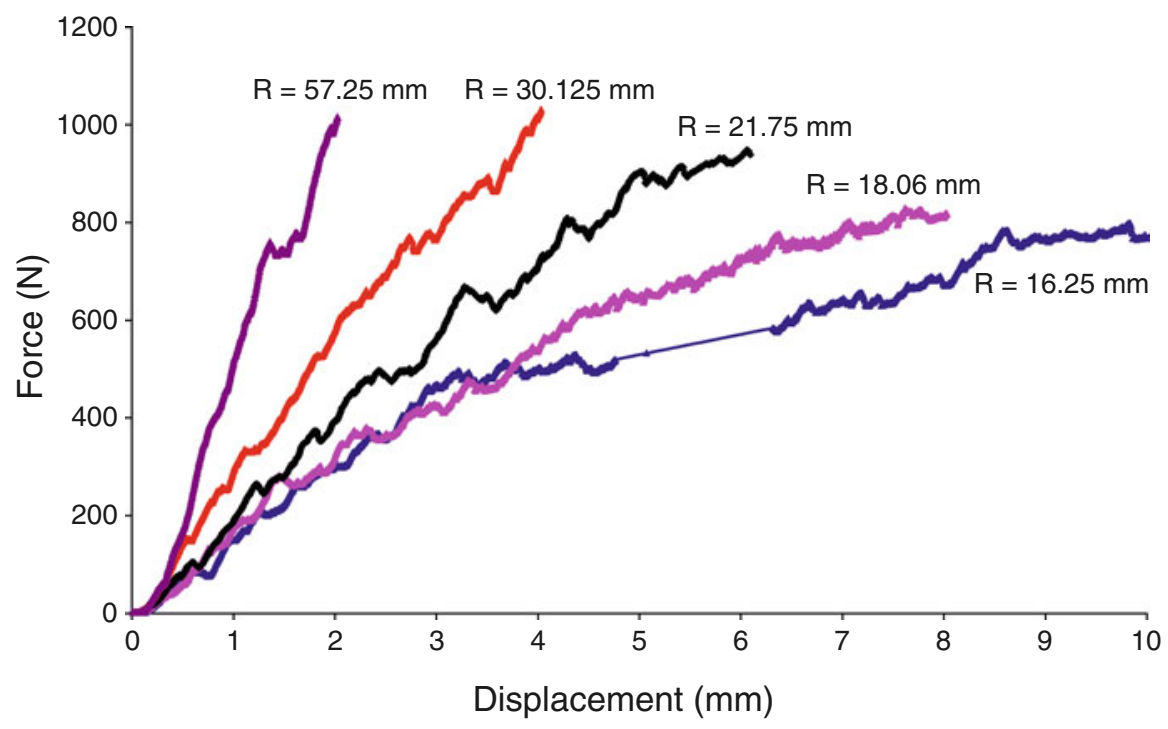

Fig. 20 Indentation test results for spherical indenters

the beginning of indentation (located at the center of the first cell in contact or not). Good test repetition was observed for each indenter.

The contact laws obtained from the tests can be seen in Fig. 20. A small undulation is visible, which corresponds to the drop in load of the vertical edges in the perimeter of the indenter. These undulations are less visible for larger impactor radii $(R=57.25 \mathrm{~mm}$, Fig. 20$)$ because the vertical edges inside the damaged surface are crushed at almost the same time. At the end of all tests, the final loading was identical (Fig. 20) except for tests with small impactor radii $(\mathrm{R}=18.06 \mathrm{~mm}$ and $\mathrm{R}=16.25 \mathrm{~mm}$ ) (Fig. 21). It seems that this difference is due to the folding out of the vertical edges (instead of perfect vertical crushing) which begins from a certain depth of indentation. For the other tests, the same level of loading was reached at the same indentation displacement corresponding to the same number of folded vertical edges. During the tests, the honeycomb took the same shape as the surface of the indenter. The vertical edges situated just outside the crushed zone did not undergo any deformation, showing that there was no interaction between two neighboring vertical edges. These observations reconfirm the assumption that only the vertical edges "work" during indentation on a free-standing Nomex honeycomb structure.

The analytical calculation based on the discrete approach presented in Sect. 2.1.1 and the test results for the various indenters are compared in the following figures. A good correlation between calculation and test is obtained with a difference of less than $10 \%$ for all the indenters (Figs. 22, 23, 24), except those with the smaller 


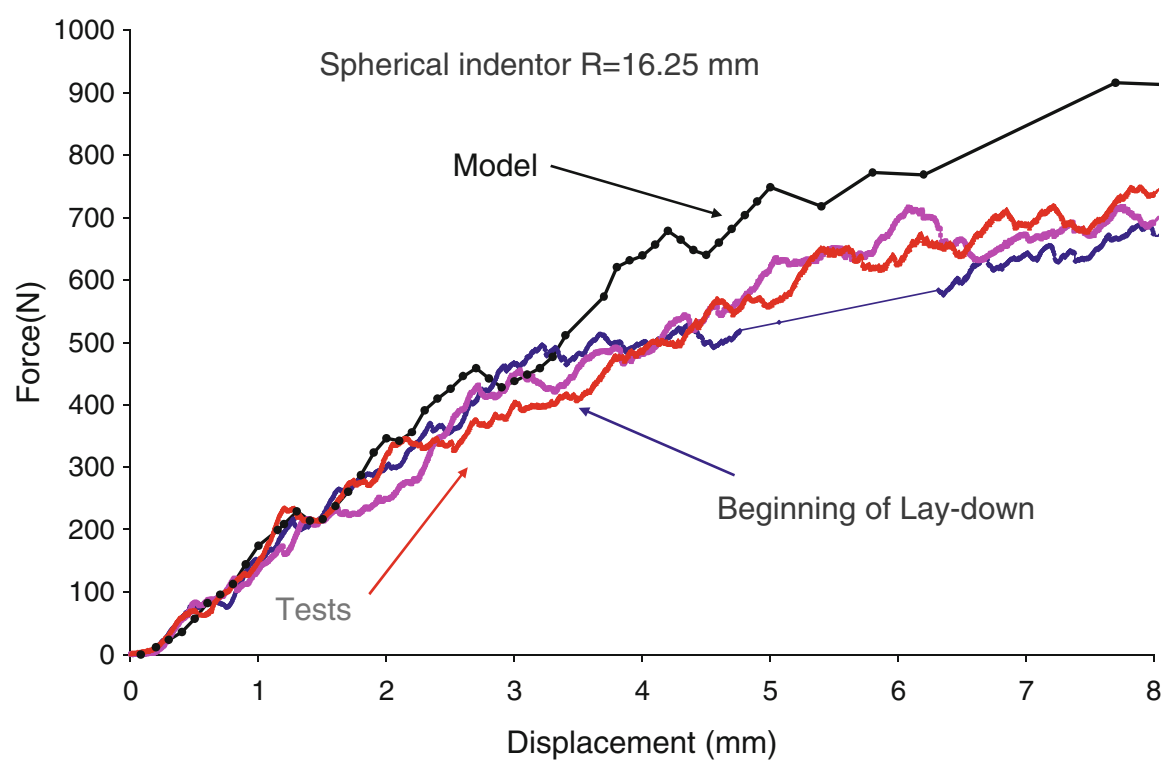

Fig. 21 Comparison between discrete model and test for a spherical indenter with a radius of $16.25 \mathrm{~mm}$

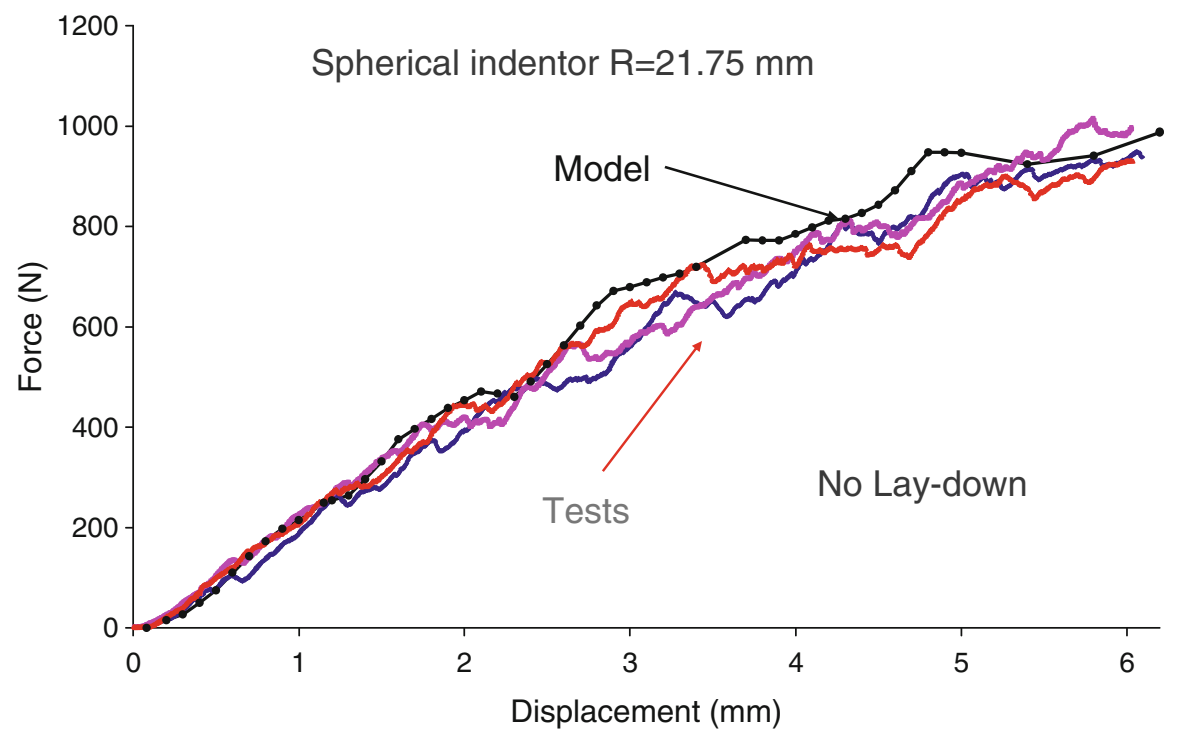

Fig. 22 Comparison between discrete model and test for a spherical indenter with a radius of $21.75 \mathrm{~mm}$ 


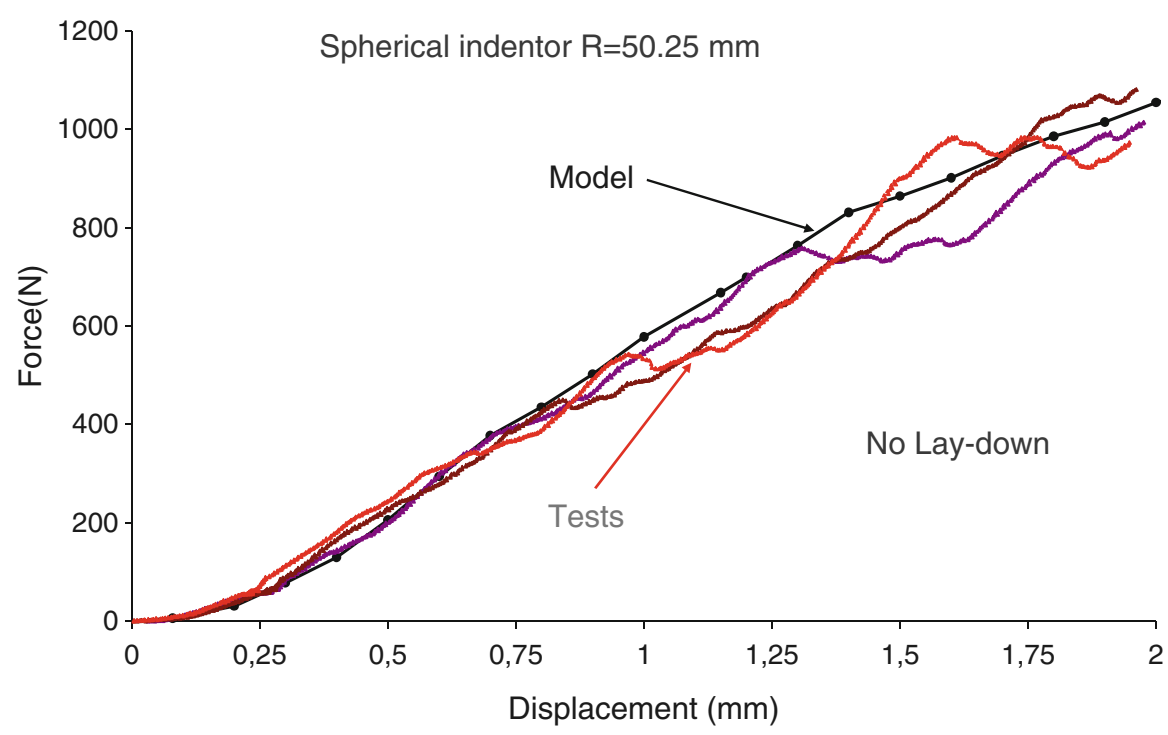

Fig. 23 Comparison between discrete model and test for a spherical indenter with a radius of $57.25 \mathrm{~mm}$

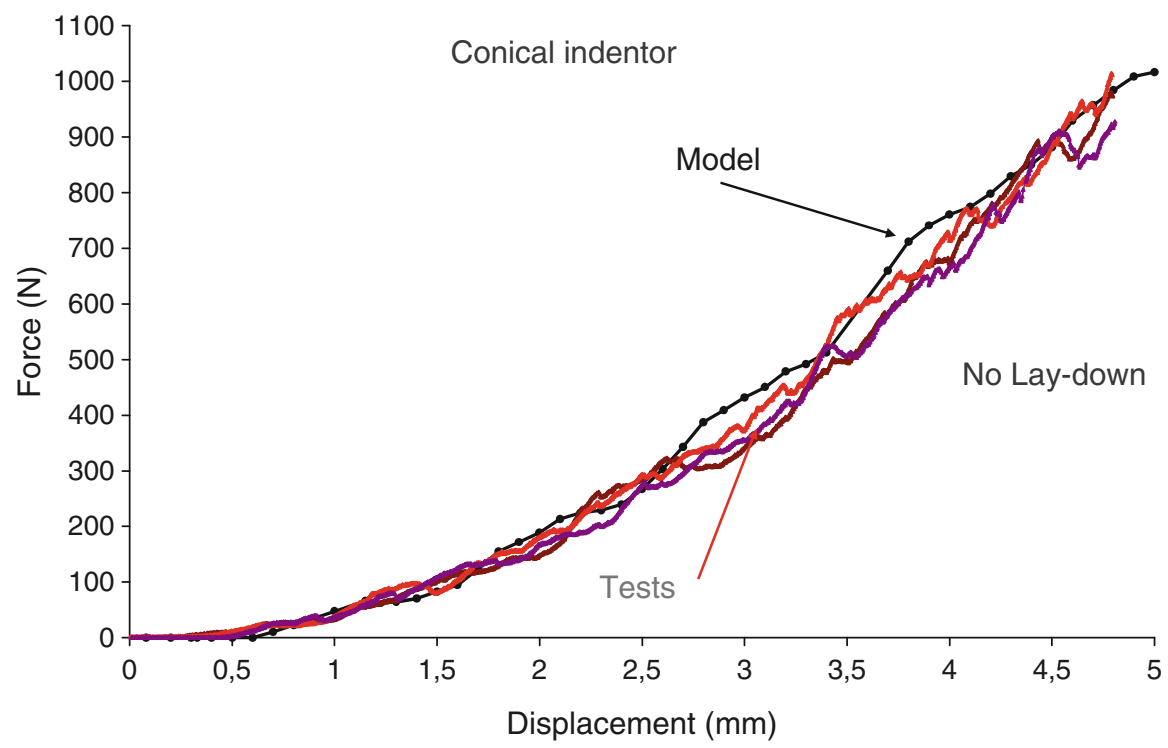

Fig. 24 Comparison between discrete model and test for a conical indenter 
diameters because of the folding out phenomenon (Fig. 21). Moreover, we note that the model generates oscillations similar to those observed in the tests, which tends to show that the approach seizes the mechanical behavior of the crushing of the honeycomb core.

In this subsection, the discrete approach has been validated, confirming the assumptions and the methodology suggested previously. However, since the model is based on the independence of the cell edges' behavior, the limits of this assumption will be analyzed.

\subsubsection{Verification of the Assumption of Independent Behavior of Edges}

The crushing force of one edge is now formulated in the following way:

$$
F=F_{\text {crush }}\left(w_{i}\right)+\sum_{i=1}^{3} F_{\text {shear }} \cdot H\left(w_{i}-w_{j}-w_{\text {limit }}\right)
$$

where $w_{i}$ is the vertical depth of crushing of cell edge $i . w_{j}, j=1-3$, are the crushing depths of the adjacent edges. $\mathrm{H}\left(\mathrm{w}_{\mathrm{i}}-\mathrm{w}_{\mathrm{j}}-\mathrm{w}_{\text {Limit }}\right)$ is a Heaviside function with:

$$
\mathrm{H}\left(\mathrm{w}_{\mathrm{i}}-\mathrm{w}_{\mathrm{j}}-\mathrm{w}_{\text {Limit }}\right)= \begin{cases}0 & \text { if } w_{i}-w_{j}-w_{\text {Limit }} \leq 0 \\ 1 & \text { if } w_{i}-w_{j}-w_{\text {Limit }}>0\end{cases}
$$

The influence of $\mathrm{F}_{\text {shear }}$ was investigated and $\mathrm{w}_{\text {Limit }}$ was determined from the results of tests using cylindrical indenters that created shear stress in the walls located in the circumferential zone of the indenter as explained by Wierzbicki et al [31]. Quasi-static tests using three different radii $(8,14.75$ and $25 \mathrm{~mm})$ of cylindrical indenters were conducted on the same honeycomb as in the previous subsection (see Fig. 25). Two tests were performed for each radius but only single-test curves are presented because the behavior hardly varied. The circumference of the cylindrical indenter can be observed to coincide either with a vertical edge (POINT 1, Fig. 25) or with a wall (POINT 2, Fig. 24). According to the position on the circumference, it can be assumed that either the edge is subjected to compression or the wall is under shear load.

Figure 26 compares the contact laws obtained from experiment and computation on the discrete model without taking the shear of the walls into account, for the three indenters, in terms of force versus indentation depth. The curves are nearly superimposed at the beginning and the difference starts to appear from a point corresponding to the shear of the wall in the circumferential zone. It is interesting to note that this difference begins to appear at indentation depths of about $0.32 \mathrm{~mm}$ independently of the indenter diameter. It should also be noted that the number of cell walls on the circumferential zone is proportional to the radius of the indenter. There were 18, 30 and 56 cells for radii of 8, 14.75 and $25 \mathrm{~mm}$ respectively (Fig. 27). 


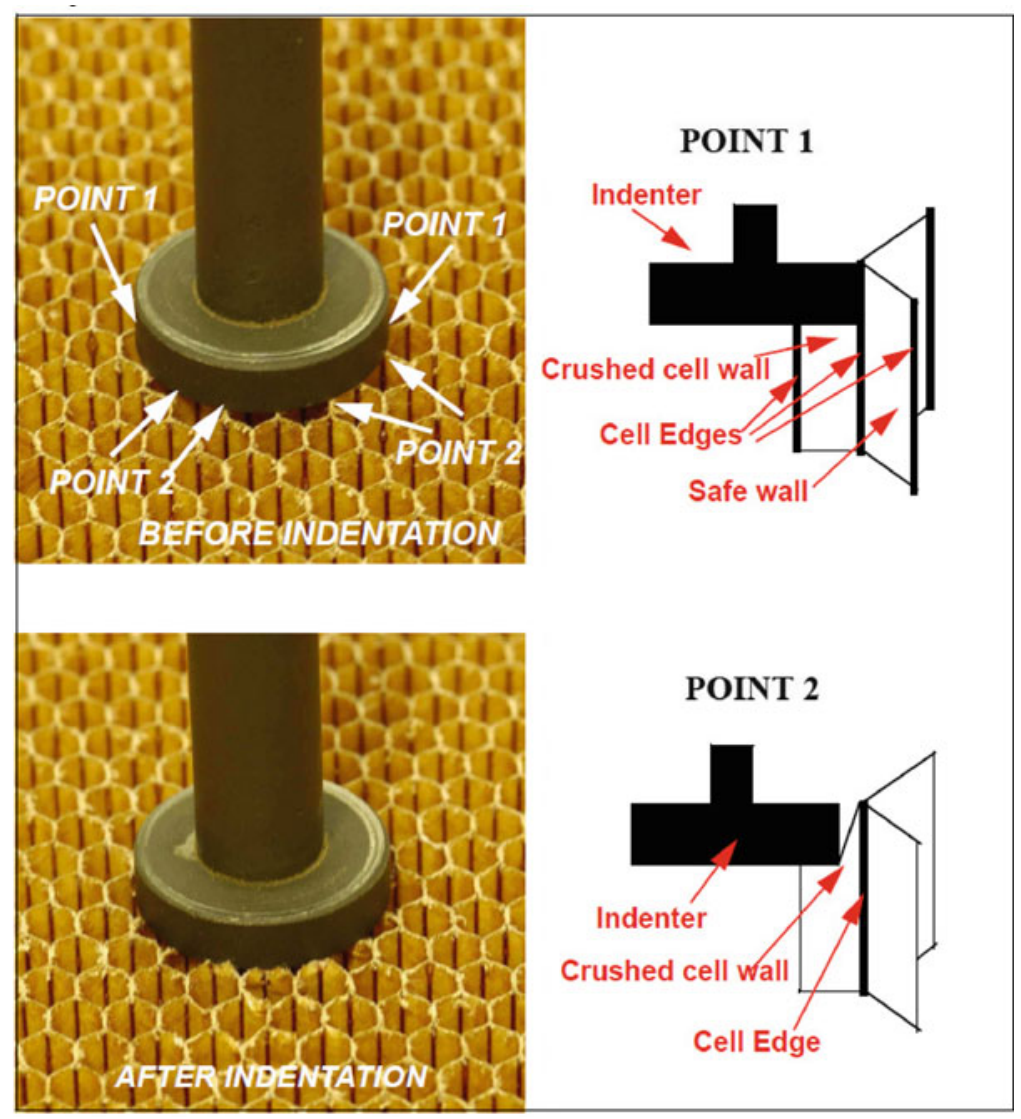

Fig. 25 Description of the indentation test with a cylindrical indenter

Since it is assumed that these walls are subjected to shear load, the shear force is also proportional to the indenter radius. This additional shear force, $\mathrm{F}_{\text {Sup }}$ can be expressed as

$$
\mathrm{F}_{\text {Sup }}=2 \pi \mathrm{r} \cdot \mathrm{q}_{\text {shear }} \text {, }
$$

Where $\mathrm{r}$ is the radius of the cylindrical indenter and $\mathrm{q}_{\text {shear }}$ is the shear force per unit length in the circumferential zone.

The unit shear force $\mathrm{q}_{\text {shear }}$ can thus be obtained by dividing the difference between the computation and the test by $2 \pi r$. Calculations show that the unit force $\mathrm{q}_{\text {shear }}$ is not very different for the three indenter radii (Fig. 26). However, the peak force is smaller for the $8 \mathrm{~mm}$ radius, possibly because of the greater dispersion due to the location of the indenter and the small number of walls subjected to shear load. This result globally confirms the hypothesis that the extra indentation force is taken 

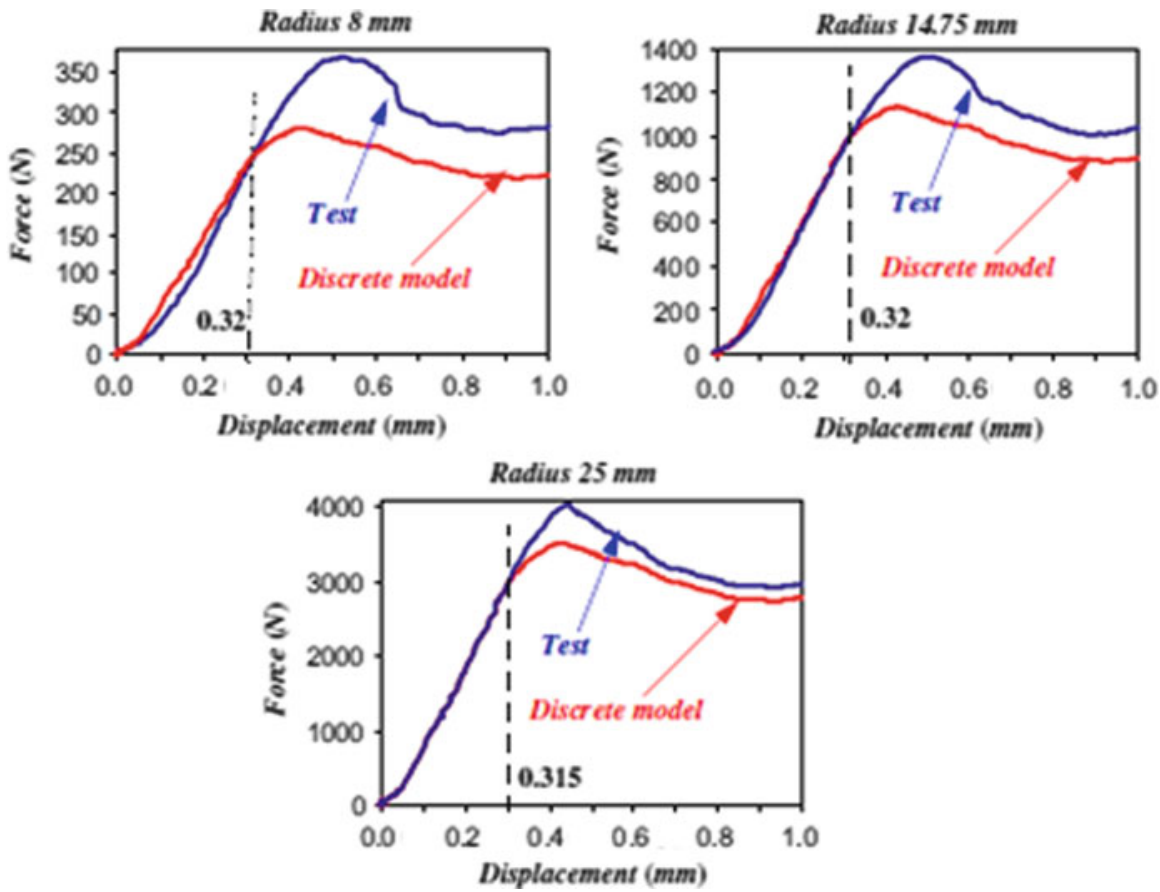

Fig. 26 Comparison of experimental contact law using cylindrical indenter and discrete model

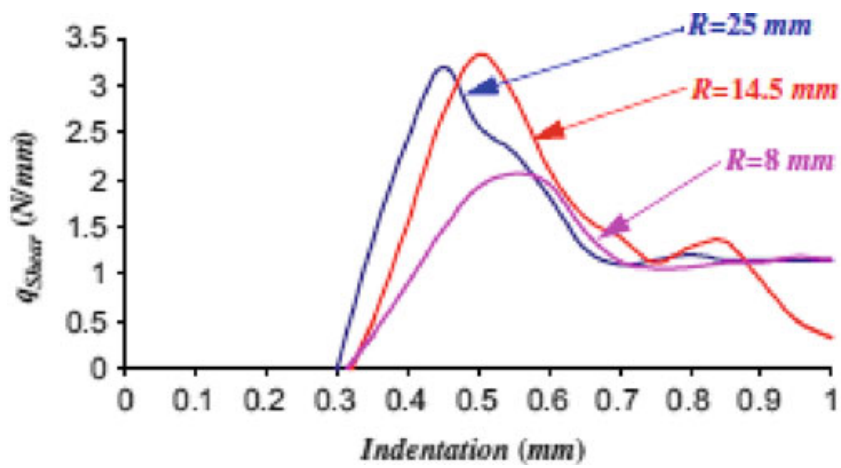

Fig. 27 Peripheral shear force per unit length

up by shear load at the periphery of indenter and is in agreement with Wierzbicki et al.'s results [31]. The results also demonstrate that the additional force, due to shear only, occurs from a certain indentation depth limit: $\Delta \mathrm{w}_{\text {Limit }} \approx 0.32 \mathrm{~mm}$. Below this threshold, the error induced by assuming that the honeycomb can be modeled simply by its vertical edges, which behave independently of each other and are subjected only to compression load, seems to be negligible. A simple geometrical 


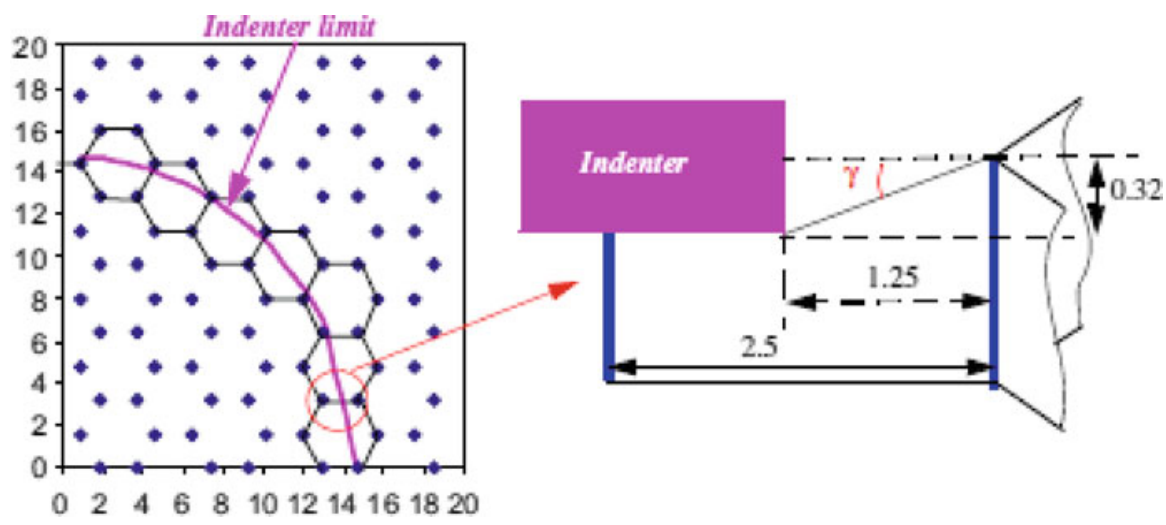

Fig. 28 Geometry for the computation of the limit $\gamma$

analysis (Fig. 28) shows that the corresponding limit angle is $0.27 \mathrm{rad}$, about $15^{\circ}$. This calculation was performed assuming that the circumference of the indenter passed through the middle of the cell, which avoided having to take the reaction of the vertical edge into account. It was then verified a posteriori that, in the case of experiments using spherical indenters, this limit was not reached. The limit angle varied between $0.007 \mathrm{rad}$ (radius $57.25 \mathrm{~mm}$ ) and $0.025 \mathrm{rad}$ (radius $16.25 \mathrm{~mm}$ ) which is well below the calculated threshold. To see if the angle obtained had a real physical meaning, a complementary test was carried out with a conical indenter of half-angle $18^{\circ}\left(>15^{\circ}\right)$ at the summit. It was observed that the edge-independence hypothesis still remained valid as the correlation between calculation and test results was very good (Fig. 24), which suggests that the actual threshold is little higher.

In consequence, for the indentation of a sandwich structure, it will be possible to model the honeycomb by its vertical edges alone if the deformation of the skin is not too pronounced and the difference in crushing between two neighboring edges does not exceed $w_{\text {Limit }}$, which is generally the case. For all our studies, $w_{i}-w_{j}$ was always less than $\mathrm{w}_{\text {Limit }}$. Therefore, we did not try to determine the $\mathrm{F}_{\text {shear }}$ law because it is only needed for sharp projectiles acting on thin skins. In such cases, the skin is generally perforated, which is outside the scope of our research.

\subsection{Conclusions}

A phenomenological study of crushing has led us to propose an original model of Nomex honeycomb subjected to indentation loading. Because, in this study, we considered the honeycomb as a structure and not a material, it has been demonstrated that the compression load is essentially taken by the vertical edges of the hexagonal cell. This is the first step and the key-point in efficiently modeling 
impacts on sandwich structures and setting up fast maintenance loops. Thus, the honeycomb can be represented by only its vertical edges, the crushing law for which can be obtained by a uniform compression test on a honeycomb block. It seems that the approach can be used for other honeycomb materials since the deformation mechanism is very similar. However a doubt exists for rigid walls, as in the case of aluminum core, because the buckling load of the wall is quite high and it is not sure that the post-buckling behavior occurs. Moreover, the hypothesis of edge independence would probably not be satisfied because of the stiffness of aluminum alloy. This key result allows the honeycomb to be modeled in indentation with a grid of nonlinear springs located exactly on the honeycomb vertical edges. The approach was then validated by experiments of indentation of Nomex honeycomb core with various conical and spherical indenters. By using a flat, cylindrical indenter, it was also demonstrated that the assumption of edge independence remains valid for nottoo-sharp indenters. In the next section, this approach will be extended to sandwich structures with the same honeycomb core and metallic skins.

\section{Impact on Sandwich Structures with Metallic Skins}

In this section, a method is developed to model low-velocity/low-energy impacts on metal-skinned sandwich structures. Metal skins were used in order to avoid the complex failure damage mode of composite laminated skin. Experiments and numerical studies were carried out on sandwich structures with the same Nomex honeycomb core as described in the last section. Unlike classical modeling, which considers the core (honeycomb or foam) as a material and a continuum, the previous section has demonstrated the relevance of considering the honeycomb as a structure. Since it acts as a structure, the boundaries are important. So, in a first part, the interaction between the skin and the honeycomb core will be studied first by analyzing the indentation of a sandwich plate on a rigid foundation. Then, to overcome, the main limitation of a grid of vertical springs, which is not able to take the transverse shear in the core into account, a multi-level approach to the impact on a sandwich structure will be proposed.

\subsection{Indentation of Sandwich Plates Supported by Rigid Foundation}

In this subsection, indentation of sandwich plates with thin or thick skins is analyzed from an experimental and a numerical point of view. The approach proposed in the previous section is enhanced by taking the interactions between the skins and the honeycomb core into account. 
Table 3 Detail of the sandwich specimens made

\begin{tabular}{llll}
\hline Sandwich materials & $\begin{array}{l}\text { Skin thickness } \\
(\mathrm{mm})\end{array}$ & $\begin{array}{l}\text { Specimen size } \\
(\mathrm{mm})\end{array}$ & Number \\
\hline $\begin{array}{l}\text { Skin: brass core: Nomex (HRH } \\
78,1 / 8,3) 48 \mathrm{~kg} / \mathrm{m}^{3}, 15 \mathrm{~mm}\end{array}$ & 0.1 & $100 * 100$ & 6 \\
thick & 1 & $100 * 100$ & 6 \\
\hline & 1 & $220 * 100$ & 6 \\
\hline
\end{tabular}

Fig. 29 Description of the indentation tests on sandwich specimens

\subsubsection{Experiments}

Quasi-static indentation tests were carried out on $100 \mathrm{~mm} \times 100 \mathrm{~mm}$ sandwich structures. Brass skins of 0.1 and $1 \mathrm{~mm}$ thickness were bonded to the Nomex honeycomb with a layer of REDUX 312/5 glue. Tension tests were performed on brass skin specimens for the two thicknesses. Brass was chosen because of its marked plastic behavior and its maximum strain, which avoid cracks appearing during the indentation. For the 0.1-mm specimen, the elastic modulus was 103,100 MPa and the yield stress was about $433 \mathrm{MPa}$. For the 1-mm specimen, the elastic modulus was 70,400 MPa and the yield stress was about $104 \mathrm{MPa}$. It should be noted that the two specimens had different alloy compositions. Several specimens were made, as listed in Table 3.

Indentation of all specimens was performed using the same INSTRON ${ }^{\mathrm{TM}}$ machine and the same spherical indenters of different radii $(57.25,30.125$ and $21.75 \mathrm{~mm}$ ). Tests were performed at a speed of $0.5 \mathrm{~mm} / \mathrm{min}$, which can be considered as quasi-static loading. The specimens were fully supported on a rigid metal foundation (Fig. 29). The loads were measured by the machine's sensor but displacements were measured using a dial comparator positioned on the indenter. Three tests were completed for each type of sandwich structure (with thin or thick skin) and for each indenter.

Figure 30 shows the damage area after indentation for a specimen with a thickness of $0.1 \mathrm{~mm}$. The cracks appear in the center of the damaged area for specimens indented by the 31.75 and $21.25 \mathrm{~mm}$ diameter indenters. 


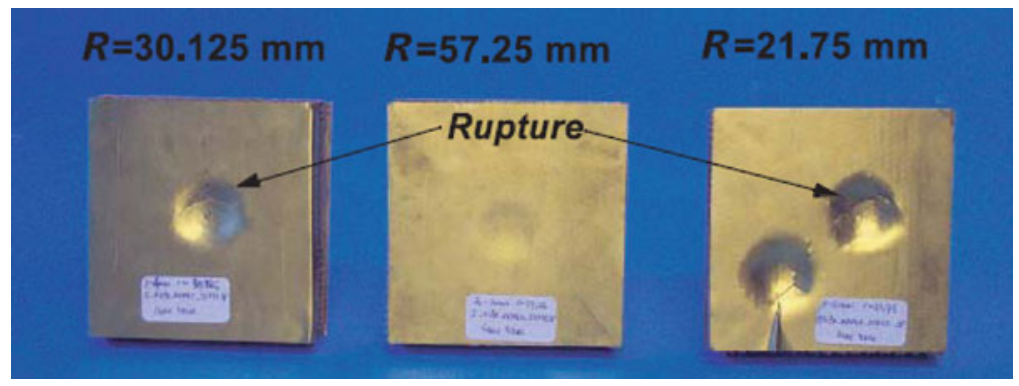

Fig. 30 Indentations on sandwich specimens

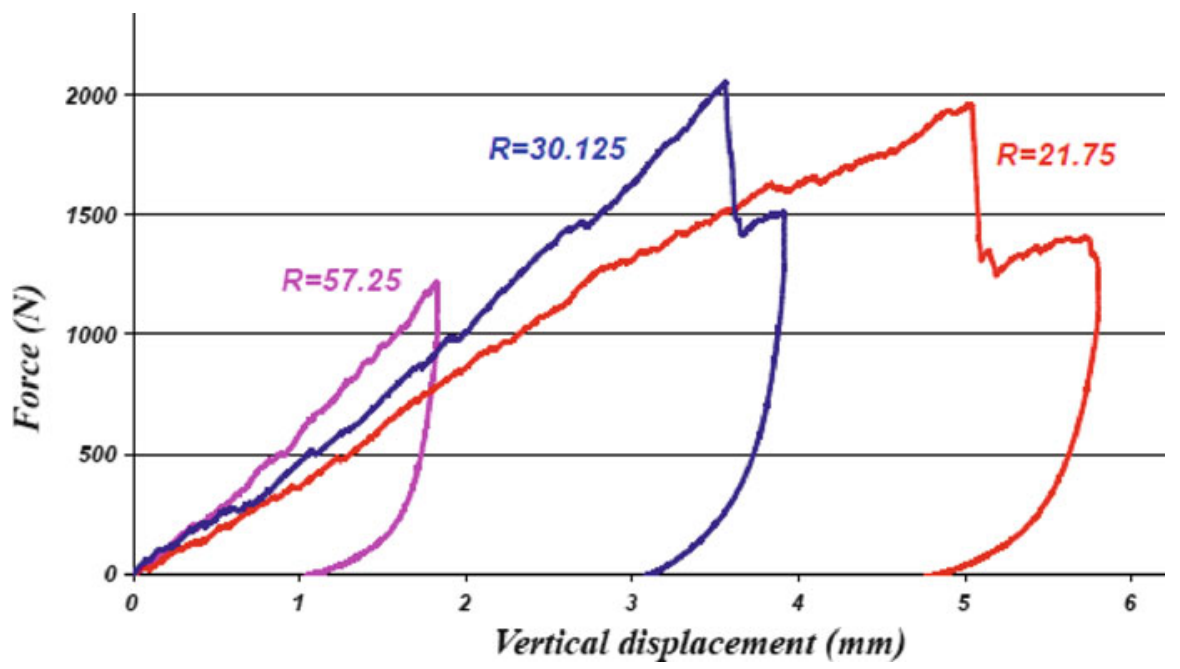

Fig. 31 Force/displacement curve for sandwich with brass skin thickness of $0.1 \mathrm{~mm}$

The contact laws obtained showed low dispersion of the results except for extreme loads in the case of $0.1 \mathrm{~mm}$ thin skins. This seems to have been due to the appearance of cracks in the bottom of the indentation, in spite of the qualities of the alloy. Experimental contact laws are presented in Fig. 31 (skin $0.1 \mathrm{~mm}$ ) and Fig. 32 (skin $1 \mathrm{~mm}$ ). For specimens with skin thickness of $0.1 \mathrm{~mm}$, the curves have no particularities except small undulations similar to those observed in the test with honeycomb alone. For sandwiches with skins $1 \mathrm{~mm}$ thick, the stiffness was very high at the beginning and lower thereafter. This qualitative change can be attributed to the collapse of the first cell of the honeycomb under the indenter as the change of slope occurs at a value of indentation displacement of $0.29 \mathrm{~mm}$, which also corresponds to the transition from the "peak" (or maximum force) to the "plateau" zone of the honeycomb force-displacement curve obtained previously from uniform compression testing on a block of honeycomb alone. Moreover, a specific sound was heard at the same time. 


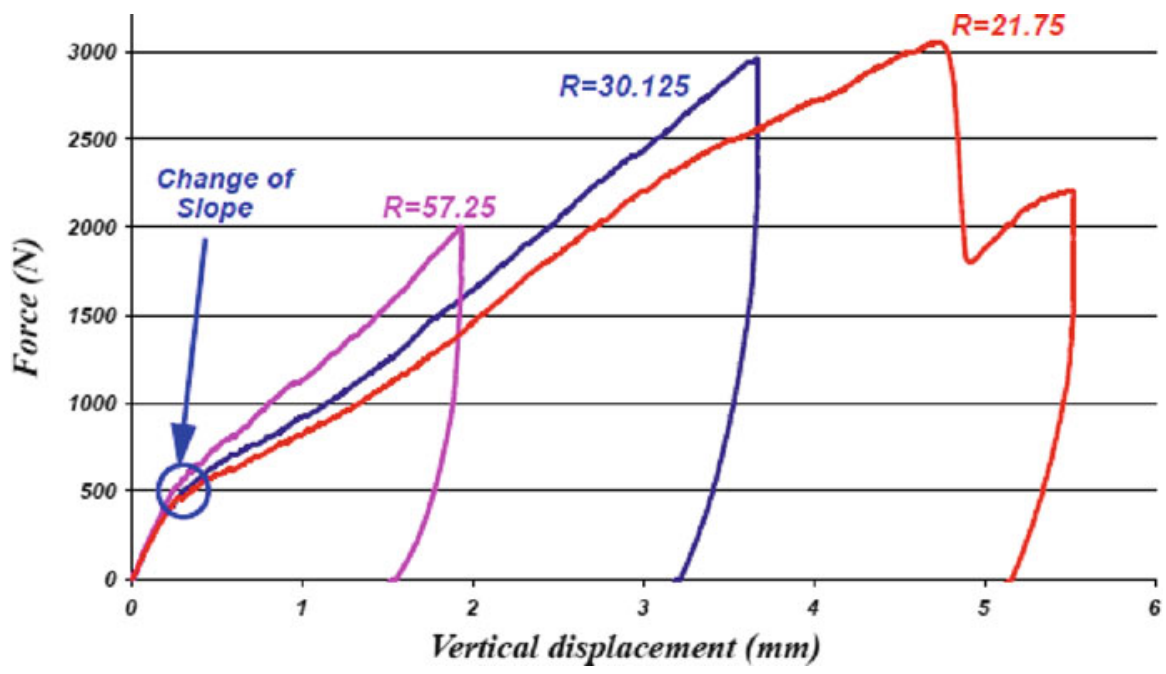

Fig. 32 Force/displacement curve for sandwich with brass skin thickness of $1 \mathrm{~mm}$

The different behaviors observed with thick and thin skin suggests that the mode of folding of the vertical edges must be different. It is likely that the deflection of thin skin, which has a low bending stiffness, follows the shape of the indenter almost perfectly (Fig. 33) while the thick skin deforms differently (Fig. 33) because its quadratic bending moment is 1,000 times greater.

Thus the bending deflection of the thick skin imposes local rotations on the edges. Moreover, in the literature, experimental observations have shown that the edges remain perpendicular to the skin locally [32] due to a perfect honeycomb-skin bond. In addition, uniform compression tests with one or two skins showed the sensitivity of the folding mechanism to the boundary conditions. It is clear that this behavior involving the rotation of edges must be included in the model proposed previously. Therefore, an enhanced compression law is proposed in the next subsection. It is also important to note here that the conventional continuum solid modeling cannot take this sensitivity to boundary conditions in rotation into account.

\subsubsection{Enhanced Compression law and Test/Numerical Model Comparison}

As demonstrated in the previous part, the local rotations must be taken into account as they modify the crush law of a cell edge from a "with peak" law to a "no peak" law. So, the following form is proposed for a generalized crush law of a cell edge when there is no shear:

$$
F=F_{\text {crush }}\left(w_{i}, \theta_{i}\right)
$$




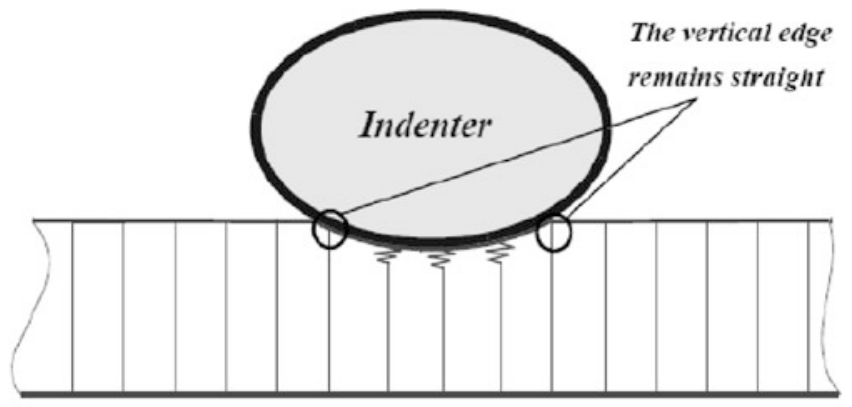

(a) : Sandwich with thin skins.

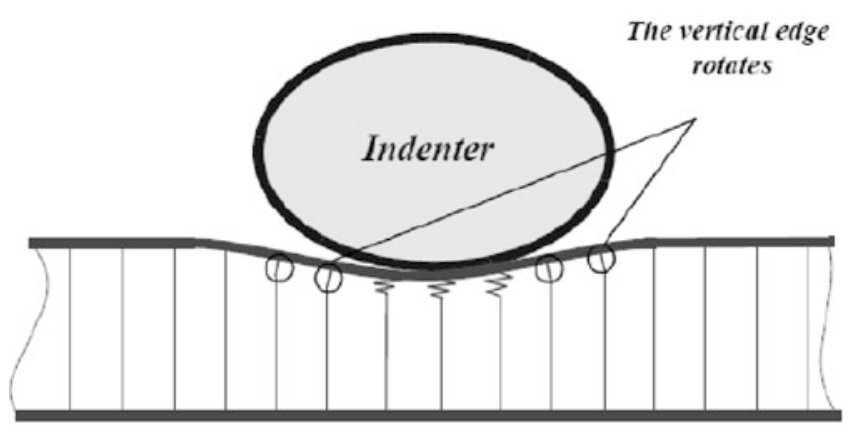

(b) : Sandwich with thick skins.

Fig. 33 Physical explanation of the different behavior between sandwiches with thin and thick skins

where $\mathrm{w}_{\mathrm{i}}$ and $\theta_{\mathrm{i}}$ are the vertical depth of crushing and the local rotation on the upper part of cell edge i. The function $\mathrm{F}_{\text {crush }}\left(\mathrm{w}_{\mathrm{i}}, \theta_{\mathrm{i}}\right)$ is plotted in Fig. 34. Three different crushing laws were used and are plotted in Fig. 34: "with peak" $F_{w p}$, "no peak" $F_{n p}$ and an intermediate law $F_{i}$ :

The choice between the different laws depends on the value of the local rotation at the interface between the core and the skin following these rules:

- if $\theta_{i}=0$ the experimental "with peak" $F_{w p}$ law is used (see the "two-skins" curve Fig. 14).

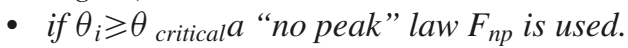

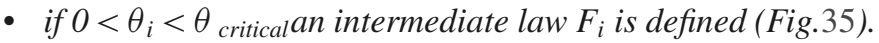

An implicit nonlinear finite element model was made (see Fig. 36). The software used was the SAMCEF ${ }^{\mathrm{TM}}$ code [33]. Nonlinear springs were placed at the same locations as the positions of the honeycomb cell angles.

The generalized law was implemented using special features of the software. The metal skins were modeled by Mindlin plate elements for thin skin $(0.1 \mathrm{~mm})$ specimens and by volume elements in the thickness for thick skins (1 mm). Using 


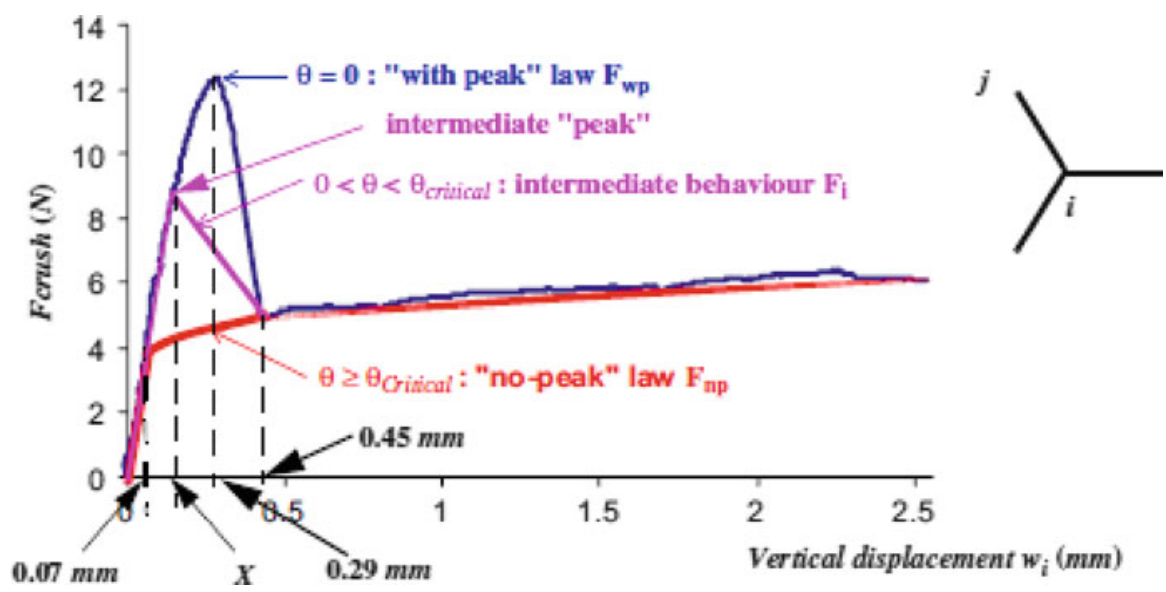

Fig. 34 Generalized crushing law $\mathrm{F}_{\text {crush }}\left(\mathrm{w}_{\mathrm{i}}, \theta_{\mathrm{i}}\right)$ of cell edge $i$

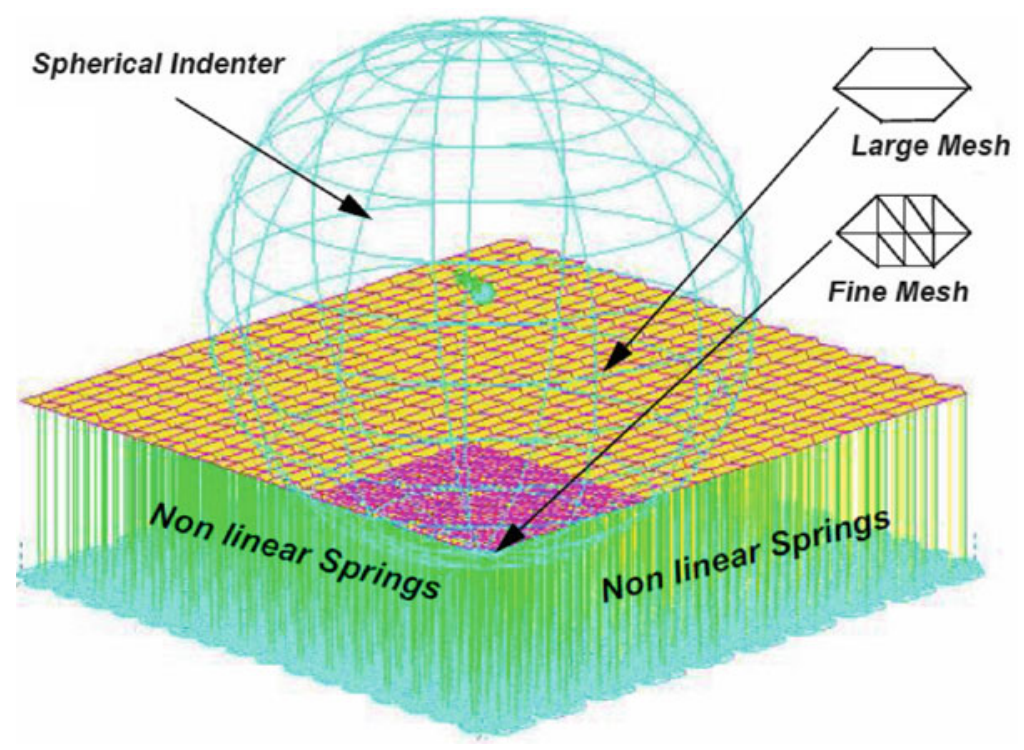

Fig. 35 Finite element modeling of the indentation problem on sandwich with thin metal skins

this method, the triaxial stress state of the metallic skin located directly below the indenter was modeled satisfactorily. A fine mesh was created in the contact area just under the indenter to generate a smooth contact law without any slope discontinuity. A sensitivity study of the mesh gave a convergence result if five volume elements through the thickness and 36 elements per cell in the contact area were used. The local rotation $\theta_{i}$ corresponded to the rotation of the upper node of the spring, which also belonged to the skin. This local rotation $\theta_{\mathrm{i}}$ was obtained directly with Mindlin 


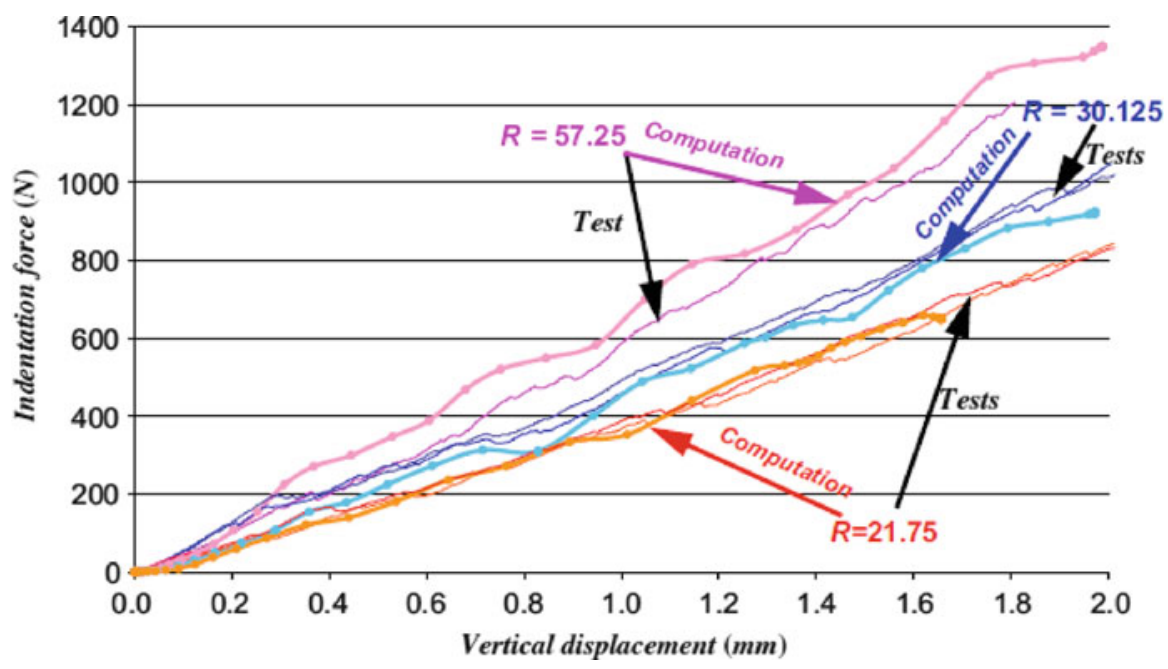

Fig. 36 Test/numerical model correlation in the case of sandwich with thin metal skins

plate elements but it had to be computed in the case of volume elements for the thick skin (more details can be found in [34]). In both cases, the rotation was assumed to be:

$$
\theta_{i}=\sqrt{R_{x}^{2}+R_{y}^{2}}
$$

where $R_{x}$ and $R_{y}$ are the local rotations of the interface nodes between the skin and the spring. The angle $\theta_{\text {critical }}$ is found by analyzing the rotations obtained numerically on the edges of the first cell. After several numerical tests, we set $\theta_{\text {critical }}=2.3^{\circ}$ [35]. Different numerical tests were performed on the position of the connection point and the law of decrease between $\theta$ and $\theta_{\text {critical }}$ (linear or parabolic decrease). The computations showed less influence of these two parameters. The elasticplastic behavior laws for brass skins were obtained from conventional tensile tests. Taking advantage of the symmetry of the structure, only one-quarter of the plate was modeled. The numerical simulation was limited to $2 \mathrm{~mm}$ of indentation, which largely exceeds the threshold value of detectability known as BVID (barely visible impact damage).

The results of computation were compared to the tests on sandwiches with thin skins (Fig. 36) and a good test/computation comparison was obtained for all three radii of indenter. Globally, the undulations observed during the test were also found numerically and corresponded to the drop in load after the peak load of each vertical edge located at the circumference of the indented area. For the thin skin, the rotation always proved to be less than $2.3^{\circ}$. It should therefore be possible to use the simple law with peak $\mathrm{F}_{\mathrm{wp}}$ for all vertical edges. The good correlation between computational and experimental results was to be expected since the deformation 


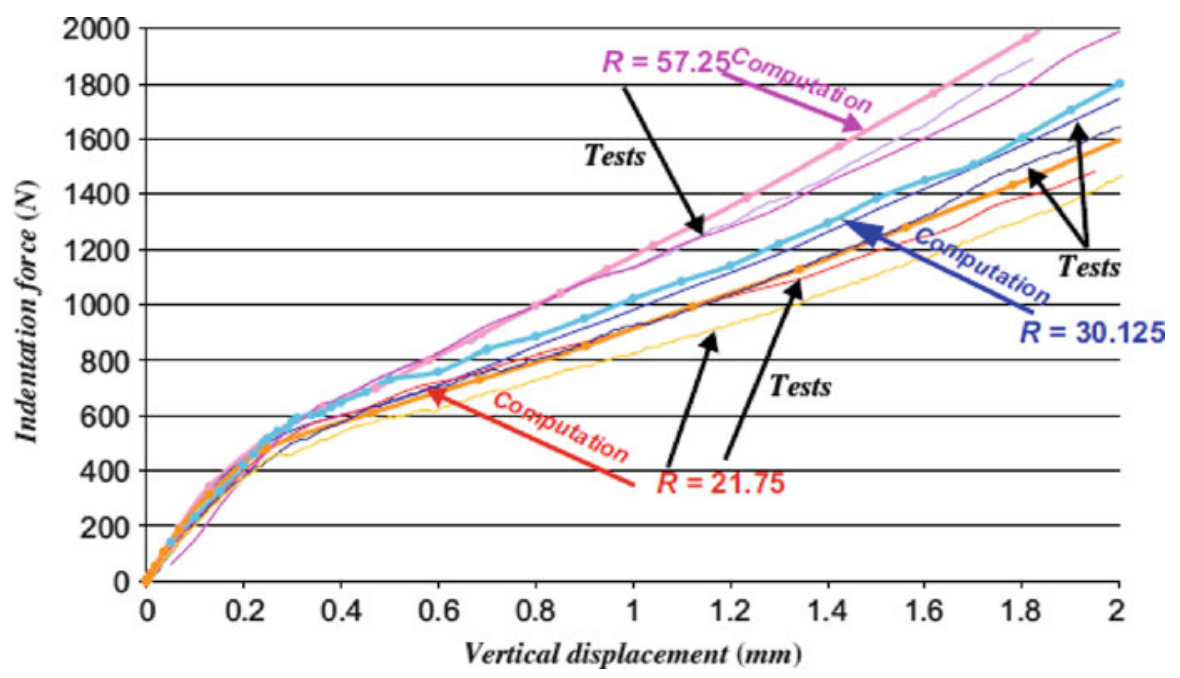

Fig. 37 Test/numerical model correlation in the case of sandwich with thick metal skins

of the thin skin exactly followed the indenter shape during indentation. Also, the phenomenon of folding back that was found from the indentation on the block of honeycomb alone using small indenter radii did not appear for the indentation on the sandwich structure. The good correlation is thus valid for any radius of indenter for the case of indentation of a sandwich structure with thin skin.

For thick skins, if the $F_{w p}$ law was not corrected to take account of the rotation, there was a difference of about $15 \%$ between the computational and the experimental results. This can be explained by the fact that the rigid skin did not follow the shape of the indenter when it bent. The bend caused rotations at the menisci before the edges involved had reached peak load [34]. When the rotation is taken into account, the comparison for sandwich structures using thick skin gives a globally acceptable result considering the dispersion of test results (Fig. 37).

\subsection{Impact on Sandwich Structure}

In practice, impacted aeronautical sandwich structures are usually simply supported or clamped but are never fully supported by a rigid foundation. Moreover, one of the main limitations of the discrete approach at this stage of development is the impossibility to model the shear stresses in the core. Thus, in this subsection, a multi-level approach is proposed to overcome this difficulty [36]. 


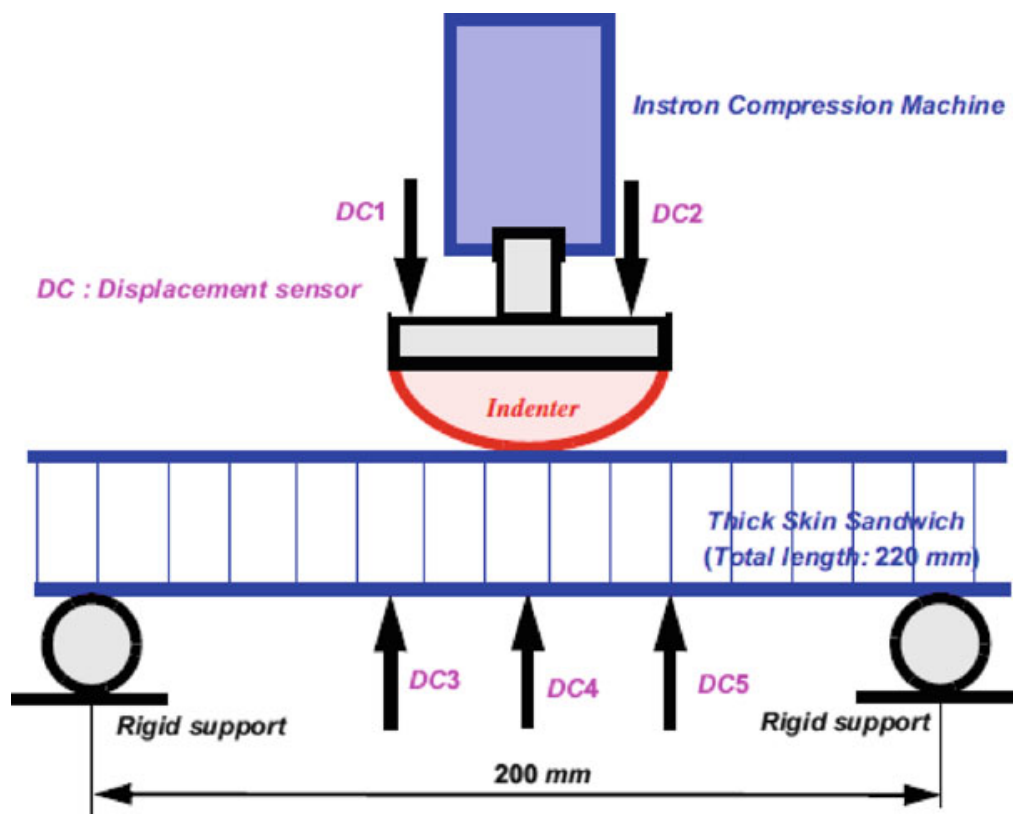

Fig. 38 Three-point bending test principle

\subsubsection{Analysis of the Coupling Between Bending Stresses and Indentation}

From a practical point of view, it is important to know whether or not a coupling effect exists between the indentation and the stress field generated by a bending load on a sandwich structure. It is the condition for eventually proposing a multilevel approach that separates the phenomena. Three Nomex honeycomb specimens measuring $220 \times 100 \mathrm{~mm}$ with 1 -mm-thick brass skins were produced (Table 3). Globally, the experimental procedure and the manufacturing of the specimen were the same as described previously.

The three-point bending test principle is shown in Fig. 38. The distance between the cylindrical steel supports was $200 \mathrm{~mm}$ and three displacement sensors (DC3DC5) were located on the lower skin to measure the deflection of the specimen. Two displacement sensors (DC1 and DC2) were also located on the upper face of the indenter.

Three tests were completed with indenter radii of 21.75, 30.125 and $57.25 \mathrm{~mm}$. The depth of indentation was obtained by calculating the difference in displacement between the points on the upper and lower skins just below the indenter [((DC1 + DC2)/2-DC4) in Fig. 37]. The force/indentation curves could then be directly compared with those obtained previously from the tests on rigid flat supports (Fig. 39) and it was seen that the force/indentation contact laws were 

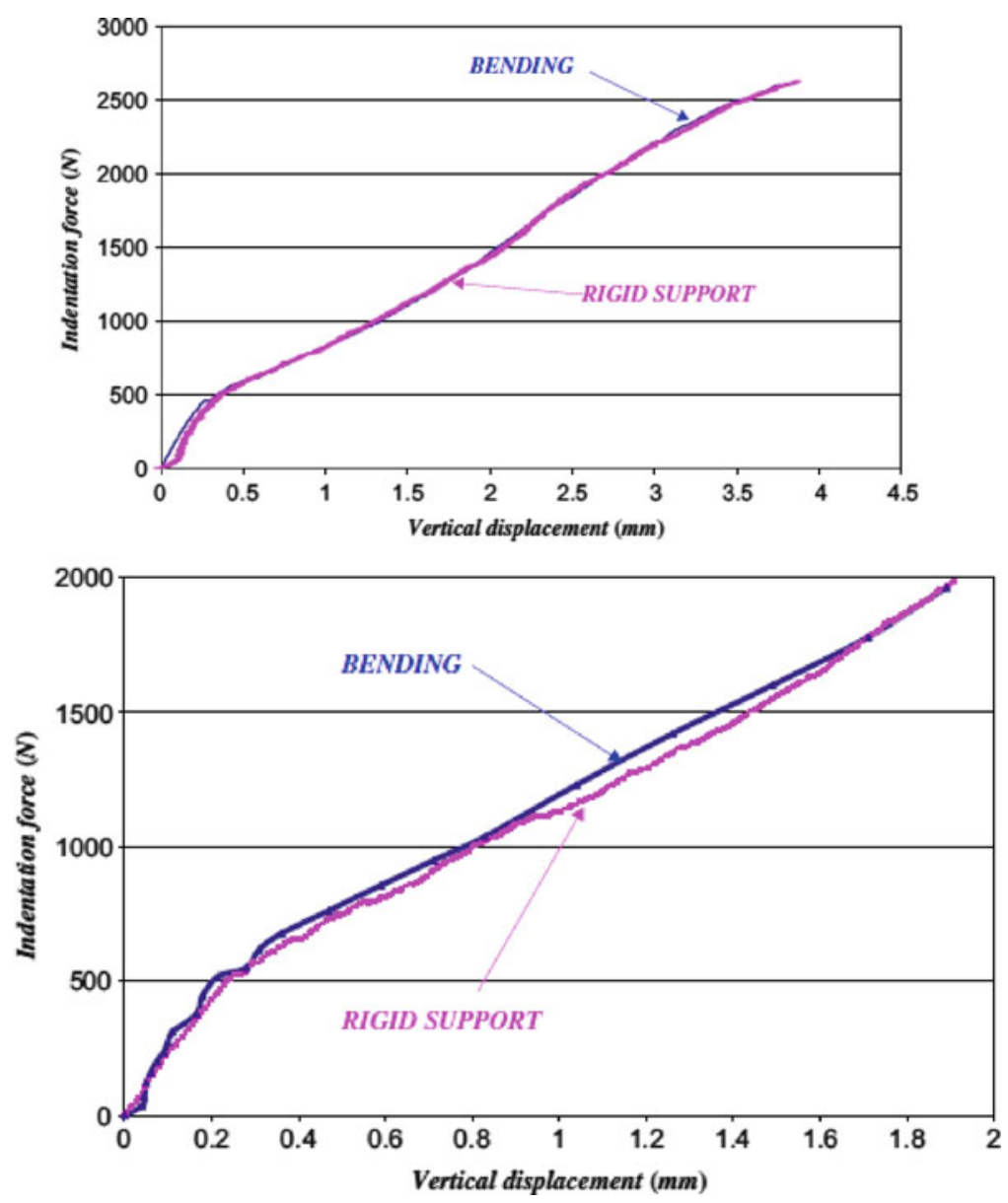

Fig. 39 Comparison of the force/crush experimental curves in the case of a rigid support and three-point bending, indenter $\mathrm{R}=21.75 \mathrm{~mm}$ (top) or $57.25 \mathrm{~mm}$ (bottom)

superimposed. Experimentally, for the configuration tested, it appears that there is no nonlinear coupling and, consequently, there is a superimposition of global bending and local indentation effects.

When a honeycomb sandwich structure undergoes bending, the transverse shear of the core plays an important role in the deflection and has to be taken into consideration. It is obvious that the proposed modeling of the core by a series of nonlinear vertical springs cannot take this transverse shear stress into account. However, the bending and indentation effects seem to be uncoupled. So, to represent the bending effect of the sandwich, equivalent nodal compression loads were added laterally at the nodes located at the edge of the honeycomb block and at the indented skin side (Fig. 40). The computation result of this model was compared to the numerical simulations discussed in Sect. 3.1 and, as shown in Fig. 40, the results 

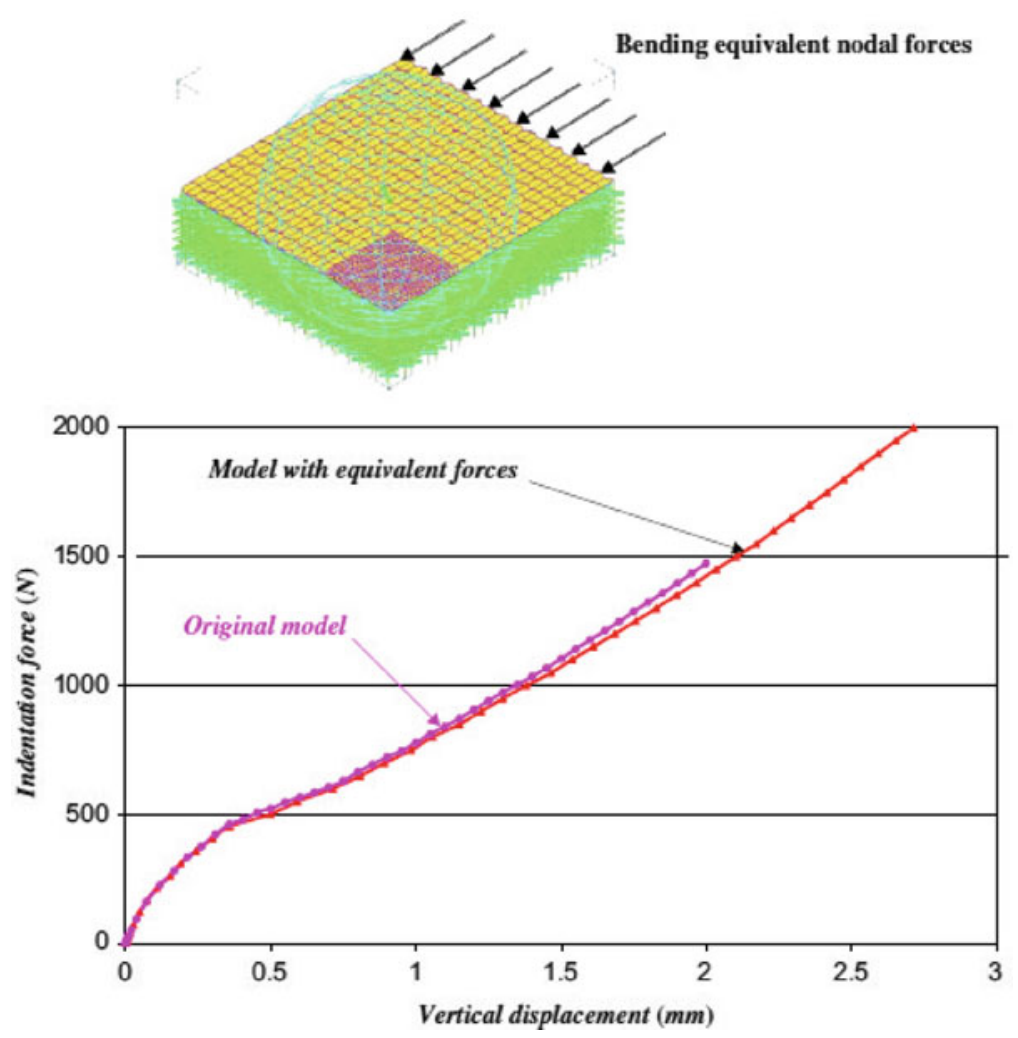

Fig. 40 Adapted indentation model for bending loads and comparisons between previous modeling and the model with nodal forces, for 21.75-mm indenter

were equivalent. This approach enables the practical problem of sandwich structure indentation to be represented, since the bending/indentation uncoupling is again present. Physically, this uncoupling can be attributed to the existence of a plasticized area under the indenter area, at a very early stage. This area becomes saturated in stress and insensitive to the loading increments on the sandwich skin. The only possible coupling must appear at the initiation of the indentation area, which must logically be earlier, when the skin is loaded under lateral compression. However, this phenomenon was not observable for the configuration tested.

At this stage of the study, it is possible to model the static indentation of metalskinned sandwich structures and to propose a multi-level approach.

\subsubsection{Multi-level Approach and Application to Dynamic Loading}

In the previous subsection, the possibility of obtaining the static contact law numerically was demonstrated. However, in industrial cases, the geometry can be 


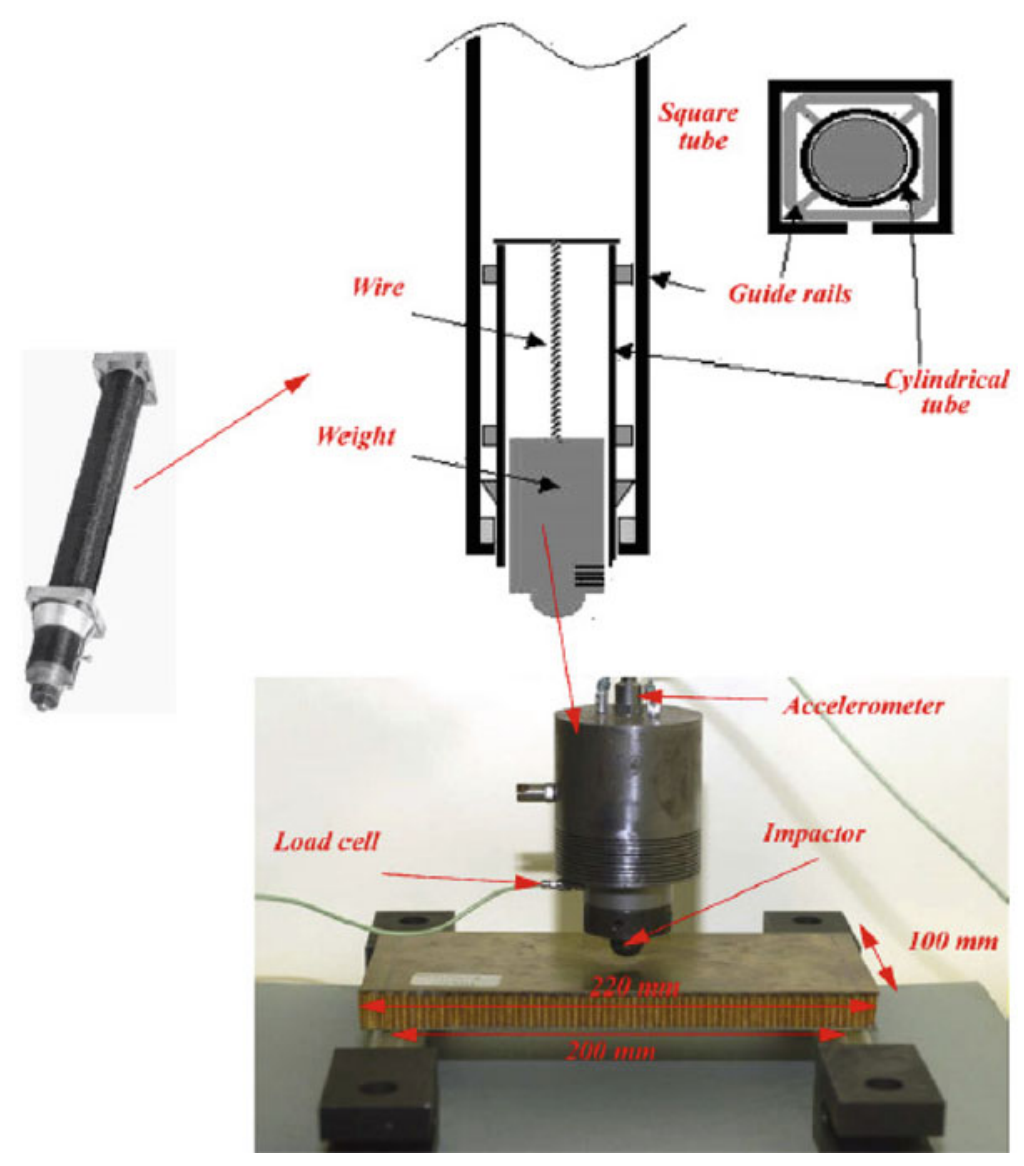

Fig. 41 Load drop test rig

more complex with various shapes and different local stiffnesses. So, the objective of this part of the study is to determine whether the approach developed in the last section is suitable for modeling the dynamic behavior of sandwich structures with metallic skins under low-velocity and low-energy impact. For this purpose, dynamic impact tests were performed using mass drop test equipment (see Fig. 41). The sandwich plates used for the experiments were of the same type as the ones for the three-point bending tests $(100 \mathrm{~mm} \times 220 \mathrm{~mm}$, core thickness $15 \mathrm{~mm}$ and skin thickness $1 \mathrm{~mm}$ ). The boundary conditions were also the same (see Fig. 38). The impactor having spherical tip of radius 30.125 or $57.25 \mathrm{~mm}$, hit the center of the plate. The masses of the impactors were respectively 885 and $865 \mathrm{~g}$. The impact speeds recorded were 2.58 and $2.80 \mathrm{~m} / \mathrm{s}$ respectively. The impact energy was about $3 \mathrm{~J}$. The impactor was equipped with a load cell and an accelerator to provide the deflection and the force during the impact. The redundancy of these two data items was voluntary. Nevertheless, practically, the force signal gave less interference and 


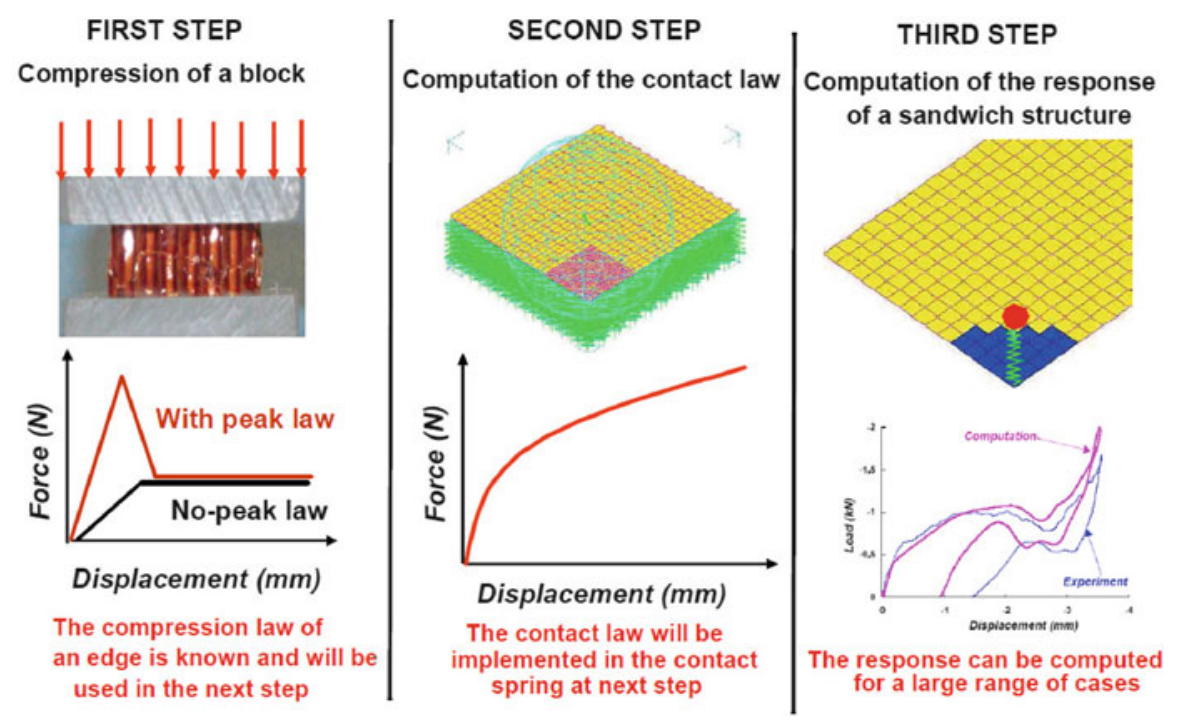

Fig. 42 Multi-level approach principle

it was the only information that was used to measure the force. The force/time and force/ displacement curves are shown in Fig. 44. The complex law of the dynamic contact force should, a priori, be the superimposition of the dynamic response of the sandwich structure and the local indentation.

To model the dynamic test, two assumptions were made:

- The global behavior of the structure did not depend on the local response during impact. This hypothesis is in accordance with the local nature of the impact reported in the literature.

- The static/dynamic equivalence was assumed for the range of structures and impacts studied. Thus, it was possible to use the static contact law computed previously.

With these assumptions, a multi-scale approach could be proposed (see Fig. 42). The local indentation law was computed first. The only parameter necessary was the crushing law for the spring, which was obtained simply by a basic uniform compression test on a block of honeycomb. As the local dynamic effects were neglected, a nonlinear spring was used to represent the contact law in the global model as shown in Fig. 42. The compression law for this spring was the indentation law previously computed in Sect. 3.1 This proposition is similar to the approach of Choi and Lim [37] for laminated plates.

An implicit finite element model was made. The sandwich structure was modeled by Mindlin plate finite elements (Fig. 43). The materials of the structure were assumed to be linearly elastic. The mass density of the brass skin and the Nomex were 8,000 and $48 \mathrm{~kg} / \mathrm{m}^{3}$ respectively. The transverse moduli of the core were 


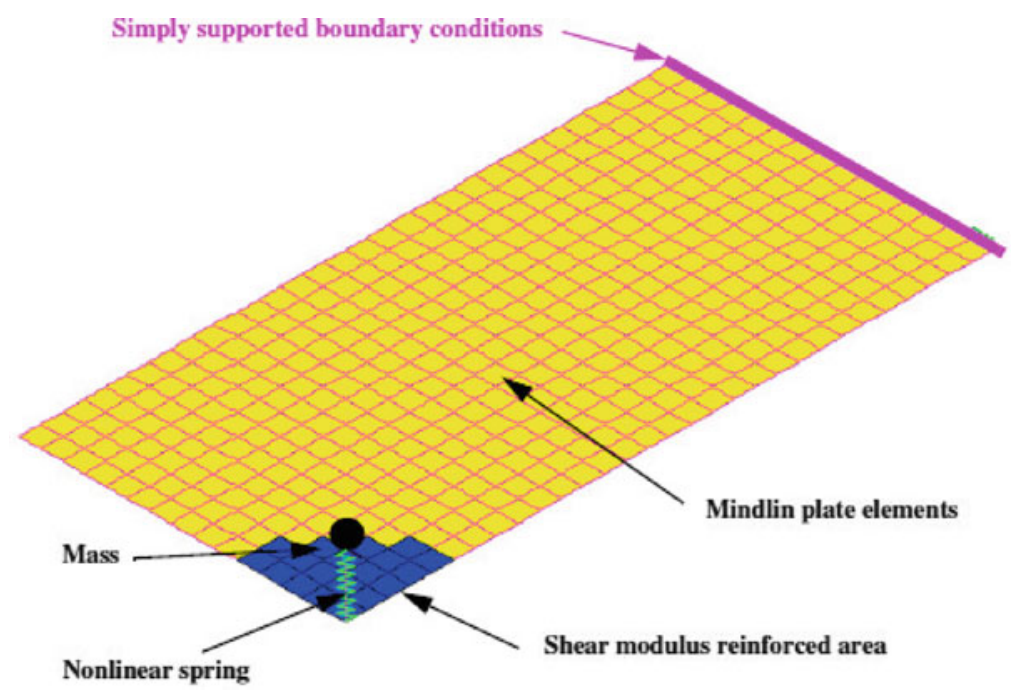

Fig. 43 Spring-mass finite element model

$\mathrm{Gyz}=44, \mathrm{Gxz}=30$ and Ezz $=120 \mathrm{MPa}$. Following the assumptions and to avoid local dynamic effects, it was decided to increase the transverse shear modulus of the core artificially on the right of the indenter with the following values: $\mathrm{Gyz}=\mathrm{Gxz}=5,000 \mathrm{MPa}$. Numerical tests were performed to demonstrate the little influence of the area dimension and the modulus of the local reinforcement on the global response of the structure. In our case, the nonlinear spring law was obtained numerically. The linear stiffness of the spring was $2.67 \mathrm{kN} / \mathrm{mm}$, the yield stress corresponded to a force of $0.4 \mathrm{kN}$ and the plastic stiffnesses were 0.714 and $0.93 \mathrm{kN} /$ $\mathrm{mm}$ for the 30.125 and 57.25 indenters respectively. The initial velocities were those measured $(2.58$ and $2.80 \mathrm{~m} / \mathrm{s}$ respectively). For the dynamic computation, a Hilbert-Hughes-Taylor algorithm with automatic time stepping (implicit predictorcorrector scheme) was selected.

In spite of the relative simplicity of the model used, the numerical simulations fit the experimental results correctly (Fig. 44). The maximum contact force was found, and will provide the damage area by a return to the indentation model. The staticdynamic equivalence for this range of structures and impacts, which was mainly observed experimentally, was also confirmed numerically. Besides, the possibility of making indentations on fully supported specimens was demonstrated. This result also globally validates the approach and the hypotheses made. The simplicity of the model should be an advantage in dealing with complex structures and multi-impact phenomena. 

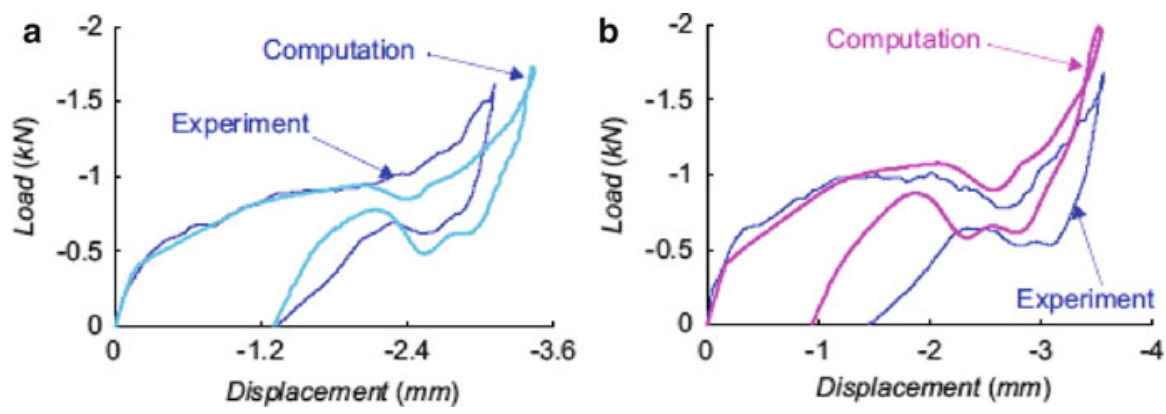

Fig. 44 Dynamic load-displacement law: (a) $30.125 \mathrm{~mm}$ and (b) $57.25 \mathrm{~mm}$ impactor

\subsection{Conclusions}

A method has been developed to model low-velocity/low-energy impacts on metalskinned sandwich structures, and gives good correlation of contact laws. An analysis of the crushing from a structural point of view has enabled us to propose an original way of modeling Nomex honeycomb core using a grid of nonlinear springs. In practice, the springs in implicit finite elements provide a faster and a more robust computation, especially when the stiffness varies and decreases suddenly as is found to occur in brittle materials such as Nomex. The local rotation of the upper surface of the honeycomb that interfaces with the skin plays a role in the initiation of vertical edge buckling. This interface effect between skin and honeycomb is then taken into account in the model. Direct application of this modeling enables the contact law to be computed when metal-skinned sandwiches are quasi statically indented on a flat support. This approach gives highly accurate correlation with indentation tests on a flat support or under three-point bending. The proposed multi-level approach consists of three steps. First, a basic compression test must be performed on a block of honeycomb to obtain the initial crushing law. Second, using this law in nonlinear springs, it is possible to obtain the contact law using a finite element model and a nonlinear static computation. Finally, with the hypothesis of neglecting the dynamic effect at contact, a basic finite element spring-mass model using a nonlinear contact law computed in the last step is able to model a dynamic test.

As good correlation is obtained, the hypothesis of equivalence between static indentation and dynamic test is validated. This basic approach could be useful to model complex structures under impact or multi-impact. It is important to note again that the impact simulation is complete and is, finally, based only on a simple, economical compression test on a block of honeycomb core. It avoids the use of indentation tests on the complete structure to identify the Meyer's law coefficient [9]. It also shows that the phenomenon remains local and, for the range of structures studied, is independent of the boundary conditions and the dimension of the plate. 
It would seem that the approach that has been developed can be used for other cellular cores made from other soft materials thanks to their similar and common crushing mechanism.

The use of metallic skin in this study enables a step-by-step approach to the modeling of the impact but this remains a limitation in practice since it is rare for sandwich structures to be made using metallic skin in industry nowadays. The real challenge will still be to couple this modeling approach with laminated skin. In this case, the plasticity behavior will be replaced by a determination of the damage state in both the honeycomb core and the composite skin and the possible coupling between the stress state of the global structure and the indentation phenomenon will have to be taken into account. Knowing the local state, it will then be possible to compute the residual strength by a second model. This approach will be developed in the next section.

\section{Residual Dent and Post-impact Behavior}

In this section, the discrete approach proposed in the previous section will be used to make a complete computation loop including indentation, computation of the residual print (or dent) geometry and computation of the compression after indentation (CAI) strength. In the first subsection, the approach is limited to a sandwich with metallic skins. Nevertheless, the discrete approach allows us to identify the failure mechanisms during CAI and the role of core crushing before the collapse of the sandwich panel. Thus, a core crush criterion can be identified [38]. This original criterion is then applied in the second subsection to determine the residual strength of impacted sandwich structures with composite skins [39].

\subsection{Residual Dent and Compression After Impact on Sandwiches with Metallic Skins}

Experiments have shown that the depth of residual dent will be different from the maximum static indentation $[1,19]$ because of "elastic" recovery. However, from the aviation regulations point of view, a limit of detectable print called barely visible impact damage (BVID) after impact is defined and, beyond this limit, the structure should be designed for damage tolerance [1, 40]. This threshold is based on visual inspection [40, 41]. Thus, it is important to be able to determine this residual print geometry first, which, as far as we know, has been the subject of only a small number of studies in terms of the numerical and analytical models that have been made. Palazotto [14] has proposed a finite elements model of impact using three loops of iterative computation to determine the damage on the honeycomb, the damage on the composite skin and the geometry of the print successively. Horrigan [19] has 
proposed a continuum damage model to calculate the behavior of honeycomb. But, because of the continuum approach, the core damaged area could not be predicted correctly. Most authors, in particular in the case of foam cores [42, 43], separate the core into different regions (cavity, crushed or damaged, undamaged) to model the indentation and the compression after impact behavior. Destructive sectioning of sandwich panels is most often used to characterize the damaged or undamaged geometry for implementation in a finite element model. Concerning the strength of compression after impact, due to the weakness of the core after impact, several authors propose wrinkling models to compute the residual strength [44, 45]. Xie and Vizzini also couple this type of model with a skin failure criterion [46, 47].

Minakuchi et al. [48, 49] have proposed an efficient segment-wise analytical model using a discretization of the honeycomb similar to the discrete model approach proposed earlier [28]. This is used to compute the residual dent of a sandwich beam with laminated skins. A complete state-of-the art can also be found in [50].

In previous sections, honeycomb was represented by a grid of vertical springs in which the behavior law in compression was calibrated from uniform compressive loading experiments. In the following subsections, the law is developed further by integrating the cyclic behavior (compression loading and unloading) of honeycomb that allows the defect recovery of honeycomb after compression and the residual print geometry of the sandwiches structures after indentation to be simulated. The law is also used to compute the residual strength of an impacted sandwich plate subjected to edgewise compression.

\subsubsection{Experimental Procedure and Test Results}

Specimens (Fig. 45) were prepared by taking care to obtain high surface smoothness and high dimensional precision $( \pm 0.01 \mathrm{~mm})$, which are the necessary conditions to obtain a correct uniform compressive test. The standard dimension of the specimen was $150 \times 100 \mathrm{~mm}$. Two brass skins (thickness $0.5 \mathrm{~mm}$ ) were bonded to Nomex honeycomb core HRH 78,1/4,3 (thickness $15 \mathrm{~mm}$ ). Resins were molded into both extremities of each specimen. To transfer the compressive load properly, two plates of brass $1 \mathrm{~mm}$ thick were added as reinforcement in the resin-Nomex junction area.

These specimens were previously indented on a flat support (Fig. 29) and the indentation was carried out by imposing a displacement with a constant speed of $0.5 \mathrm{~mm} / \mathrm{mn}$. A spherical indenter made of steel with radius of $57.25 \mathrm{~mm}$ was used and several depths of maximum indentation $\mathrm{d}=0,0.5,1,1.5$ and $2 \mathrm{~mm}$ were used to obtain different damage areas. For compression (CAI) tests after indentation, test supports and specimens corresponded to the AIRBUS standards so that we could compare the test results with industrial ones. To observe the evolution of damage geometry in terms of its depth and its form during compressive loading, a method of 3D Image correlation using two cameras was employed (Fig. 46). Strain gauges were also used to observe the distribution of compression flux on the two skins. The compressive load acting on the specimens was measured directly from the 


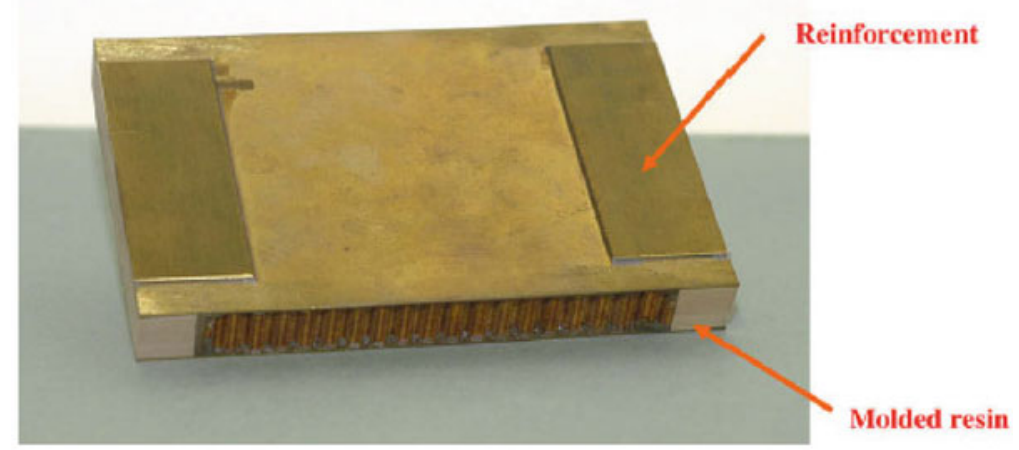

Fig. 45 Specimen for CAI tests

INSTRON machine and the displacement of the compression surface was measured using LVDT displacement measurement.

The experimental contact laws are plotted in Fig. 47. We note that the relaxation phenomenon is highly nonlinear and that the difference between the depth of the residual dent and the maximum depth of the indentation is significant. Qualitatively, although the depth of the residual print is very small, it can come from a significant indentation that has generated significant honeycomb crush. Furthermore, we observe that the relative difference is not constant and decreases as the depth of the indentation increases.

The shape of the residual imprint was also measured by 3D image correlation (Fig. 48). The radius of the surface of the residual dent increased with the depth of the indentation. The values measured in this way were consistent with the displacement of the indenter measured by lever comparators. Table 4 summarizes the values measured in each test and the relative differences.

The curves of compressive load as a function of its displacement for five indented specimens with different depths of indentation, d, are plotted in Fig. 49. For all the specimens, the initial stiffness was identical and corresponded to the elastic behavior of skins. Analytical calculation showed that the point where the slope changed just after the elastic behavior of skins coincided with the yield limit of the skin. Thus, it seems that, at the beginning of compression, the dimension of the damage area caused by indentation does not have a significant influence.

The second slope was also practically identical for all specimens. This slope seems to be controlled by the plastic behavior of the skins. As the force of compression increased, an inflexion was observed just after the passage of maximum force, which can be qualified as the residual strength of the indented structure. This residual strength depended on the depth of the maximum indentation, d. It decreased significantly with an increase of the maximum indentation depth, $\mathrm{d}$, and hence the damage in the core due to indentation was greater (Fig. 50). 

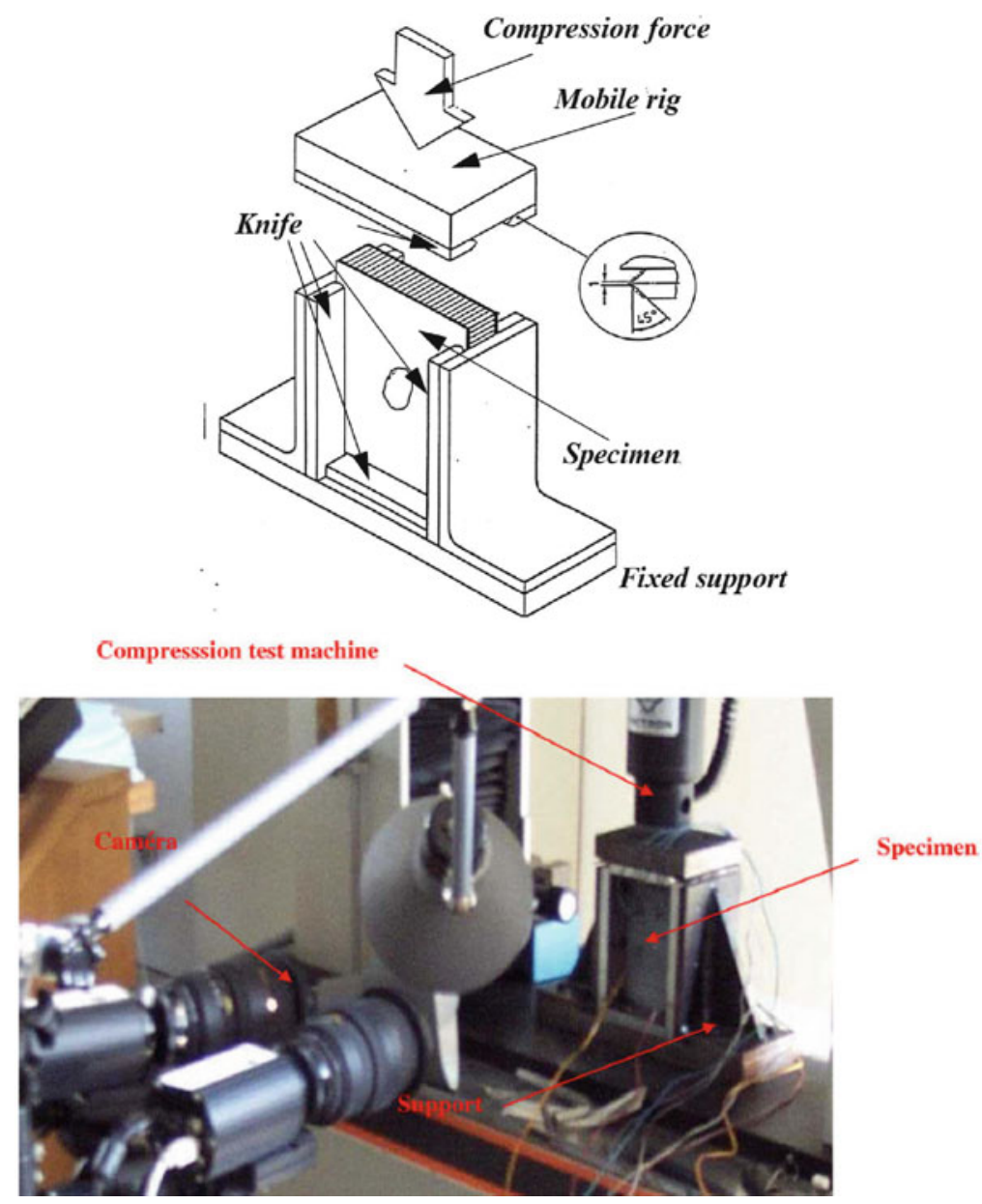

Fig. 46 CAI test device

The dent depth evolution of the residual print during loading is also drawn in Fig. 51.

By observation using Digital Image Correlation (DIC), the evolution of the damage area can be described as follows:

- In the region of elastic behavior of the skins, the shape of the residual print geometry after indentation remains circular and its depth hardly varies.

- At the beginning of plastic behavior of the skins, the form of the print begins to become elliptical, progressively, in the direction of lateral axis a. At the same time, in the direction of longitudinal axis, $b$, no evolution is observed. The print depth is also observed to increase progressively. 


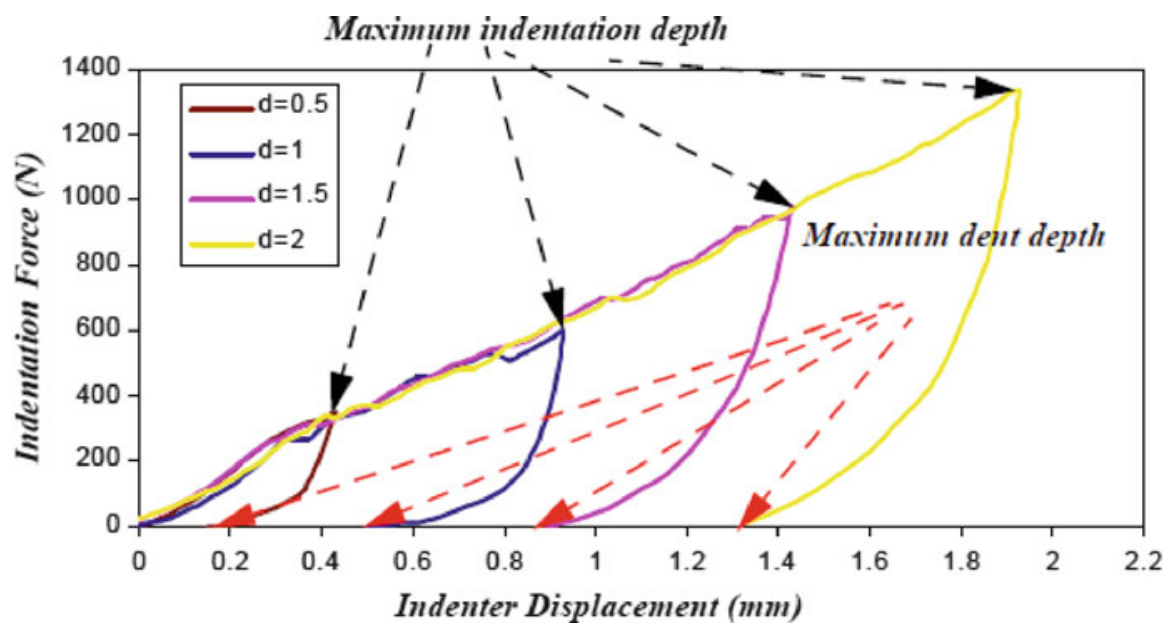

Fig. 47 Force/displacement curves using an indenter of radius $\mathrm{R}=57.25 \mathrm{~mm}$

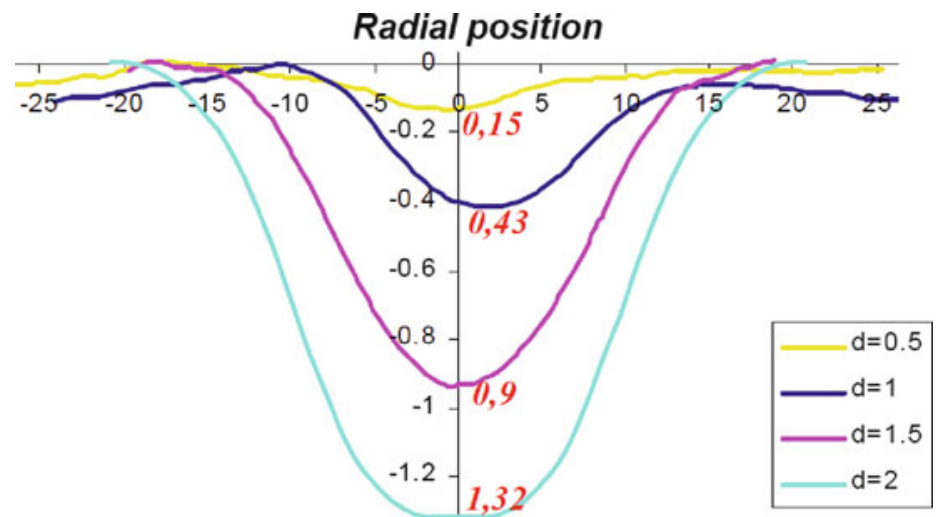

Depth of the dent

Fig. 48 Mapping of the residual dent profile (digital image correlation)

Table 4 Comparison of the depth of the indentation and the residual dent depth

\begin{tabular}{lcccc}
\hline Maximum indentation depth $(\mathrm{mm})$ & 0.5 & 1 & 1.5 & 2 \\
\hline Residual dent depth (mm) & 0.15 & 0.43 & 0.9 & 1.32 \\
Difference (\%) & 70 & 57 & 43 & 34 \\
\hline
\end{tabular}

- Approaching maximum compressive load (residual strength of the structure), the print depth increases abruptly. The same observation is also obtained for the evolution of radii about the lateral axis, a, which finally reach the edges of specimen. It is also interesting to note that the deflection of non-indented skin below the indented area also increases rather quickly. 


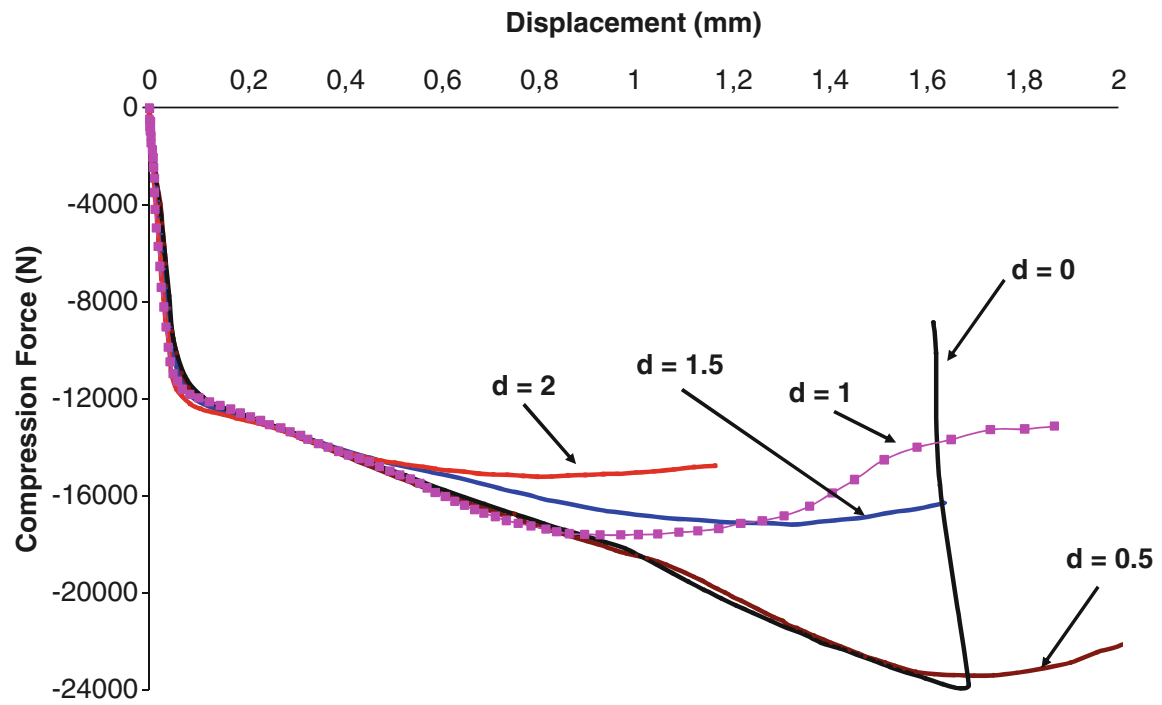

Fig. 49 Evolution of the dent under compression after impact loading for maximum indentation $\mathrm{d}_{\max }$ from 0.5 to $2 \mathrm{~mm}$

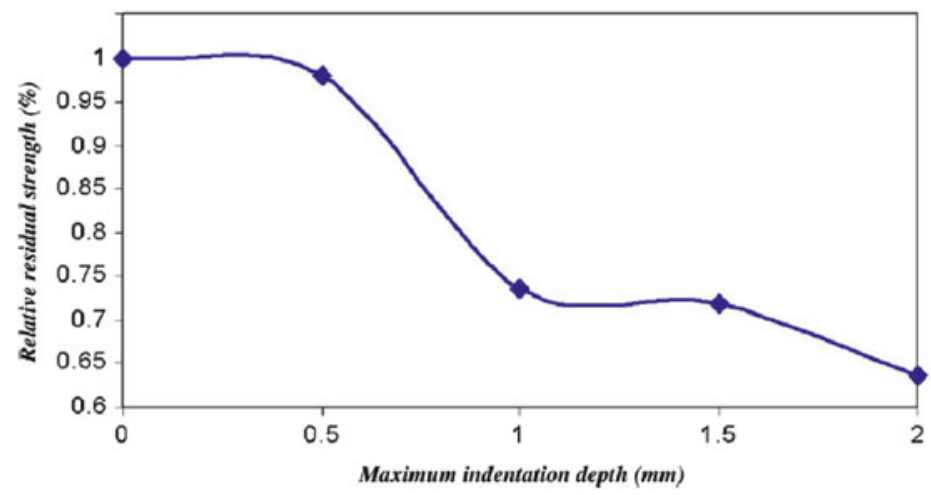

Fig. 50 Relative residual strength as a function of indentation depth

For the specimen that was indented only with maximum indentation depth $\mathrm{d}=0.5 \mathrm{~mm}$ and which had a corresponding residual print depth of $0.1 \mathrm{~mm}$, the evolution of the damage geometry was quite different. This specimen, with only $2 \%$ of decrease in terms of residual strength, behaved almost as a non-indented specimen. However, the elliptical evolution of the damage geometry was also observed with an abrupt progression when approaching the maximum compressive loading. This behavior was similar from all qualitative points of view to that observed for a thin composite skin [51]. 


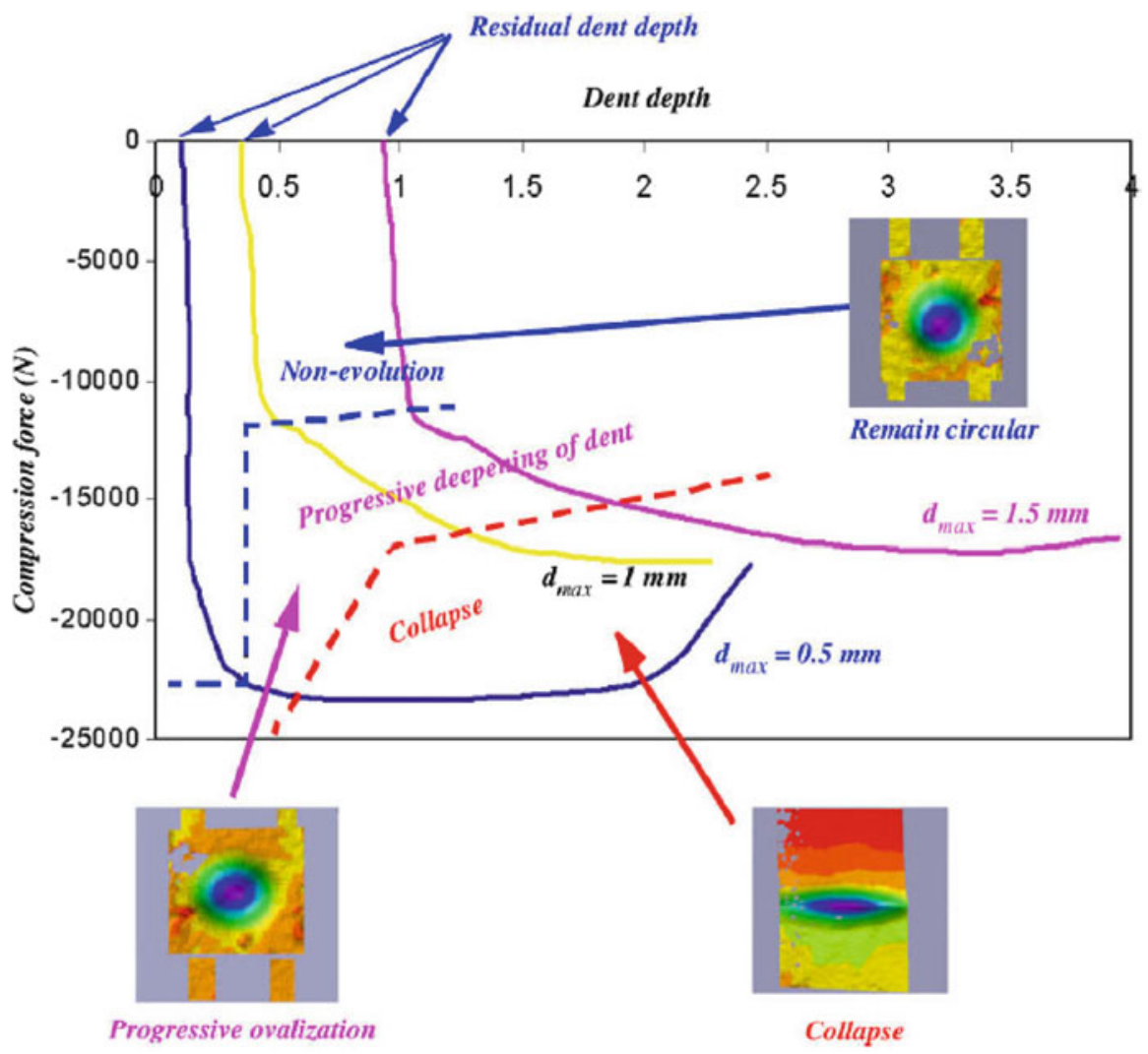

Fig. 51 Evolution of the dent under compression after impact loading for maximum dents $d_{\max }$ of $0.5,1$ and $1.5 \mathrm{~mm}$ and identification of different behaviors with the help of DIC

\subsubsection{Application of the Discrete Approach}

Globally, the same finite element model using implicit SAMCEF software that was used for the study of indentation was employed here (see Fig. 52).

The principles of the model are as follows:

- Indented skin is modeled by Mindlin-type elements. This skin has free boundary conditions except at the position of the CAI test supports (z-axis degree of freedom (d.o.f.) locked). These boundary conditions did not exist during indentation (Figs. 52 and 54). However, the literature shows that indentation causes a local damage area and, for the size of specimen used in this study, the boundary conditions are not sensitive. This insensitivity was confirmed by a posteriori numerical computation. The compression law for the brass skin was obtained from tests on a virgin (non indented) sandwich specimen and it appeared that the yield stress in compression was $110 \mathrm{MPa}$ instead of the $100 \mathrm{MPa}$ obtained for traction. Also, the hardening law was slightly different. 


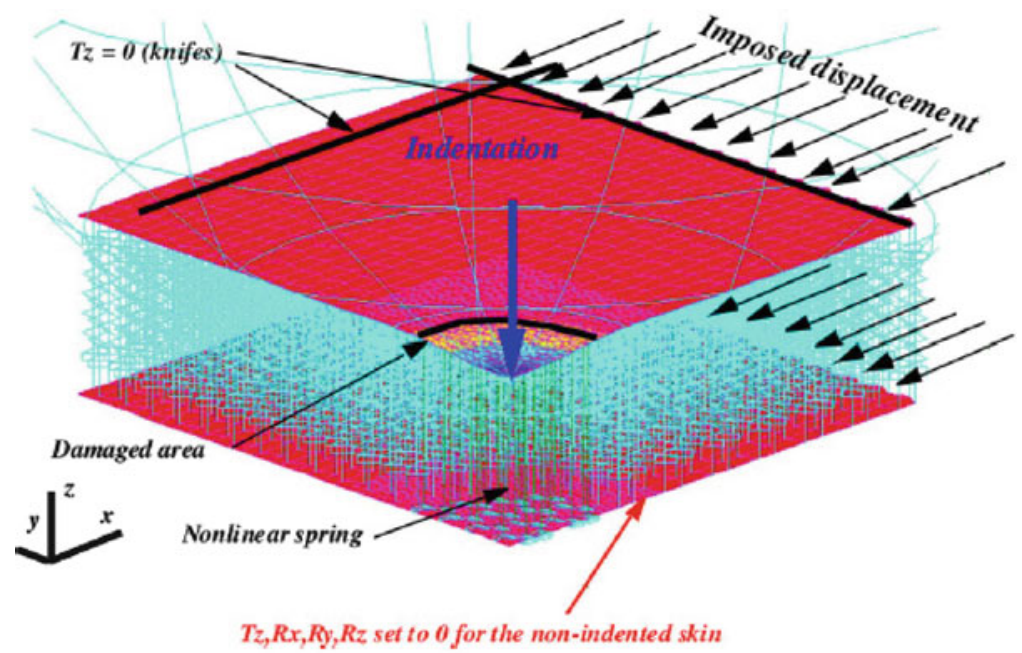

Fig. 52 Finite element model for compression after impact

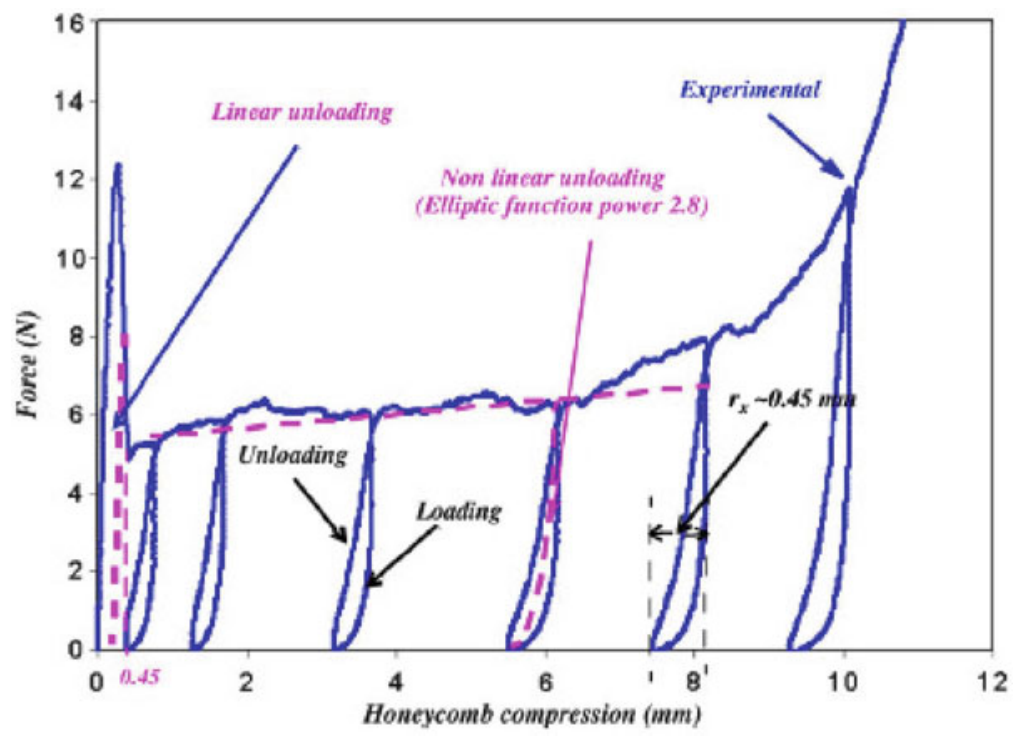

Fig. 53 Compression behavior of Nomex honeycomb with cycling

- Hexagonal Nomex honeycomb was modeled by a grid of non-linear vertical springs placed geometrically at the same positions as the honeycomb vertical edges. Its behavior law was obtained experimentally from a cycled compression uniform loading test on a small block of Nomex honeycomb (Fig. 53). Until $0.4 \mathrm{~mm}$ of displacement of the uniform compression surface, compression 


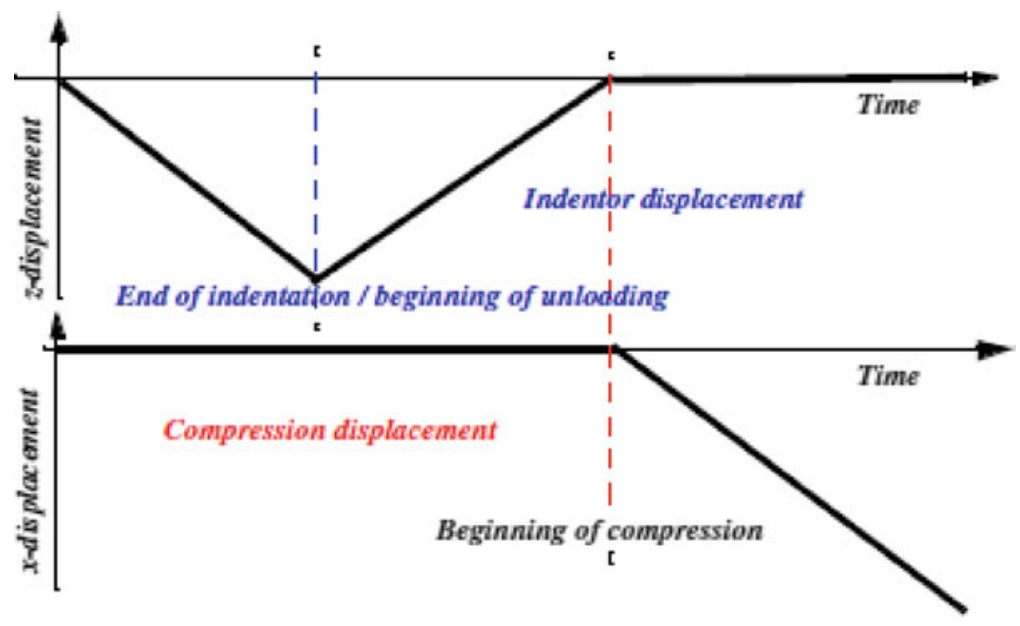

Fig. 54 Time-function displacement laws for compression after impact modeling. The first graph corresponds to the imposed displacement of the spherical indenter, the second to the displacement imposed on the upper skin

unloading gave a linear return of displacement with the same slope as the compression one. Beyond that displacement, the return was no longer linear (ellipse with a power of 2.8). The hysteresis behavior found from the test was assumed negligible and was not taken into account in the FEM computation.

- Non-indented skin had to be modeled with the same model as indented skin but almost all the degrees of freedom were blocked, except for its in-plane displacement (in this case translation in $\mathrm{x}$ and $\mathrm{y}$ ) to allow non-indented skin to deform like a membrane during compression.

The lower skin was added because the distribution of the forces between the two skins varied as the defect progressed. It is obvious that the discrete model used before cannot directly represent the bending of the sandwich and, hence, the out-ofplane displacement of the non-indented skin. In fact, all the degrees of freedom of this skin were locked except for the displacements in the plane of the sandwich ( $\mathrm{x}$ and $\mathrm{y}$ axis) so that the skin could deform during the compression. However, this assumption was justified because the deflection of non-indented skin below the indented area measured during tests was very small and became significant only when the compressive load approached the maximum one. Also, globally, the deflection of non-indented skin still remained negligible compared to the depth of the indented area. Moreover, the computation was more robust numerically when the boundary conditions were conserved for complete computation involving different phases. The load acting on a structure was simulated by imposing first a vertical displacement of the indenter towards negative $Z$ (compression loading) and positive $\mathrm{Z}$ (compression unloading), then followed by imposing the displacement on the edges of the structure to simulate the lateral compression load (CAI) on the indented structure (Fig. 54). 

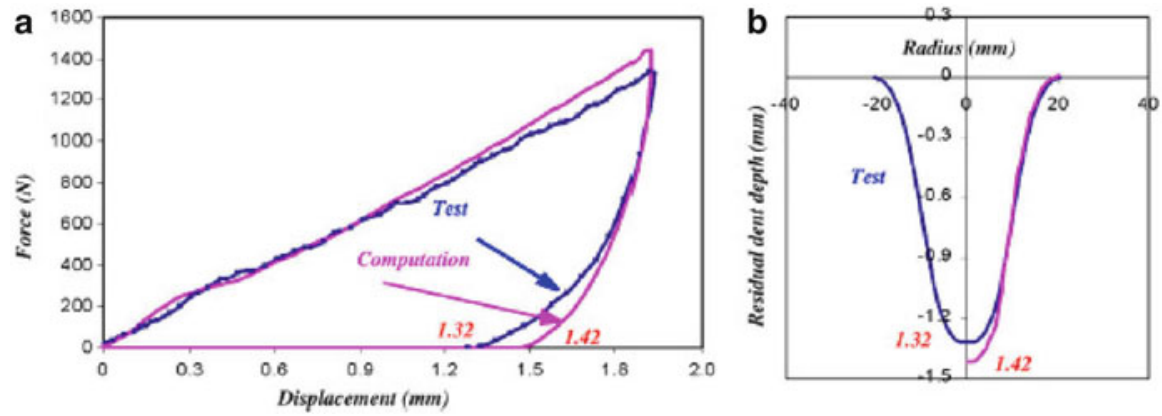

Fig. 55 Contact law and residual dent test compared with computation for a maximum indentation of $2 \mathrm{~mm}$

\subsubsection{Test/Numerical Model Comparison: Residual Dent and CAI}

The comparison between test and computation during the indentation phase is described in Fig. 55 for the case of maximum indentation $\mathrm{d}=2 \mathrm{~mm}$. The curve of indentation force as a function of indenter displacement is plotted in Fig. 55a and the profile of the residual print about the longitudinal axis b is plotted in Fig. 55b. The depth of the residual print obtained from the computation is $1.42 \mathrm{~mm}$ whereas $1.32 \mathrm{~mm}$ is obtained from the test measurement, which gives the difference of $7 \%$. For all specimens, the difference of residual print between computation and test varies from $25 \%$ for the smallest indentation depth $(\mathrm{d}=0.5 \mathrm{~mm})$ to $7 \%$ for the deepest one $(\mathrm{d}=2 \mathrm{~mm})$. The curves obtained from the indentation test are correctly simulated by computation [35] and also globally for the geometry of the residual print after indentation.

In the compressive loading after indentation phase, the evolution of the residual print was studied by analyzing two parameters: depth of residual print and profile about the major axis, a. The minor axis did not vary significantly. Test/computation comparisons for these two parameters are represented in Fig. 55 for the specimen indented with maximum indentation $\mathrm{d}=1.5 \mathrm{~mm}$. Globally, numerical computations give the same evolution as test results. The small difference at the beginning of the compression is due to the difference of residual print depth between computation and test from the previous phase. However, there is also a significant difference in terms of the final depth of the damage area (in the maximum compressive load region) because the out-of-plane deflection of the structure is not taken into account in the computation.

Nevertheless, the maximum compressive load, hence the residual strength of the indented sandwich structure, was perfectly simulated. Also, the evolution of the damage area in terms of its profile about the major axis was perfectly simulated by computation (Fig. 56). A good correlation between test results and computations in terms of print geometry evolution and maximum compressive load was obtained for almost all indented specimens except in the case of small indentation $\mathrm{d}=0.5 \mathrm{~mm}$ (Fig. 57). For this test, the depth of the residual print was very small, only $0.15 \mathrm{~mm}$. 

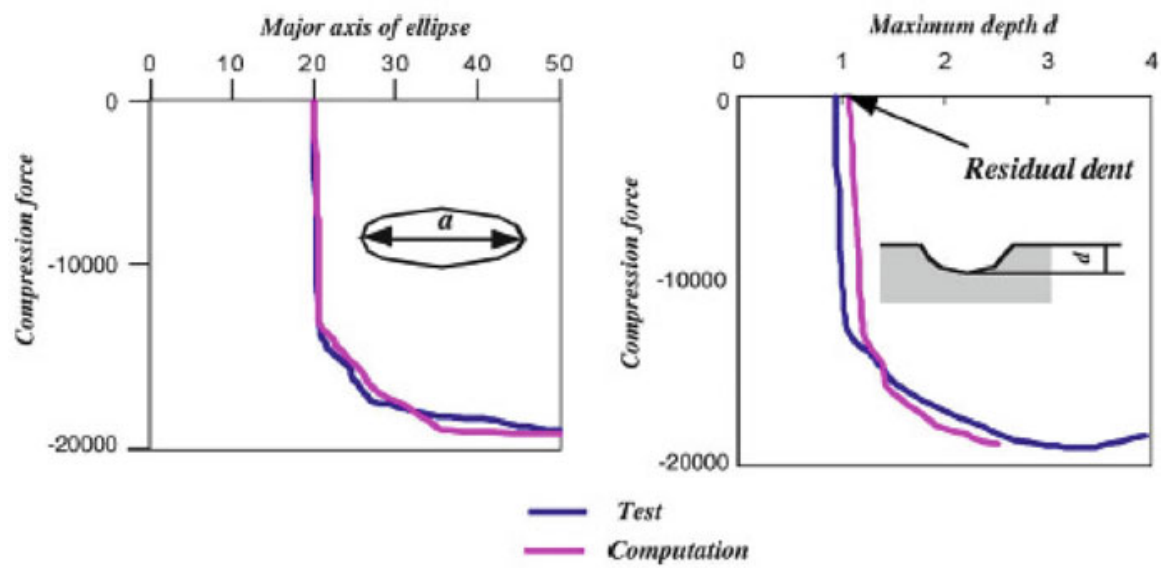

Fig. 56 Correlation of the maximum depth and the major axis of the ellipse of the dent during compression for the maximum indentation depth of $1.5 \mathrm{~mm}$

Investigations were carried out to find out whether an initial geometry defect, such as skin curving, would stabilize the indented structure whereas this defect was not taken into account in computation. It was also possible that, regarding the smallness of residual print depth, the difference came from an insufficiently refined mesh that created early numerical instability. Globally, in this section, it has been shown that the discrete approach is also able to predict the residual dent after impact.

\subsubsection{Failure Mechanisms and Core Crush Criterion}

In this part, the reaction of the first uncrushed springs placed in the dent evolution direction about the major axis of the ellipse and in the circumference of the residual print (see Fig. 58) is analyzed. The force in these springs (1-3) is initially low and does not increase during the appearance and progressive extension of the ellipse. After a drop in the spring force, which is due to the appearance of a bump at the periphery of the ellipse that stretches the springs, a sudden increase in the compression force is observed until it reaches the critical force (the peak) for the first spring at the periphery (no. 1). The collapse of this first edge occurs only shortly before the abrupt progression of the ellipse, which takes place when the second edge (spring no. 2), situated on the major axis of the ellipse, collapses in turn. Numerically, it is shown here that the advance of the defect coincides with the physical phenomenon of local core crush. Therefore, the collapse of the first edge located on the major axis of the ellipse modeled by its spring can be proposed as the criterion for determining the computed residual strength. Logically, this criterion should always underestimate the experimental residual strength, but not too much, since the ellipse generally appears just before the catastrophic failure of the specimens [50]. 

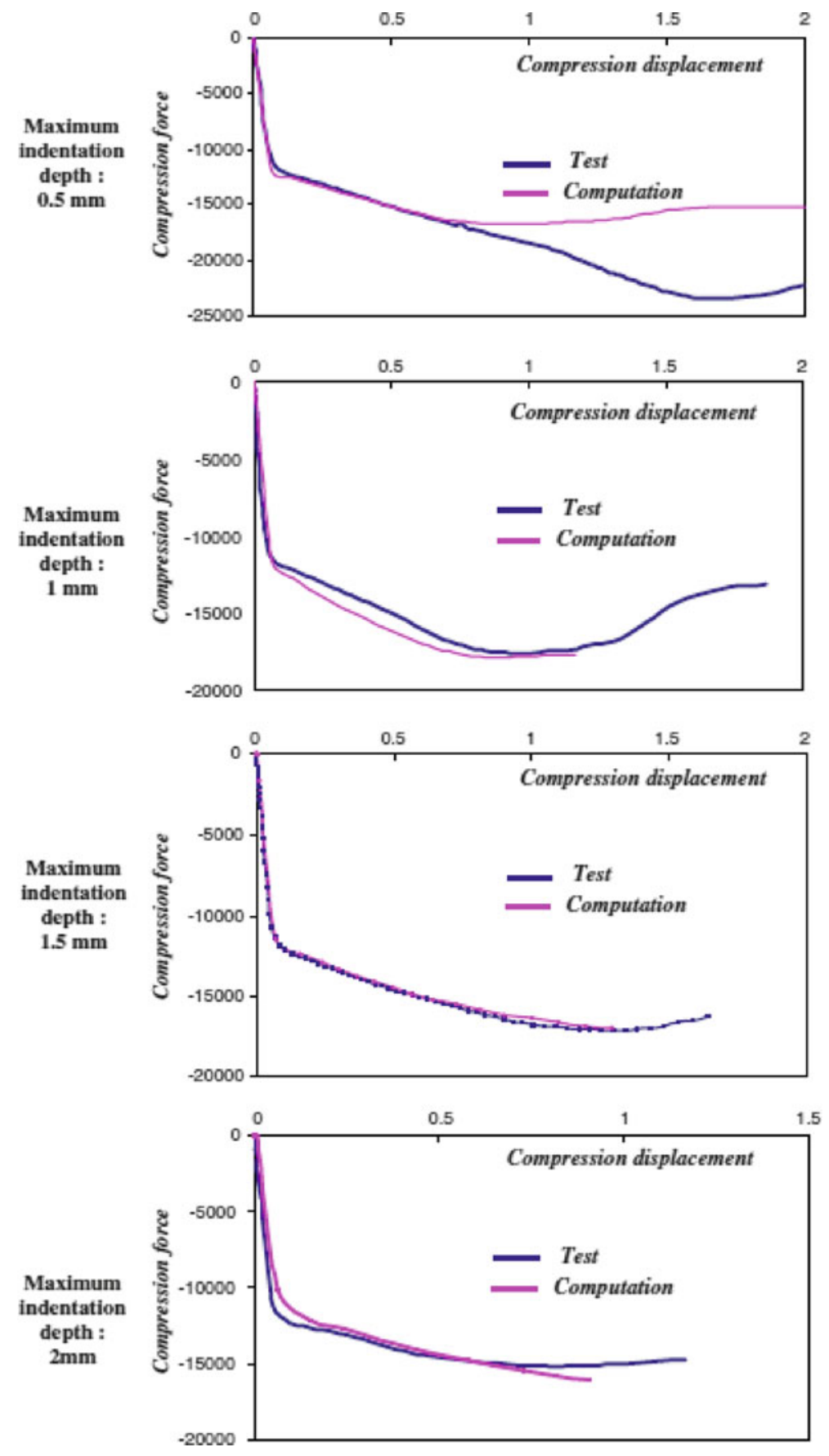

Fig. 57 Comparison of compression after impact: tests and modeling 


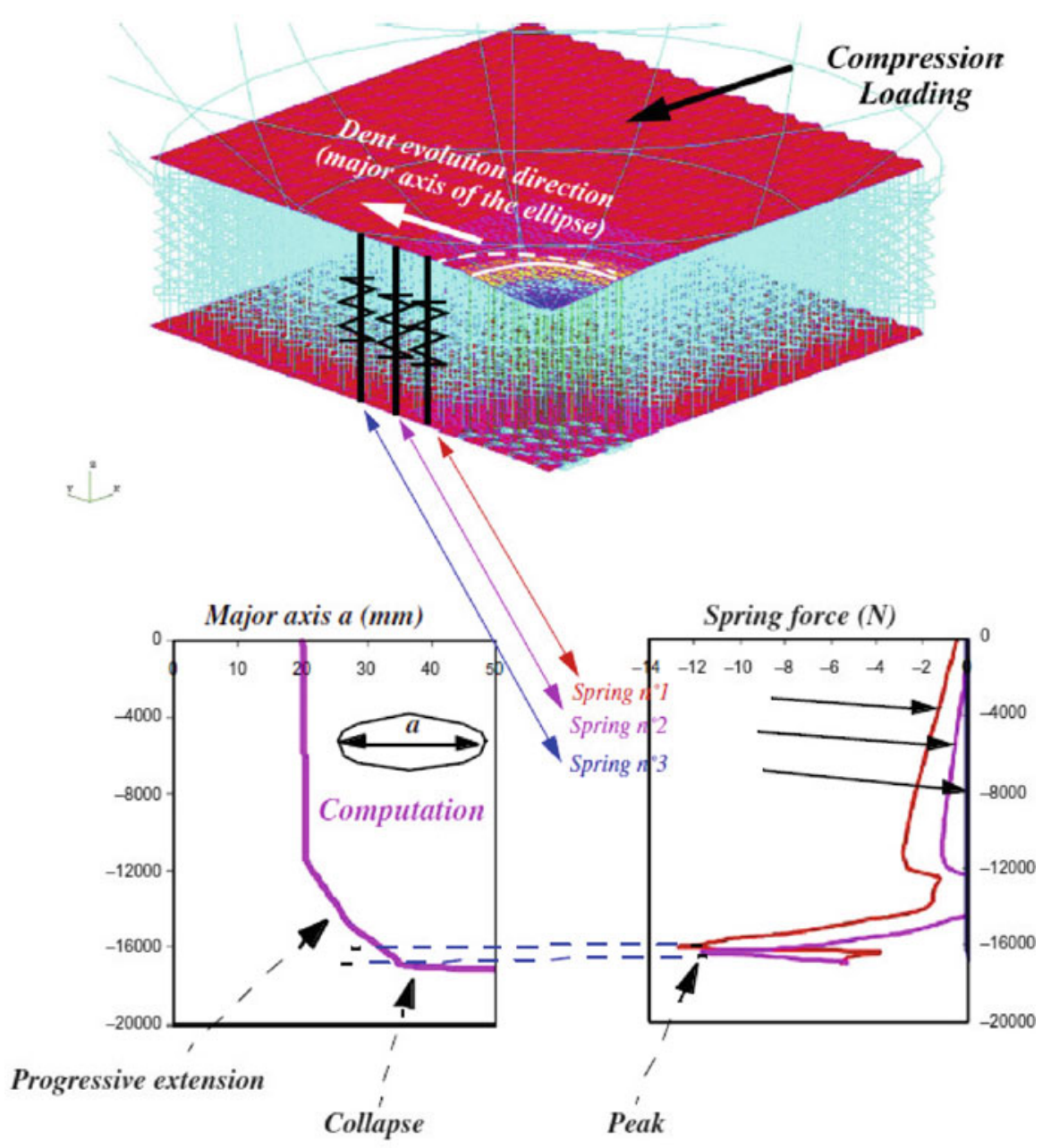

Fig. 58 Analysis of the collapse of pristine core after impact

Thus, the analysis of the tests combined with the discrete modeling of the core shows that the phenomenon occurring during CAI is due to interaction between three mechanical behaviors:

- A geometrical nonlinearity due to the skin's neutral axis offset in the dent area.

- A nonlinear response of the core due to the crushed state and the classic "with peak" response of the undamaged area.

- The response of the skin due to its type of damage after impact: plasticity for metallic skins and delamination or crack growth for laminated skins. 


\subsection{Application to Sandwich Structures with Composite Skins}

In this section, the discrete model is applied to the case of compression after impact on sandwich structures with composite laminate skin. The core crush criterion presented in the previous subsection will be used to evaluate the CAI strength. The difficulty in modeling the phenomena lies in the determination, a priori, of the damage area of the core and the skin according to the delamination area and geometry of impact. In practice, these data could be the input recorded in parallel as explained in Sect. 1.1. The model developed here is inspired by the works of Lacy and Hwang $[52,53]$ which demonstrate the ability to model the behavior of laminate sandwich structures after impact globally. In this study, the initial damage geometry after impact was measured directly from the specimen using destructive and nondestructive inspection. A fixed behavior law for composite skins was also used on the impacted area (50\% of module degradation). In the following subsections, the model used in this study will first be described and then a comparison will be made with the tests results provided by the same authors $[52,54]$.

\subsubsection{Model Geometry and Assumptions}

Only a quarter of the plate was modeled due to symmetries and the overall shape as shown in Fig. 58. Thus the model size area was $101.6 \times 127 \mathrm{~mm}^{2}$. The geometry parameters of the impact-damaged area are described in Fig. 59 using the same notations as in $[52,53]$. For all specimens reported here, the thickness of the core $t_{c}$ was $19.1 \mathrm{~mm}$. The facesheet indentation depth, $\mathrm{d}_{\mathrm{I}}$, and radius, $\mathrm{R}_{\mathrm{I}}$, could be measured directly on specimens or on a real structure. In the new finite element model, the geometry of the dent is represented by Coons surfaces. The crushed core radius should be found by NDI techniques. It seems to be more difficult, in the case of sandwich structures, to determine the delaminated area precisely. Thus, the degraded facesheet radius $R_{F}$ will be taken to be equal to:

$$
R_{F}=\frac{R_{I}+R_{C}}{2}
$$

The core used in [55] was made of Nomex honeycomb, $48 \mathrm{~kg} / \mathrm{m}^{3}$ and had a cell size of $4.76 \mathrm{~mm}$ and a transverse modulus $\mathrm{E}$ equal to $137.9 \mathrm{MPa}$. Its maximum compressive strength was $2.41 \mathrm{MPa}$ and the plateau stress was $1.03 \mathrm{MPa}$. Knowing all these values, for a given surface, it was easy to transform the continuum values into discrete ones for the springs located at the corners of the cells. Law "A" for an intact honeycomb under compression is given in Fig. 60.

The peak force was found to be $23 \mathrm{~N}$ and the crush force was $9.86 \mathrm{~N}$. The compression displacements were calculated directly from the strains given in [52]. This law was applied to the springs representing the pristine core, i.e. located at a radius $\mathrm{R}>\mathrm{R}_{\mathrm{C}}$. For the springs representing the crushed core, law " $\mathrm{B}$ " was applied. 


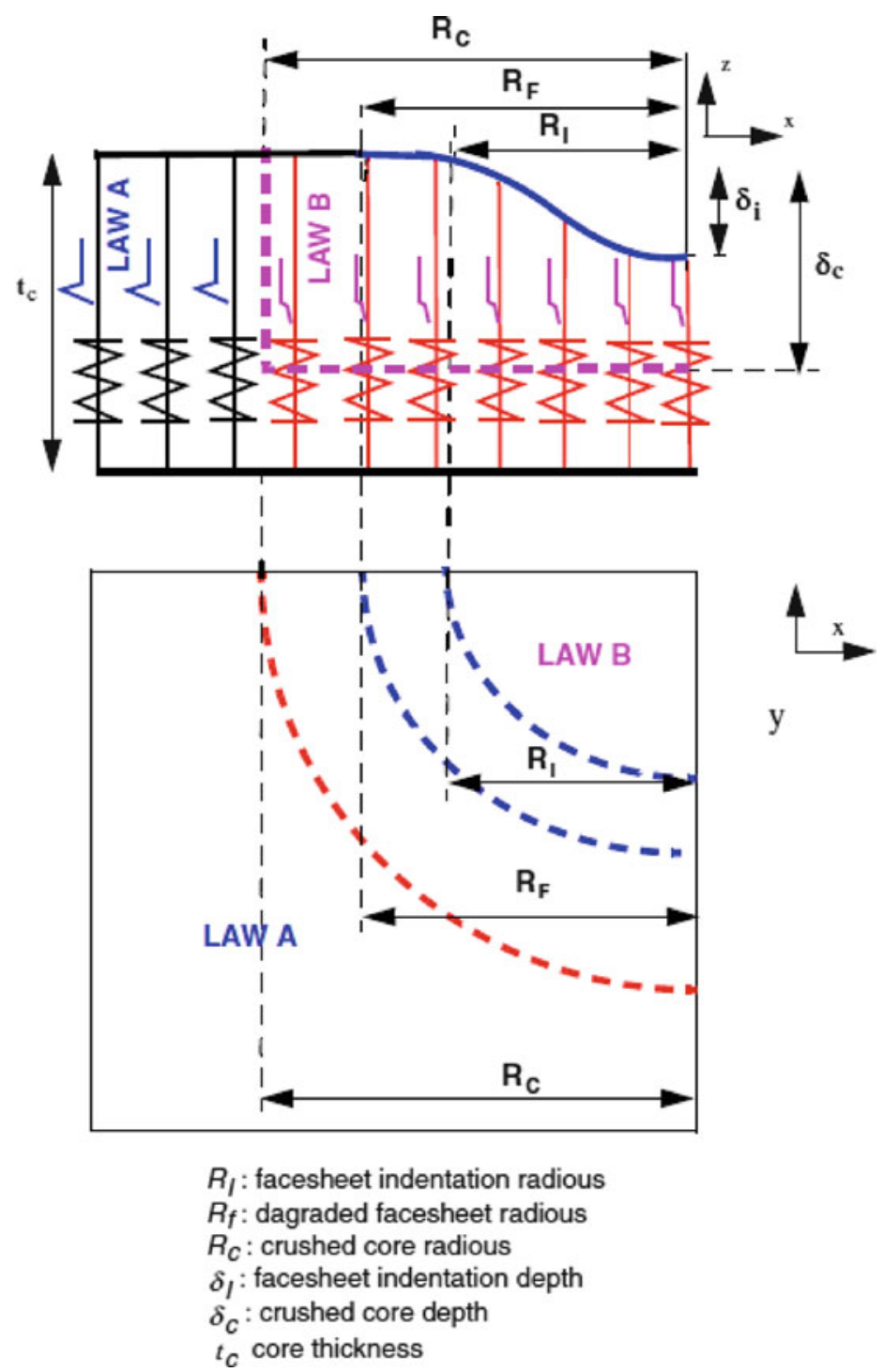

Fig. 59 Geometry of the impact-damaged region

These laws are of same type as in [52] and are in accordance with a previous cycling test performed by the authors on Nomex honeycomb (see Fig. 53 and [39]). The true value of the crushed core depth $\delta_{\mathrm{C}}$ was, until now, obtained by destructive sectioning. In an initial approach, the values given in [52] will be taken and applied to all springs located in the crushed area (see Fig. 59). When this is done, the evolution of the crushed depth is not represented but an a posteriori sensitivity 


\section{Spring Force}

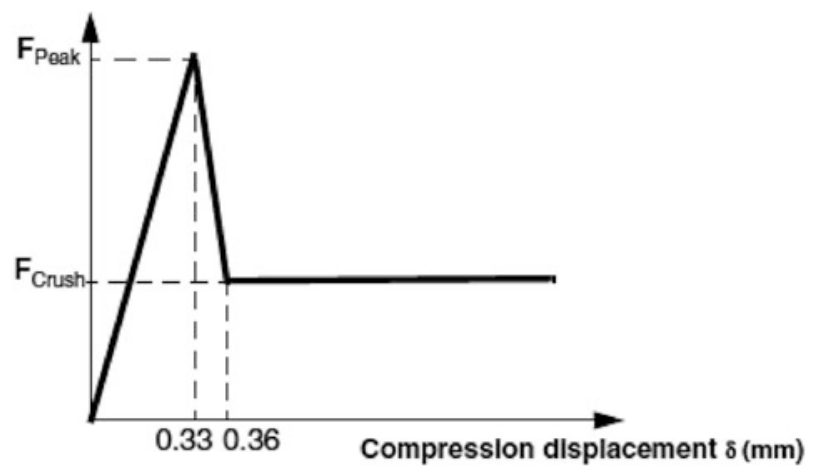

\section{LAW A: Spring force for an intact honeycomb}

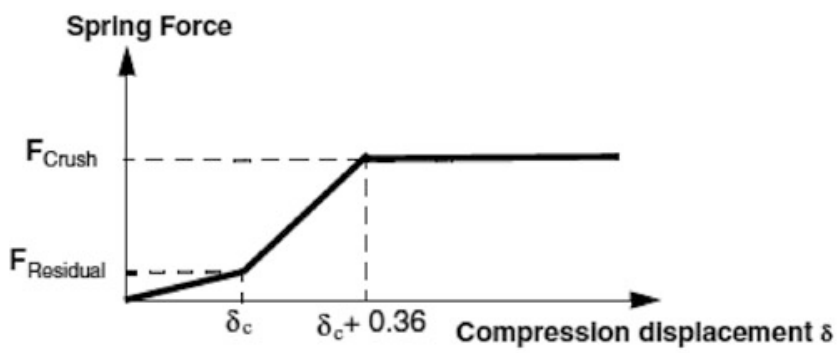

LAW B: Spring force for a damaged honeycomb

Fig. 60 Spring forces

analysis will demonstrate that the influence of this parameter is weak. The residual force $F_{\text {Residual }}$ is also a weak parameter and was set to $1 \mathrm{~N}$, mainly for numerical stability reasons.

The skin was modeled by orthotropic Mindlin elements (see Fig. 58). The skins of the specimens tested by Tomblin et al. [54] were a laminate made of Newport NB321/3K70P plain wave carbon fabric. The stacking sequence was [90/45]n with $\mathrm{n}=1,2,3$. Thus the skin thickness was equal to $0.4,0.8$ or $1.2 \mathrm{~mm}$. According to the material characteristics of the ply given in [54], the orthotropic equivalent moduli were calculated and implemented in the finite element model for the element located at a radius $\mathrm{R}>\mathrm{R}_{\mathrm{F}}$ : $\mathrm{E}_{1}=\mathrm{E}_{2}=47,200 \mathrm{MPa}, \mathrm{E}_{12}=17,800 \mathrm{MPa}, \mathrm{G}_{12}=17,800 \mathrm{MPa}$, $\nu_{12}=0.328$. The same transverse characteristics as in [52] were implemented. For the damaged area, specific hypotheses were assumed concerning the stiffness matrix terms. For a given stacking sequence and for Mindlin's theory, this matrix can be written as:

$$
\left[\begin{array}{lll}
A & B & 0 \\
B & D & 0 \\
0 & 0 & K
\end{array}\right]
$$


Table 5 Impact characteristics, damage dimensions (Reproduced from [52])

\begin{tabular}{|c|c|c|c|c|c|c|c|}
\hline Test & $\begin{array}{l}\text { Skin thickness } \\
(\mathrm{mm})\end{array}$ & $\begin{array}{l}\text { Impactor } \\
\text { size }(\mathrm{mm})\end{array}$ & Energy $(\mathrm{J})$ & $\begin{array}{l}\begin{array}{l}R_{\text {Indented }} \\
(\mathrm{mm})\end{array} \\
\end{array}$ & $\begin{array}{l}R_{\text {Crushed }} \\
(\mathrm{mm})\end{array}$ & $\begin{array}{l}\text { Indentation } \\
\text { depth } \delta_{\chi}(\mu \mu)\end{array}$ & $\begin{array}{l}\text { Crushed depth } \\
\delta_{\mathrm{c}}(\mathrm{mm})\end{array}$ \\
\hline 1 & 0.4 & 25.4 & 6.7 & 10.2 & 15.2 & 2.3 & 5.9 \\
\hline 2 & 0.04 & 76.2 & 7.2 & 15.9 & 25.4 & 0.4 & 6.2 \\
\hline 3 & 0.8 & 25.4 & 6.7 & 3.2 & 15.9 & 0.8 & 3.8 \\
\hline 4 & 0.8 & 25.4 & 20.3 & 12.7 & 21.7 & 3.2 & 7.8 \\
\hline 5 & 0.8 & 76.2 & 7.2 & 9.5 & 28.6 & 0.4 & 4.5 \\
\hline 6 & 0.8 & 76.2 & 28.2 & 34.4 & 48.7 & 4.2 & 6.6 \\
\hline 7 & 1.2 & 25.4 & 6.7 & 9.5 & 19.1 & 0.6 & 4.1 \\
\hline 8 & 1.2 & 76.2 & 11.1 & 12.7 & 28.6 & 0.6 & 4.8 \\
\hline
\end{tabular}

[A] represents the membrane stiffness matrix. In the damaged area, this matrix should be affected by fiber breakages. Generally, these breakages are very localized at the center of the impact, thus the matrix [A] is not modified.

[D] represents the bending stiffness matrix. For thin skins, it is possible to assume the presence of a delamination located at the middle of the thickness and for $\mathrm{R}<\mathrm{R}_{\mathrm{F}}$. This hypothesis leads to a decrease in bending stiffness equal to $1 /(n+1)^{2}$ where $n$ is the number of delaminations in the thickness. So, the bending stiffness matrix is divided by four here: $[\mathrm{D}] / 4$.

[B] represents the membrane-bending coupling stiffness matrix. When stacking sequences are symmetric with respect to the middle surface, its value is zero. This is not the case for the stacking of the specimen, thus the same hypothesis is used and the coupling stiffness matrix is also diminished: [B]/4.

$[\mathrm{K}]$ represents the transverse shear stiffness matrix. It should be affected by matrix cracking but the influence on the residual strength is weak and $[\mathrm{K}]$ is not modified.

During the loading, the skin remained linear elastic and no damage growth was modeled. A geometric nonlinear analysis was made using a line-search method. Different meshes were tested (quadrilateral cells or triangles) with different refinements showing a weak influence on the criterion. In the next paragraph, the model will be compared with eight tests performed by Tomblin et al. [54] for which all the data are available in [52].

\subsubsection{Comparisons with Tests and Sensitivity Analysis Results}

The data available in [52] are recalled in Table 5. Typical responses of the first uncrushed springs located on the major axis of the ellipse are given in Fig. 61 and are extracted from the computation of test case $n^{\circ} 4$.

Springs representing the undamaged cells reach their peak forces one after another, showing the mechanism of extension of the dent. However, only the load corresponding to the first peak has a physical meaning since it is assumed that there is no damage growth in the skin or appearance of a crack before the dent progression. 


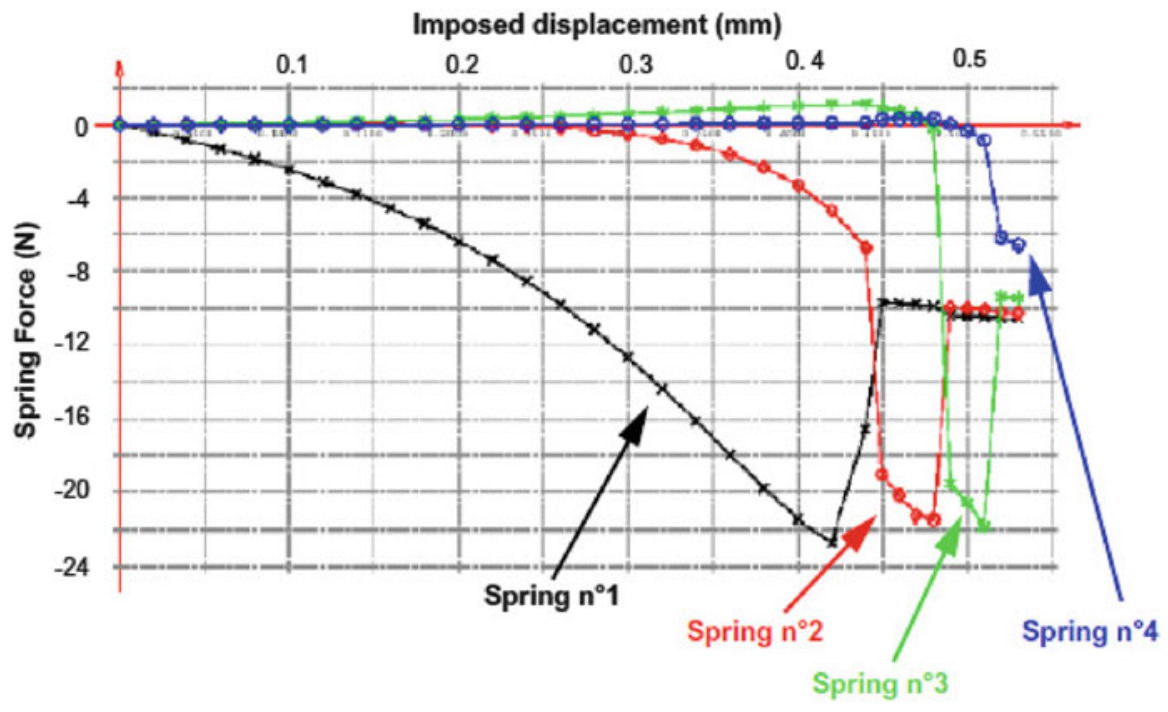

Fig. 61 Typical response given by the model (case no. 4)

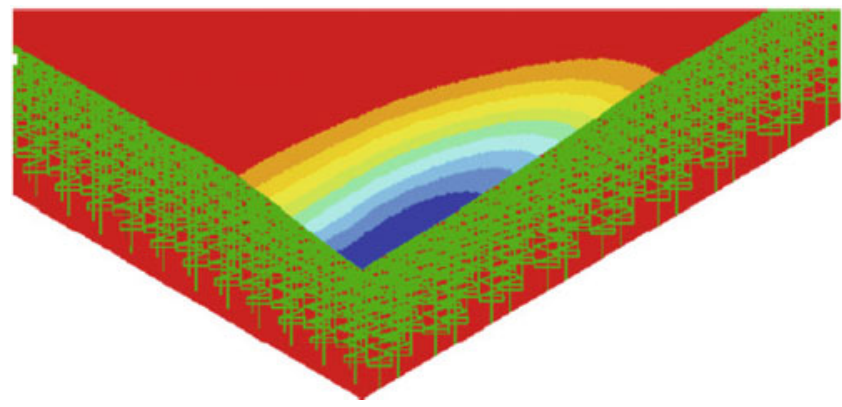

Fig. 62 Shape of the dent at the critical load

The load-displacement curve (not given) is globally linear and shows nothing in particular. When the first spring "crushes", the computed loading corresponding to the criterion is $291.5 \mathrm{~N} / \mathrm{mm}$. The second spring is crushed at $328 \mathrm{~N} / \mathrm{mm}$. The experimental failure of this sandwich was at $317.5 \mathrm{~N} / \mathrm{mm}$. Thus the criterion underpredicts the failure by about $8 \%$.

The out-of plane displacement field for the load criterion can be seen in Fig. 62, showing an extension of the dent in an elliptical shape. It is interesting to see the maximum strain field for this load in Fig. 63. Although all the skin is in compression, at the apex of the dent, one face of the skin is under tension (see Fig. 62) due to local bending. The main strain reaches the very high level of 12,200 $\mu$ strains. Thus, this strain field implies that a crack could occur at this location, which is in agreement with the failure scenario identified by several authors $[50,51,56]$. The same order 


\section{Compression direction}

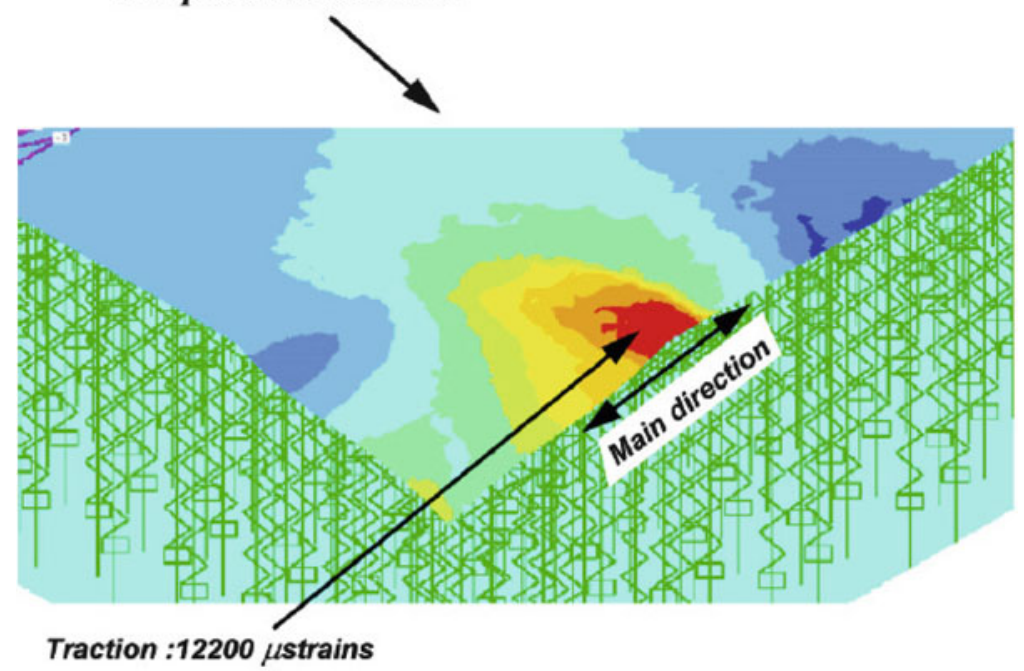

Fig. 63 Main strain field, lower skin, critical load 291.5 N/mm

of magnitude is frequently reached for thin skins of 0.4 and $0.8 \mathrm{~mm}$ but it becomes smaller for thicker skins of $1.2 \mathrm{~mm}$ (about 8,500 $\mu$ strains). A complementary analysis should be made on this point but the critical value of the crack opening for these materials remains to be found for this problem and cannot be provided by the authors.

In Table 6, the comparison is given for the eight cases proposed by Lacy and Hwang [52]. Globally, the comparison is good and the residual strength is under-predicted by $8-25 \%$. In two cases ( 3 and 7 ), the criterion did not work and over-predicted the experiment by 16 and $25 \%$. The approach seems not to work in the case of low energy impact with small indenters that cause too-small dents. The same behavior was pointed out in the case of metallic skins [38, 47]. Maybe, for small dents, the geometrical imperfections are of the same order of magnitude and should be taken into account. In case $\mathrm{n}^{\circ} 5$, the residual strength is under-predicted by $25 \%$. The second spring collapses at a load of $315 \mathrm{~N} / \mathrm{mm}(-11 \%)$ showing a very progressive extension of the dent. Moreover, for the criterion load, at the apex of the ellipse, the maximum tensile strain is only $8,870 \mu$ strains, which suggests that no cracks appear at this load and could explain the value being under-predicted by $25 \%$. In such cases, the analysis should be coupled with modeling of skin damage and failure estimation as proposed in [53] to improve the estimation. However, the present model has the advantage of giving results within $10 \mathrm{~min}$ on a personal computer thanks to the use of springs and the linear behavior in the skins. This approach is thus suitable for an industrial context where quick loops are required.

To validate the approach, a sensitivity study was also conducted [39] and showed the following points: 
Table 6 Results given by the core crush criterion

\begin{tabular}{llclll}
\hline Test & $\begin{array}{l}\text { Impactor } \\
\text { size }(\mathrm{mm})\end{array}$ & $\begin{array}{l}\text { Energy } \\
\text { (Joules) }\end{array}$ & CAI test $(\mathrm{N} / \mathrm{mm})$ & $\begin{array}{l}\text { CAI criterion } \\
(\mathrm{N} / \mathrm{mm})\end{array}$ & Difference (\%) \\
\hline 1 & 25.4 & 6.7 & 185.6 & 165 & -12 \\
2 & 76.2 & 7.2 & 165.5 & 150 & -9.6 \\
3 & 25.4 & 6.7 & 356 & 413 & +16 \\
4 & 25.4 & 20.3 & 317.5 & 291.6 & -8.15 \\
5 & 76.2 & 7.2 & 354.5 & 265 & -25 \\
6 & 76.2 & 28.2 & 236.9 & 196 & -17.3 \\
7 & 25.4 & 6.7 & 482.6 & 600 & +25 \\
8 & 76.2 & 11.1 & 429.6 & 398 & -7.3 \\
\hline
\end{tabular}

- The hypothesis on [A] is weak. If it is divided by 2 , the differences on the computed residual strength are less than $10 \%$ and mostly situated between 0 and $5 \%$.

- The hypotheses on [B] and [C] are also weak. Computations were made with no delamination, one delamination and three delaminations (Matrix [B] and [D] divided by 16). With no delamination, in comparison with one delamination, the residual strength given by the criterion is increased from 3 to $20 \%$ and with three delaminations the residual strength is decreased from 0.4 to $15 \%$. The sensitivity is generally less than $\pm 5 \%$ on thin skins $(0.4$ and $0.8 \mathrm{~mm})$ and is higher for the $1.2 \mathrm{~mm}$ thick skin (cases 7 and 8 ). This hypothesis seems weak for skins less than $0.8 \mathrm{~mm}$ thick but will be more and more sensitive for thicker skins. However, for the cases analyzed, the proposed reduction in stiffness seems to be the better approximation.

- As it is not possible to measure the crushed depth, $\delta_{c}$, in practice, a variation of $\pm 50 \%$ was tested and the influence on the residual strength computed was less than $5 \%$ in most cases. Nevertheless, it is necessary to estimate the core depth to obtain accurate results [39]. In practice, this can be done by using the data already available in any aircraft company.

- A doubt also exists on the measurement by NDI of the core crushed radius $R_{C}$ and the value finally used, especially for minor damage. A sensitivity study on this radius was carried out by varying the radius value by $+/ 1$ cell diameter $(4.76 \mathrm{~mm})$. Generally, the crushed core radius had an important influence on the strength given by the criterion and, thus, the given value has to be as close as possible to reality.

Overall, the strength given by the criterion is robust with respect to our hypotheses for the skin and the core. The main sensitivity was found for the crushed core radius and it has to be measured carefully. Moreover, by changing different parameters, the predicted strength evolves following the expected mechanical behavior and thus confirms the pertinence of the criterion. 


\section{Conclusions and Prospects}

An original method for modeling the impact and post-impact behavior of sandwich structures has been proposed and validated. It is based on the demonstration that the Nomex honeycomb behaves in a post-buckling mode very early and that compression forces are taken up by the corners or vertical edges of honeycomb cells in the same way as by the stiffeners in aircraft structures. Thus it is possible to represent the honeycomb discretely by a grid of springs located at the six corners of the hexagonal cells. The only experimental characterization for this study is the uniform compression testing on a block of 100 cells to find the law of compression for each corner. This approach represents the phenomenon of indentation on honeycomb alone or on sandwiches very well. It has also been shown that local deformations of the skin under the indenter cause, via the meniscus of glue, local rotations of the core which significantly alter the compression response of the honeycomb. The limitations of this approach were sought in terms of independence of the behavior of edges. The hypothesis was verified for indenters that were not too sharp. However, the approach has not been validated for a comprehensive range of materials. It is not proved that this approach can be extended to cores with stiffer materials or thicker cell walls. Before applying this method to other cores, preliminary tests of indentation on the honeycomb core alone (as in Fig. 18) should be carried out.

Moreover, an important limitation of the approach is that the modeling of vertical springs makes it impossible to represent the transverse shear in the core. So it is, a priori, impossible to model the bending of a sandwich. To overcome this problem, a multi-level approach was proposed and validated by impact tests using a drop weight test on a sandwich plate supported by two pin supports. This approach should also allow the multi-impact phenomena of complex structures to be modeled easily. However, the study was limited to metallic skins because the behavior of laminated skins under impact is very complex. Two lines of research are therefore needed for this issue:

- The use of the discrete model proposed by Bouvet et al in this book to model the impacted skins.

- The modeling of the complex nonlinear behavior of the honeycomb cells. The model should be able to take account of the buckling and post-buckling of cells under compression and shear and eventually the coupling between these two modes.

The study also examined the post-impact behavior of these structures and the discrete approach demonstrated the mechanical phenomena at work in compression after impact. It was shown that the behavior was related to three nonlinearities:

- A geometrical nonlinearity due to the skin's neutral axis being offset in the dent area.

- A nonlinear response of the core due to the crushed state and the classical "with peak" response of the undamaged area. 
- The response of the skin due to its type of damage after impact: plasticity for metallic skins and delamination or crack growth for laminated skins.

An original failure criterion was also proposed, based on the beginning of the extension of the damage dent that causes the destruction of some cells in the core. The study was carried out for metal and composite skins and the relevance of the criterion in compression after impact was demonstrated. However, it seems it would be appropriate to combine this criterion with a skin failure criterion (maximum strain for example). In some cases where the sandwiches are very damaged, extension of the defect takes place in a very progressive way. In these cases, the core crush criterion led to an underestimation of the residual strength of the structure. It is also important to note that the entire study is based on the compression after impact tests standardized by aircraft manufacturers. B. Castanié and al. [51] have conducted tests of compression /shear after impact on a specific test rig closer to real structures. In this configuration, under compression, the same initial evolution of the residual dent was observed but, in contrast to classical CAI test results, a slow progression of the crack initiated at the apex of the ellipse was observed. The shear behavior seems to be closer to that of drilled composite. In case of combined loading, the response is a mix of the two. It is important to note that these configurations give residual strengths higher than the conventional CAI tests.

Thus, the field of research is still open as far as combined loading after impact is concerned. This approach should also be combined with studies on impact with pre-loading. It is also important to use more realistic sizing of sandwich structures under impact load in order to obtain a better idea of the real margins.

\section{References}

1. Guedra-Degeorges D, Thevenet P, Maison S (1997) Damage tolerance of sandwich structures. Proceedings of the Euromech 360 colloquium. Kluwer Academic Publisher, Saint Etienne

2. Bernard ML (1987) Impact resistance and damage tolerance of composite sandwich plates. TELAC report 87-11. S.M thesis, MIT

3. Bernard ML, Lagace PA (1989) Impact resistance of composite sandwich plates. J Reinf Plast Compos 8(9):432-445

4. Llorente S, Weems D, Fay R (1990) Evaluation of advanced sandwich structure designed for improved durability and damage tolerance. In: American helicopter Society 46th annual forum proceedings, Washington, DC, pp 825-831

5. Caldwell MS, Borris PW, Falabella R (1990) Impact damage testing of bonded sandwich panels. In: 22nd international SAMPE technical conference, Boston, MA, USA, 6-8 Nov 1990

6. Sun CT, Wu CL (1991) Low velocity impact of composite sandwich panels. In: Proceedings of 32nd AIAA/ASME/ASCE/AHS/ASC structural, structural dynamic, materials conference, Baltimore, pp 1123-1129

7. Williamson JE (1991) Response mechanism in the impact of graphite/epoxy honeycomb sandwich panels. TELAC report 91-12, Technology for advanced composites, MIT

8. Williamson JE, Lagace PA (1994) Response mechanism in the impact of graphite/epoxy honeycomb sandwich panels. In: Proceedings of the 8th technical conference of the American Society for Composite, Cleveland, pp 287-297 
9. Abrate S (1998) Impact on composite structures. Cambridge University Press, New York

10. Goldsmith W, Sackman J-L (1992) Experimental study of energy absorption in impact on sandwich plates. Int J Impact Eng 12(2):241-262

11. Jamjian M, Goldsmith W, Sackman JL (1994) Response of an infinite plate on a honeycomb foundation to a rigid cylindrical impactor. Int J Impact Eng 15(3):183-200

12. Wierzbicki T (1983) Crushing analysis of metal honeycomb. Int J Impact Eng 1:157-174

13. Ferri R, Sankar BV (1997) Static indentation and low velocity impact tests on sandwich plates. In: Proceedings of the 1997 ASME international mechanical engineering Congress and exposition, Dallas, vol 55, pp 485-490

14. Herup EJ, Palazotto AN (1997) Low-velocity impact damage initiation in graphite/epoxy/nomex honeycomb-sandwich plates. Compos Sci Technol 57:1581-1598

15. Swanson RS, Jongman K (2003) Design of sandwich structures under contact loading. Compos Struct 59:403-413

16. Soden P (1996) Indentation of composite sandwich beams. J Strain Anal 31(5):353-360

17. Olsson R, McManus HL (1996) Improved theory for contact indentation of sandwich panels. AIAA J 34(6): 1238-1244

18. Besant T, Davies GAO, Hitchings D (2001) Finite element modelling of low velocity impact of composite sandwich panels. Compos Part A 32:1189-1196

19. Horrigan DPW, Aitken RR, Moltschaniwskyj G (2000) Modelling of crushing due to impact on honeycomb sandwich. J Sandw Struct 2:131-151

20. Palazotto AN, Herup EJ (2000) Finite elements analysis of low velocity impact on composite sandwich plates. Compos Struct 49:209-227

21. Heimbs S (2009) Virtual testing of sandwich core structures using dynamic finite element simulations. Comput Mater Sci 45:205-216

22. Giglio M, Manes A, Gilioli A Investigations on sandwich core properties through an experimental-numerical approach. Compos Part B. doi:10.1016/j.compositesb.2011.08.016

23. Singace AA (1999) Axial crushing analysis of tubes deforming in the multilobe mode. Int $\mathbf{J}$ Mech Sci 41:865-890

24. Wierzbicki T, Bhat T, Abramowicz W, Brodikin D (1992) A two fold elements model of progressive crushing of tubes. Int J Solid Struct 29(24):3269-3288

25. Wu E, Jiang W-S (1999) Axial crush of metallic honeycomb. Int J Impact Eng 19(5-6):439_ 456

26. Gupta NK (1999) Some aspects of axial collapse of cylindrical thin-walled tubes. Int J Mech Sci 41:865-890

27. Gupta NK, Husain A (2000) Mathematical modeling of axial crushing of cylindrical tubes. Thin-walled Struct 38:355-375

28. Aminanda Y, Castanié B, Barrau JJ, Thevenet $\mathrm{P}$ (2005) Experimental analysis and modeling of the crushing of honeycomb cores. Appl Compos Mater 12(3-4):213-227

29. Michael C, Yung N (1997) Airframe structural design. Conmilit Press, Hong Kong

30. Barrau JJ, Crézé S, Castanié B (2005) Buckling and post-buckling of beams with flat webs. Thin-Walled Struct 43(6):877-1002

31. Wierzbicki T, Alvarez ADL, Hoo Fatt MS (1995) Impact energy absorption of sandwich plates with crushable core. In: Proceedings of the joint ASME applied mechanical materials summer meeting, Los Angeles, vol 205, pp 391-411

32. Petras A, Sutcliffe MPF (2000) Indentation failure analysis for sandwich beams. Compos Struct 50:311-318

33. http://www.samtech.com/

34. Aminanda Y, Castanié B, Barrau JJ, Thevenet P (2005) Modélisation de l'indentation des structures sandwichs à peaux métalliques. Mécanique et Industrie 6:487-98

35. Yulfian Aminanda (2004) Contribution à l'analyse et à la modélisation de structures sandwichs impactées. PhD thesis, Ecole Nationale Supérieure de l'Aéronautique et de l'Espace

36. Castanié B, Bouvet C, Aminanda Y, Barrau JJ, Thevenet P (2008) Modelling of low energy/low velocity impact on nomex honeycomb sandwich structures with metallic skins. Int J Impact Eng 35:620-634 
37. Choi IK, Lim CH (2004) Low-velocity impact analysis of composite laminates using linearized contact law. Compos Struct 66:125-32

38. Aminanda Y, Castanié B, Barrau JJ, Thevenet P (2009) Experimental and numerical analysis of the compression-after-impact of metal-skinned sandwich structures. Compos Sci Technol 69:50-59

39. Castanié B, Aminanda Y, Bouvet C, Barrau JJ (2008) Core crush criteria to determine the strength of sandwich composite structures subjected to compression after impact. Compos Struct 86:243-250

40. Fualdes C (2006) Composite@airbus. Damage tolerance philosophy. In: FAA workshop for composite damage tolerance and maintenance, Chicago, 19-21 July 2006

41. Lawrance Cook (2012) Visual inspection reliability for composite aircraft structures. $\mathrm{PhD}$ thesis Cranfield University, UK

42. Shipsha A, Hallstrom S, Zenkert D (2003) Failure mechanisms and modelling of impact damage in sandwich beams - A 2D approach: part II - analysis and modelling. J Sandw Struct Mater 5:33-51

43. Shipsha A, Zenkert D (2005) Compression-after-impact strength of sandwich panels with core crushing damage. Appl Compos Mater 12(3-4):149-164

44. Minguet PJ (1997) A model for predicting behavior of impact-damaged minimum gage sandwich panels under compression. In: Proceedings of the AIAA/ASME/ASCE/AHS/ASC 32nd structure, structural dynamics and material conference, St. Louis, pp 423-439

45. Thomson RS, Mouritz AP (1999) Skin wrinkling of impact damaged sandwich composite. J Sandw Struct Mater 1:299

46. Xie Z, Vizzini AJ (2005) Damage propagation in a composite sandwich panel subjected to increasing uniaxial compression after low-velocity impact. J Sandw Struct Mater 7:269

47. Xie Z, Vizzini AJ (2004) A feasible methodology for engineering applications in damage tolerance of composite sandwich structures. J Compos Mater 3(8):891

48. Minakuchi S, Okabe Y, Takeda N (2008) "Segment-wise model" for theoretical simulation of barely visible indentation damage in composite sandwich beams: Part I - Formulation. Compos Part A 39(1):133-144

49. Minakuchi S, Okabe Y, Takeda N (2007) "Segment-wise model" for theoretical simulation of barely visible indentation damage in composite sandwich beams: part II - experimental verification and discussion. Compos Part A 38(12):2443-2450

50. Tomblin J, Lacy T, Smith B, Hooper S, Vizzini A, Lee S (1999) Review of damage tolerance for composite sandwich airframe structures. DOT/FAA/AR-99/49

51. Castanié B, Barrau JJ, Jaouen JP, Rivallant S (2004) Combined shear/compression structural testing of asymmetric sandwich structures. Exp Mech 44(5):461-472

52. Lacy TE, Hwang Y (2003) Numerical modeling of impact-damaged sandwich composites subjected to compression-after-impact loading. Compos Struct 61:115-128

53. Thomas EL, Youngkeun Hwang (2007) Numerical estimates of the compressive strength of impact-damaged sandwich. J Compos Mater 41:367

54. Tomblin J, Raju KS, Acosta JF, Liew J, Smith JL (2002) Impact damage characterization and damage tolerance of composite sandwich airframe structures. DOT/FAA/AR-00/44

55. Baranger E, Cluzel C, Guidault P-A (2010) Modelling of the behaviour of aramid folded cores up to global crushing. Strain. doi:10.1111/j.1475-1305.2010.00753.x

56. Tsang PW, Lagace PA (1994) Failure mechanism of impact-damaged sandwich panels under uniaxial compression. In: Proceedings of the 35th AIAA/ASME/ASCE/AHS/ASC structural, structural dynamics, materials conference, Hilton Head, vol 2, pp 745-754 